\title{
Performance Assessment of Supervised Classifiers for Designing Intrusion Detection Systems: A Comprehensive Review and Recommendations for Future Research
}

\author{
Ranjit Panigrahi ${ }^{1,+}\left(\mathbb{D}\right.$, Samarjeet Borah ${ }^{1} \oplus$, Akash Kumar Bhoi ${ }^{2}{ }^{\oplus}$, Muhammad Fazal Ijaz ${ }^{3,+}(\mathbb{D}$, \\ Moumita Pramanik ${ }^{1}$, Rutvij H. Jhaveri ${ }^{4}(\mathbb{D}$ and Chiranji Lal Chowdhary $5, * \mathbb{( 1 )}$
}

Citation: Panigrahi, R.; Borah, S.; Bhoi, A.K.; Ijaz, M.F.; Pramanik, M.; Jhaveri, R.H.; Chowdhary, C.L. Performance Assessment of Supervised Classifiers for Designing Intrusion Detection Systems: A Comprehensive Review and Recommendations for Future Research. Mathematics 2021, 9, 690. https: / /doi.org/10.3390/math9060690

Academic Editor: Daniel

Gómez Gonzalez

Received: 17 February 2021

Accepted: 20 March 2021

Published: 23 March 2021

Publisher's Note: MDPI stays neutral with regard to jurisdictional claims in published maps and institutional affiliations.

Copyright: (c) 2021 by the authors Licensee MDPI, Basel, Switzerland. This article is an open access article distributed under the terms and conditions of the Creative Commons Attribution (CC BY) license (https:// creativecommons.org/licenses/by/ $4.0 /)$.
1 Department of Computer Applications, Sikkim Manipal Institute of Technology, Sikkim Manipal University, Majitar 737136, Sikkim, India; ranjit.panigrahi@gmail.com (R.P.); samarjeetborah@gmail.com (S.B.); moumita.pramanik@gmail.com (M.P.)

2 Department of Electrical and Electronics Engineering, Sikkim Manipal Institute of Technology, Sikkim Manipal University, Majitar 737136, Sikkim, India; akashkrbhoi@gmail.com

3 Department of Intelligent Mechatronics Engineering, Sejong University, Seoul 05006, Korea; fazal@sejong.ac.kr

4 Department of Computer Science and Engineering, School of Technology, Pandit Deendayal Energy University, Gandhinagar 382007, India; rutvij.jhaveri@sot.pdpu.ac.in

5 School of Information Technology \& Engineering, Vellore Institute of Technology, Vellore 632014, India

* Correspondence: chiranji.lal@vit.ac.in

+ These authors contributed equally to this work and are first co-authors.

Abstract: Supervised learning and pattern recognition is a crucial area of research in information retrieval, knowledge engineering, image processing, medical imaging, and intrusion detection. Numerous algorithms have been designed to address such complex application domains. Despite an enormous array of supervised classifiers, researchers are yet to recognize a robust classification mechanism that accurately and quickly classifies the target dataset, especially in the field of intrusion detection systems (IDSs). Most of the existing literature considers the accuracy and false-positive rate for assessing the performance of classification algorithms. The absence of other performance measures, such as model build time, misclassification rate, and precision, should be considered the main limitation for classifier performance evaluation. This paper's main contribution is to analyze the current literature status in the field of network intrusion detection, highlighting the number of classifiers used, dataset size, performance outputs, inferences, and research gaps. Therefore, fifty-four state-of-the-art classifiers of various different groups, i.e., Bayes, functions, lazy, rule-based, and decision tree, have been analyzed and explored in detail, considering the sixteen most popular performance measures. This research work aims to recognize a robust classifier, which is suitable for consideration as the base learner, while designing a host-based or network-based intrusion detection system. The NSLKDD, ISCXIDS2012, and CICIDS2017 datasets have been used for training and testing purposes. Furthermore, a widespread decision-making algorithm, referred to as Techniques for Order Preference by Similarity to the Ideal Solution (TOPSIS), allocated ranks to the classifiers based on observed performance reading on the concern datasets. The J48Consolidated provided the highest accuracy of $99.868 \%$, a misclassification rate of $0.1319 \%$, and a Kappa value of 0.998 . Therefore, this classifier has been proposed as the ideal classifier for designing IDSs.

Keywords: classifiers ranking; class-imbalance learning; IDS; IDS base learner; intrusion detection systems; network-based IDS

\section{Introduction}

The footprint of artificial intelligence-enabled Internet of Things (IoT) devices [1] in our day-to-day life attracts hackers and potential intrusions. In 2017, WannaCry ransomware, a self-propagating malware, devastatingly impacted computing resources by infecting more 
than 50,000 NHS systems [2]. The network threats such as WannaCry become a nightmare for the security manager and remain an open research area. Many intrusion detection schemes have been proposed to counter malicious activities in a computer network [3-6]. All the network anomaly counter mechanisms are either unsupervised, supervised, or a combination of both. The supervised algorithms are rigorously used to design state-ofthe-art intrusion detectors. This is because the ability to learn from examples makes the supervised classifiers robust and powerful. In data science, an array of supervised classifiers exists, and each one of them claims to be the best among others. However, in the real world of classification processes, the scenario is somewhat different. The supervised classifiers are susceptible to misclassification if overfit or underfit during the training process [7]. Another aspect is a class-imbalance issue [8] in the underlying dataset of a classification model. A supervised classifier always favors the majority class if the training is incorporated on a high class-imbalance dataset $[9,10]$. Apart from the class-imbalance issue, the data purity also decides the performance of the supervised classifiers. The data are stored and are available in numerous formats and include several outliers such as missing class information, NULL, and NaN values. The raw data with outliers drastically limit the performance of the classifiers. The classifiers reveal unrealistic results with the data of outliers [11,12]. This leads to the development of robust and versatile classifiers for impure data. In this regard, numerous researchers are concerned about pattern recognition, and data extraction $[13,14]$, which is the main objective of data mining, and perhaps one of the motivational aspects for exploring [15-17] supervised machine learning algorithms. Numerous classification mechanisms are available in the literature to handle impure data, especially in designing full-bodied network intrusion detection systems (IDS). However, the central question of the researchers is associated with the selection of the optimum classifiers to develop a base learner for IDS.

Furthermore, there is a lack of a standard guideline to select the most suitable classifier for their datasets. Multiple studies have been conducted on the before-mentioned problem. However, most of the proposed studies available in the literature evaluate the classifiers using standard performance measures such as classification accuracy and false-positive rate [18-22]. It is worth mentioning that the quality of a classifier does not depend only on the classification accuracy. Other performance measures such as misclassification rate, precision, recall, and F-Score empirically define the classifier's performance quality. Therefore, it is necessary to study a comprehensive review that can be used as a guideline to analyze classifiers using various performance measures in various datasets. Therefore, the main objective of this paper is to examine several research papers in the field of hostbased and network-based intrusion detection considering multiple aspects. This study analyzes the type of classification used, the datasets used to consider the sample size, performance measures discussed in evaluating classifier performance, inferences, and research gaps encountered.

Moreover, the proposed study provides a guideline for designing a host-based or network-based intrusion detection system. This study's main contribution is to present an in-depth analysis of fifty-four widely used classifiers considering six different classifier groups across thirteen performance measures. These classifiers are comprehensively analyzed through three well-recognized binary and multiclass NSLKDD, ISCXIDS2012, and CICIDS2017 datasets. The decision-making algorithm referred to as Techniques for Order Preference by Similarity to the Ideal Solution (TOPSIS) $[23,24]$ is incorporated as a reliable feature to allocate weight to these classifiers. These weights are subsequently used for ranking the performance of the classifiers. Consequently, the best classifier for a dataset and the best of each group of classifiers is proposed. Moreover, the best classifier across all the datasets is suggested as the most generic classifier for designing an IDS.

The research of this analysis is structured as follows. In Section 2, the most recent study of supervised classifiers is delineated; the materials and methods has been mentioned in Section 3. Furthermore, in Section 4, the results of the analysis has been discussed. Section 5 is dedicated for J48Consolidated classifier, followed by the conclusion in Section 6 . 


\section{Related Works}

Supervised classifiers are extensively used in the field of network security. The most potential applications of machine learning techniques are in risk assessment after the deployment of various security apparatus [25], identifying risks associated with various network attacks and in predicting the extent of damage a network threat can do. Apart from these, supervised classification techniques have been explored and analyzed by numerous researchers in a variety of application areas. Most of those studies' analyses focused on a detailed exploration to validate a theory or performance evaluation to come across a versatile classifier [26-28]. The performance of supervised classifiers has been explored in intrusion detection [29], robotics [18], semantic web [19], human posture recognition [30], face recognition [20], biomedical data classification [31], handwritten character recognition [22] and land cover classification [21]. Furthermore, an innovative semi-supervised heterogeneous ensemble classifier called Multi-train [32] was also proposed, where a justifiable comparison was made with other supervised classifiers, such as k-Nearest Neighbour $(\mathrm{kNN}), \mathrm{J} 48$, Naïve Bayes, and random tree. Multi-train was also successfully achieved, and its prediction accuracy of unlabeled data was improved, which, therefore, can reduce the risk of incorrectly labeling the unlabeled data. A study on this topic, which exclusively deals with classifiers' accuracy measures using multiple standard datasets, is proposed by Labatut et al. [33]. An empirical analysis of supervised classifiers was carried out by Caruana et al. [34] using eleven datasets with eight performance measures, where the calibrated boosted trees appeared as the best learning algorithm. Besides, a systematic analysis of supervised classifiers was carried out by Amancio et al. [35] under varying classifiers' settings.

The focus of this paper is to analyze the performance of various supervised classifiers using IDS datasets. Therefore, the authors have decided to review related articles in the literature that examined different classifiers using IDS datasets. The classifier analysis is expected to provide a platform for the researchers to devise state-of-the-art IDSs and quantitative risk assessment schemes for various cyber defense systems. Numerous studies and their detailed analytical findings related to supervised classifiers have been outlined in Table 1.

Table 1 summarizes the taxonomy of analyzed articles. In the last column, an attempt has been made to outline the inferences/limitation or research gaps encountered. The summarization of these analyses provides scope for meta-analysis about the supervised classifiers, which ultimately shows direction or justification for further investigation in the field of supervised classification using intrusion detection datasets. From Table 1, it has been observed that the decision tree and function-based approaches are mostly explored. The usage statistics of supervised classifiers are presented in Figure 1.

According to Figure 1, J48 (C4.5) and Random Forest of decision trees and functionbased SVM and Multilayer Perceptron (Neural Network) have been analyzed considerably by numerous researchers. In this work, the authors have tried to understand the reason behind decision trees' popularity and function-based approaches. Therefore, the authors have summarized the performance metrics results used to explore those classifiers in the analyzed papers. Most of the researchers focused on accuracy scores; therefore, the authors used the accuracy score as a base measure to understand the reason behind the use of decision trees and function-based classifiers.

Therefore, in this study, the authors have calculated the minimum, maximum, and average accuracy of Bayes, Decision trees, Functions, Lazy, and Rules group of classifiers concerning the literature outlined in Table 1 . The calculated detection accuracy of the research papers surveyed is presented in Figure 2. In Figure 2, almost all groups of classifiers show a maximum accuracy rate of more than $99 \%$. 
Table 1. Detailed findings and analysis of supervised classifiers.

\begin{tabular}{|c|c|c|c|c|c|c|}
\hline $\begin{array}{l}\text { Inferences/Observations/ } \\
\text { Limitations/Research Gaps }\end{array}$ & $\begin{array}{l}\text { With } 20 \text { features, BayesNet shows } \\
\text { the highest amount of accuracy of } \\
99.3 \% \text { for classifying DDoS } \\
\text { attacks, and PART shows } 98.9 \% \\
\text { for classifying Probe attacks. No } \\
\text { class imbalance issue was found. } \\
\text { Tested on an older dataset, which } \\
\text { is now obsolete. Completely } \\
\text { ignored U2R and R2L attacks. } \\
\text { Hence, classifiers performance } \\
\text { may vary with the inclusion of } \\
\text { U2R and R2L instances }\end{array}$ & $\begin{array}{l}\text { Gaussian classifier seems to be } \\
\text { effective for R2L and Probe } \\
\text { attacks with the highest detection } \\
\text { rate of } 0.136 \text { and } 0.874, \\
\text { respectively. Naive Bayes proved } \\
\text { suitable for U2R a tactacks with the } \\
\text { highest detection rate of } 0.843 \text {, } \\
\text { Decision Tree and Random Forest } \\
\text { classified DoS attacks with the } \\
\text { highest detection rate of } 0.972 . \\
\text { Considering the highest detection } \\
\text { rate of three training sets is not } \\
\text { convincing. Instead, the average } \\
\text { detection rate could have } \\
\text { highlighted better classifiers for } \\
\text { the given scenario. }\end{array}$ & $\begin{array}{l}\text { A decent number of performance } \\
\text { measures were used to analyze } \\
\text { the classifiers, Other } \\
\text { state-of-the-art classifiers are } \\
\text { missing from the comparison. } \\
\text { Dataset sample size, number of } \\
\text { features considered are not } \\
\text { precise. Although the Naive } \\
\text { Bayes proved to be a better } \\
\text { classifier in FP Rate, the ID3 } \\
\text { performs far ahead than the Naive } \\
\text { Bayes. Class imbalance issues are } \\
\text { not considered during evaluation. }\end{array}$ & $\begin{array}{l}\text { The accuracy of the induction tree } \\
\text { is promising, with an overall rate } \\
\text { of } 99.839 / \% \text {. Although it is } \\
\text { appreciable that the induction tree } \\
\text { performs well in the class } \\
\text { imbalance KDD' } 99 \text { dataset, the } \\
\text { size of the training set and the } \\
\text { class-wise breakup of training } \\
\text { stances are not precise. The } \\
\text { reason for considering different } \\
\text { training instances for three } \\
\text { different classifiers is not clear. } \\
\text { Considering the ROC area, it is } \\
\text { evident that the Induction tree } \\
\text { correctly classified Neptune, } \\
\text { Smurf, pod, teardrop, port sweep, } \\
\text { and back attack instances. }\end{array}$ & $\begin{array}{l}\text { C4.5 scores the highest average } \\
\text { accuracy of } 64.94 \% \text { as compared } \\
\text { to } 62.7 \% \text { of } \mathrm{SVM} \text {. } \\
\text { Considering attacks accuracy, } \\
\text { C4.5 seems to be suitable for } \\
\text { detecting Probe, DoS, and U2R } \\
\text { attacks, whereas SVM classifies } \\
\text { R2L threats better. } \\
\text { Class imbalance issue is not } \\
\text { addressed. }\end{array}$ & $\begin{array}{l}\text { J48 (C4.5) proved to be an } \\
\text { accurate classifier for classifying } \\
\text { test instances. } \\
\text { Data extraction and the } \\
\text { preprocessing procedure is not } \\
\text { clearly defined. } \\
\text { The training set is a high-class } \\
\text { imbalance, so the evaluation of } \\
\text { the classifiers in terms of accuracy } \\
\text { and detection rate is not sufficient }\end{array}$ \\
\hline Performance measures used & $\begin{array}{l}\text { Accuracy } \\
\text { Kappa } \\
\text { Mean Absolute Error } \\
\text { Root Mean Squared Error }\end{array}$ & Detection Rate & $\begin{array}{l}\text { Accuracy, Kappa, RMSE, } \\
\text { Precision } \\
\text { Recall, FP Rate } \\
\text { Precision, Recall } \\
\text { FN Rate, } \\
\text { F-Measure } \\
\end{array}$ & $\begin{array}{l}\text { Accuracy, MA Error, RMS Error } \\
\text { RA Error, RRS Error, TP Rate } \\
\text { FP Rate, Precision, Recall, } \\
\text { F-Measure, ROC Area }\end{array}$ & $\begin{array}{l}\text { Accuracy } \\
\text { Detection Rate } \\
\text { FP Rate }\end{array}$ & $\begin{array}{l}\text { Accuracy } \\
\text { Detection Rate } \\
\text { FP Rate }\end{array}$ \\
\hline $\begin{array}{l}\text { Dataset, Features and } \\
\text { Sample Size }\end{array}$ & $\begin{array}{l}\text { Dataset: KDD'99 } \\
\text { FS procedure: Information Gain } \\
\text { Number of Features Selected: } 20 \\
\text { Training instances: } 492,842 \\
\text { Testing Instances: N/A }\end{array}$ & $\begin{array}{l}\text { Dataset: KDD'99 } \\
\text { Features Selected: All features } \\
\text { Training instances: } 270,000 \\
\text { Testing Instances: } 311,029\end{array}$ & $\begin{array}{l}\text { Dataset: KDD'99 } \\
\text { Features Selected: All features }\end{array}$ & $\begin{array}{l}\text { Dataset: KDD'99 } \\
\text { Features Selected: All features } \\
\text { Training instances: N/A } \\
\text { Testing Instances: } 19,870\end{array}$ & $\begin{array}{l}\text { Dataset: } \mathrm{KDD}^{\prime} 99 \\
\text { Features Selected: All features } \\
\text { Training instances: N/A }\end{array}$ & $\begin{array}{l}\text { Dataset: } \mathrm{KDD}^{\prime} 99 \\
\text { Features Selected: All features } \\
\text { Training instances: } 311,029 \\
\text { Testing Instances: } 494,014\end{array}$ \\
\hline Classifiers Evaluated & $\begin{array}{l}\text { J48 (C4.5), } \\
\text { BayesNet, } \\
\text { Naive Bayes, } \\
\text { Part, } \\
\text { Multilayer Perceptron, } \\
\text { SVM }\end{array}$ & $\begin{array}{l}\text { Gaussian, } \\
\text { Naive Bayes, } \\
\text { Decision Tree (C4.5), } \\
\text { Random Forest }\end{array}$ & $\begin{array}{l}\text { Naïve Bayes } \\
\text { J48(C4.5) } \\
\text { ID3 }\end{array}$ & $\begin{array}{l}\text { Induction Tree } \\
\text { Naiive Bayes } \\
\text { ANN }\end{array}$ & $\begin{array}{l}\text { C.5 } \\
\text { SVM }\end{array}$ & $\begin{array}{l}\text { SVM } \\
\text { J48(C4.5) } \\
\text { Multilayer Perceptron }\end{array}$ \\
\hline Author/Year/Reference & Araar et al. (2005) [36] & Gharibian et al. (2007) [37] & Panda et al. (2008) [38] & Srinivasulu et al. (2009) [39] & Wu et al. (2009) [40] & Jalil et al. (2010) [41] \\
\hline $\begin{array}{l}\text { Inferences/Observations/ } \\
\text { Limitations/Research Gaps }\end{array}$ & $\begin{array}{l}\text { Random Forest appears to be } \\
\text { effective for detecting DoS and } \\
\text { Probe attacks. } \\
\text { NB Tree is useful for detecting } \\
\text { R2L and U2R attacks } \\
\text { The classifiers' performances are } \\
\text { measured in a binary } \\
\text { environment. } \\
\text { Performance many vary in a } \\
\text { multiclass environment with a } \\
\text { very high-class imbalance rate. }\end{array}$ & $\begin{array}{l}\text { C5.0 decision tree shows the } \\
\text { highest detection rate of } 98.75 \% \\
\text { for the KDD dataset's testing } \\
\text { samples. Both DoS and Probe } \\
\text { attacks are detected with } 99.56 \% \\
\text { and } 97.25 \% \text { of the detection rate. } \\
\text { The sample size and the basis of } \\
\text { selecting the sample size in not } \\
\text { defined in the research. }\end{array}$ & $\begin{array}{l}\text { J48 evolved as the best classifier } \\
\text { with } 99.13 \% \text { accuracy. } \\
\text { OneR is very fast in classifying } \\
\text { instances. } \\
\text { The basis of sampling, training, } \\
\text { and testing size is not mentioned. } \\
\text { How the classifiers will behave in } \\
\text { a class imbalance situation is not } \\
\text { defined. }\end{array}$ & $\begin{array}{l}\text { Brilliantly evaluated. } \\
\text { It can be extended to other groups } \\
\text { of classifiers. } \\
\text { NBTree achieves } 97.76 \% \text { highest } \\
\text { accuracy. }\end{array}$ & $\begin{array}{l}\text { Random Forest proves to provide } \\
\text { a high accuracy rate for } \\
\text { classifying threats. Considering } \\
15 \text { features, Random Forest shows } \\
\text { an accuracy rate of f99.8\% for } \\
\text { Normal, 99.1\% for DoS, 98.9\% for } \\
\text { Probe, } 98.7 \% \text { for U2R, and } 97.9 \% \\
\text { for R2L. Average accuracy of } \\
\text { Random forest achieves } 98.88 \% \\
\text { for } 15 \text { features of NSL-KDD } \\
\text { dataset }\end{array}$ & $\begin{array}{l}\text { kNN proved to be the best } \\
\text { classifier in terms of accuracy. } \\
\text { No benchmark datasets were } \\
\text { used for the evaluation of } \\
\text { classifiers. } \\
\text { Class imbalance issue has not } \\
\text { been explored. }\end{array}$ \\
\hline Performance measures used & $\begin{array}{l}\text { Accuracy } \\
\text { Detection Rate } \\
\text { FP Rate } \\
\text { Testing time }\end{array}$ & Detection Rate & $\begin{array}{l}\text { Testing time, Accuracy, TP Rate } \\
\text { FP Rate, MA Error, RMS Error, RA } \\
\text { Error, RRS Error }\end{array}$ & $\begin{array}{l}\text { Training time, Accuracy, MAE, } \\
\text { RMSE, Kappa, Recall, Precision, } \\
\text { F-Measure, Precision, FP Rate }\end{array}$ & Accuracy & Accuracy \\
\hline
\end{tabular}


Table 1. Cont.

\begin{tabular}{|c|c|c|c|c|c|c|}
\hline $\begin{array}{l}\text { Dataset, Features and Sample } \\
\text { Size }\end{array}$ & $\begin{array}{l}\text { Dataset: KDD' } 99 \\
\text { Feature Selection Technique: CFS } \\
\text { Features: } 7 \\
\text { Training instances: N/A } \\
\text { Testing Instances: N/A }\end{array}$ & $\begin{array}{l}\text { Dataset: } \mathrm{KDD}^{\prime} 99 \\
\text { Feature Selection Technique: N/A } \\
\text { Training instances: N/A } \\
\text { Testing Instances: N/A }\end{array}$ & $\begin{array}{l}\text { Dataset: NSLKDD } \\
\text { Training instances: N/A } \\
\text { Testing instances: } 2747\end{array}$ & $\begin{array}{l}\text { Dataset: NSL-KDD } \\
\text { Feature election Techniques: } \\
\text { CONS: } 12 \text { features, CFS: } 3 \text { features } \\
\text { Training instances: } 25,192 \\
\text { Testing instances: } 11,850\end{array}$ & $\begin{array}{l}\text { Dataset: NSL-KDD } \\
\text { Feature Selection Techniques: CFS } \\
\text { Features: } 15 \\
\text { Training instances: } 125,937 \\
\text { Testing instances: } 22,544\end{array}$ & $\begin{array}{l}\text { Dataset: Artificial Dataset } \\
\text { Feature Selection Scheme: CFS } \\
\text { Features: } 2 \text { to } 10 \\
\text { Training instances: N/A } \\
\text { Testing instances: N/A }\end{array}$ \\
\hline Classification Type & $\begin{array}{l}\text { Binary Class } \\
\text { Normal } \\
\text { Instances of any one other class. }\end{array}$ & $\begin{array}{l}\text { Multi-Class } \\
\text { Normal } \\
\text { DoS } \\
\text { Probe }\end{array}$ & $\mathrm{N} / \mathrm{A}$ & $\begin{array}{l}\text { Multi-Class } \\
\text { Normal } \\
\text { DoS } \\
\text { Probe } \\
\text { U2R } \\
\text { R2L }\end{array}$ & $\begin{array}{l}\text { Multi-Class } \\
\text { Normal } \\
\text { DoS } \\
\text { Probe } \\
\text { U2R } \\
\text { R2L }\end{array}$ & N/A \\
\hline Classifiers Evaluated & $\begin{array}{l}\text { J48, } \\
\text { Naíve Bayes, } \\
\text { NB Tree, } \\
\text { Random Forest }\end{array}$ & $\begin{array}{l}\text { SVM, } \\
\text { Ripper Rule, } \\
\text { C5.0 decision tree }\end{array}$ & $\begin{array}{l}\text { Naive Bayes, } \\
\text { J48, } \\
\text { OneR, } \\
\text { PART, } \\
\text { RBF Network } \\
\end{array}$ & $\begin{array}{l}\text { ADTree, C4.5, LADTree, NBTree, } \\
\text { Random Tree, Random Forest, } \\
\text { REP Tree }\end{array}$ & $\begin{array}{l}\text { Random Forest } \\
\text { J48 } \\
\text { SVM } \\
\text { CART } \\
\text { Naïve Bayes } \\
\end{array}$ & $\begin{array}{l}\text { Naiive Bayes, Bayes Net, C4.5, } \\
\text { Random Forest, CART, kNN, } \\
\text { Logistic Regression, MLP, SVM }\end{array}$ \\
\hline Author/Year/Reference & Amudha et al. (2011) [42] & Naidu et al. (2012) [43] & Kalyani et al. (2012) [44] & Thaseen et al. (2013) [45] & Revathi et al. (2013) [46] & Amancio et al. (2014) [35] \\
\hline $\begin{array}{l}\text { Inferences/Observations/ } \\
\text { Limitations/Research Gaps }\end{array}$ & $\begin{array}{l}\text { Random Forest shows the highest } \\
\text { accuracy of } 97.75 \% \text { and } 100 \% \text { for } \\
\text { the LLsDDDS and CAIDA } \\
\text { Conficker dataset. } 488 \text { and } \\
\text { Random Forest both show equal } \\
\text { highest accuracy of } 99.26 \% \text { for the } \\
\text { CADIDADDOS } 2007 \text { dataset. Class } \\
\text { imbalance issue has not been } \\
\text { addressed. The type of } \\
\text { classification, whether binary or } \\
\text { multiclass, is not clear. }\end{array}$ & $\begin{array}{l}\text { Random Forest shows the highest } \\
\text { amount of accuracy of } 91.52 \% \text {. } \\
\text { Considering False Positive Rate, } \\
\text { BayesNet seems to be better. } \\
\text { The test could have been } \\
\text { conducted with varying sample } \\
\text { sizes or with the maximum } \\
\text { sample size possible to confirm } \\
\text { the suitable classifier. }\end{array}$ & $\begin{array}{l}\text { Proposed two IDS models for } \\
\text { classifying the different type of } \\
\text { attack instances. } \\
\text { Random Forest and Fuzzy Logic } \\
\text { seem to be ideal classifiers for } \\
\text { classifyying various attacks. The } \\
\text { training time of a classifier does } \\
\text { not provide a clear picture of } \\
\text { designing an IDS. Hence, testing } \\
\text { time per instance would provide a } \\
\text { precise result. }\end{array}$ & $\begin{array}{l}\text { PART shows the highest accuracy } \\
\text { of } 99.97 \% \text {. } \\
\text { Many other prominent classifiers } \\
\text { are missed from the evaluation. } \\
\text { Tested on an obsolete dataset. } \\
\text { Declaring the best classifier just } \\
\text { based on accuracy may not reveal } \\
\text { the real capabilities of the } \\
\text { classifier. } \\
\text { Other measures, such as ROC and } \\
\text { PRC values, should be considered } \\
\text { for judging the classifiers' } \\
\text { performance in class imbalance } \\
\text { learning. }\end{array}$ & $\begin{array}{l}\text { Random Forest proved to be the } \\
\text { best classifier, among others. } \\
\text { The class imbalance issue found } \\
\text { as NSL-KDD is a class imbalance } \\
\text { dataset. A similar test on other } \\
\text { state-of-the-art classifiers are } \\
\text { required }\end{array}$ & $\begin{array}{l}\text { Random Forest shows the highest } \\
\text { accuracy of } 93.77 \% \\
\text { Class imbalance issues found } \\
\text { with Normal-U2R and } \\
\text { Normal-R2L instances. Tested on } \\
\text { an obsolete dataset }\end{array}$ \\
\hline Performance measures used & $\begin{array}{l}\text { Accuracy } \\
\text { FN Rate } \\
\text { FP Rate } \\
\text { Precision } \\
\text { Recall } \\
\end{array}$ & $\begin{array}{l}\text { Training Time, Sensitivity, } \\
\text { Specificity, } \\
\text { Accuracy, FP Rate, Kappa, } \\
\text { F-Measure, Precision, ROC, }\end{array}$ & $\begin{array}{l}\text { TP Rate } \\
\text { FP Rate } \\
\text { Training Time }\end{array}$ & $\begin{array}{l}\text { Accuracy, Recall, Precision, } \\
\text { F-Measure, TP Rate, TN Rate } \\
\text { ROC Area } \\
\text { Kappa }\end{array}$ & $\begin{array}{l}\text { Accuracy } \\
\text { F-Measure } \\
\text { ROC Value } \\
\text { Precision } \\
\text { Recall } \\
\end{array}$ & $\begin{array}{l}\text { Accuracy, FP Rate, FN Rate, TP } \\
\text { Rate, } \\
\text { Precision, ROC value, RMS Error }\end{array}$ \\
\hline $\begin{array}{l}\text { Dataset, Features and } \\
\text { Sample Size }\end{array}$ & $\begin{array}{l}\text { Datasets: LLsDDoS, CAIDA, } \\
\text { DdoS2007, Conficker } \\
\text { Feature Selection Procedure: } \\
\text { Manual, Features Selected: } 7 \\
\text { Training and Testing Instances: } \\
\text { N/A }\end{array}$ & $\begin{array}{l}\text { Dataset: NSL-KDD } \\
\text { Features Selected: All features } \\
\text { Training instances: } 1166 \\
\text { Testing instances: } 7456\end{array}$ & $\begin{array}{l}\text { Dataset: KDD' } 99 \\
\text { Feature Selection Technique: } \\
\text { Information Gain } \\
\text { Features: } 20 \\
\text { Training and Testing instances: } \\
\text { N/A }\end{array}$ & $\begin{array}{l}\text { Dataset: KDD' } 99 \\
\text { No. of Features: All features } \\
\text { Training and Testing instances: } \\
\text { N/A }\end{array}$ & $\begin{array}{l}\text { Dataset: NSL-KDD } \\
\text { No. of Features selected: All } \\
\text { Training and Testing instances: } \\
\text { N/A }\end{array}$ & $\begin{array}{l}\text { Dataset: KDD'99 } \\
\text { No. of features: All } \\
\text { Training instances: } 148,753 \\
\text { Testing instances: } 60,000\end{array}$ \\
\hline Classification Type & $\mathrm{N} / \mathrm{A}$ & $\begin{array}{l}\text { Multi-Class, Normal, DoS } \\
\text { Probe } \\
\text { U2R } \\
\text { R2L }\end{array}$ & $\begin{array}{l}\text { Multi-Class } \\
\text { Normal, DoS } \\
\text { Probe } \\
\text { U2R } \\
\text { R2L }\end{array}$ & $\begin{array}{l}\text { Multi-Class } \\
\text { Normal } \\
\text { DoS } \\
\text { Probe } \\
\text { U2R } \\
\text { R2L }\end{array}$ & $\begin{array}{l}\text { Multi-Class } \\
\text { Normal } \\
\text { DoS } \\
\text { Probe } \\
\text { U2R } \\
\text { R2L }\end{array}$ & $\begin{array}{l}\text { Multi-Class } \\
\text { Normal } \\
\text { DoS } \\
\text { Probe } \\
\text { U2R } \\
\text { R2L }\end{array}$ \\
\hline Classifiers Evaluated & $\begin{array}{l}\text { Naiive Bayes, } \\
\text { RBF Network, } \\
\text { Multilayer Perceptron, } \\
\text { BayesNet, } \\
\text { IBK } \\
\text { J48,(C4.5), } \\
\text { Random Forest }\end{array}$ & $\begin{array}{l}\text { BayesNet, Logistic, IBk, JRip, } \\
\text { PART, J48, } \\
\text { Random Forest, Random Tree, } \\
\text { REPTree }\end{array}$ & $\begin{array}{l}\text { Bayes Net, Naïve Bayes, C4.5, ID3, } \\
\text { NBTree, Fuzzy Logic } \\
\text { SVM, Decision Table, } \\
\text { JRip, OneR, MLP, IBk }\end{array}$ & $\begin{array}{l}\text { Decision Table, IRip, ZeroR, OneR, } \\
\text { PART, BayesNet, Naiive Bayes, } \\
\text { MLP, SMOO, Simple Logistic, IBk } \\
\text { Kstar, LWL }\end{array}$ & $\begin{array}{l}\text { Logistic Regression } \\
\text { Gaussian Naive Bayes, SVM, } \\
\text { Random Forest }\end{array}$ & $\begin{array}{l}\text { J48 (C4.5), Random Forest, } \\
\text { Random Tree, Decision Table, } \\
\text { Multilayer Perceptron, Naive } \\
\text { Bayes, BayesNet }\end{array}$ \\
\hline Author/Year/Reference & Robinson et al. (2015) [47] & Choudhury et al. (2015) [48] & Jain et al. (2016) [49] & Bostani et al. (2017) [50] & Belavagi et al. (2016) [51] & Almseidin et al. (2017) [52] \\
\hline
\end{tabular}


Table 1. Cont

\begin{tabular}{|c|c|c|c|c|c|c|}
\hline $\begin{array}{l}\text { Inferences/Observations/ } \\
\text { Limitations/Research Gaps }\end{array}$ & $\begin{array}{l}\text { The best classifier to classify } \\
\text { attacks of the NSL-KDD dataset } \\
\text { in an anomalous traffic condition: } \\
\text { DOS attacks-Multilayer } \\
\text { Perceptron, Probe } \\
\text { attacks-BFTree, U2R } \\
\text { attacks--BH8, RLL attacks-Naïve } \\
\text { Bayes. Overall, all the classifiers } \\
\text { except Naive Bayes worked well } \\
\text { with the NSL-KDD dataset. No } \\
\text { performance measures were used } \\
\text { to validate the classifiers in this } \\
\text { class imbalance situation; } \\
\text { therefore, the classifier seems to } \\
\text { be ideal, but it may not be } \\
\text { consistent in this scenario. }\end{array}$ & $\begin{array}{l}\text { Decision Tree shows the highest } \\
\text { accuracy of } 99 \% \text {. } \\
\text { Class imbalance issue, not present. } \\
\text { Class wise samples contradict the } \\
\text { total training data size. }\end{array}$ & $\begin{array}{l}\text { Random Forest proved to be the } \\
\text { best classifier, among others. The } \\
\text { class imbalance issue found as } \\
\text { NSLL-KDD was a class imbalance } \\
\text { dataset. } \\
\text { Similarly, the U2R and R2L } \\
\text { attacks were not perfectly } \\
\text { detected due to inherent } \\
\text { class-imbalance issue. A similar } \\
\text { test on other state-of-the-art } \\
\text { classifiers is required }\end{array}$ & $\begin{array}{l}\text { With all the features of the } \\
\text { NSL-KDDD dataset, the J48 } \\
\text { classifier outperforms all other } \\
\text { classifiers. With a reduced feature } \\
\text { set through information gain } \\
\text { feature selection, the IBk seems to } \\
\text { be a better classifier. The } \\
\text { under-sampling of highly } \\
\text { dominant classes and over a } \\
\text { sampling of poor classes } \\
\text { improves the detection accuracy } \\
\text { of R2L and U2R attacks. }\end{array}$ & $\begin{array}{l}\text { The two-class decision forest } \\
\text { model evolved as the best } \\
\text { detection scheme with a detection } \\
\text { accuracy of } 99.2 \% \text {. The generic, } \\
\text { exploits, shellcode, and worms } \\
\text { attacks were also detected with } \\
99 \%, 94.49 \%, 91.79 \% \text { and } 90.9 \% \\
\text { accuracy, respectively. The } \\
\text { evaluation has been carried out } \\
\text { with the cutting-edged Microsoft } \\
\text { Azure Machine Learning Studio } \\
\text { to handle huge instances of the } \\
\text { UNSW NB-15 dataset. }\end{array}$ & $\begin{array}{l}\text { The Random Forest emerged as } \\
\text { the best classifier for multi attacks } \\
\text { scenarios. On the other hand, in a } \\
\text { binary attack scenario, the C4.5 } \\
\text { was found to be the best classifier } \\
\text { for detection. }\end{array}$ \\
\hline Performance measures used & $\begin{array}{l}\text { Accuracy } \\
\text { FP Rate } \\
\text { TP Rate } \\
\text { FN Rate } \\
\text { Precision } \\
\text { Recall } \\
\text { F-Score } \\
\end{array}$ & $\begin{array}{l}\text { Accuracy } \\
\text { Recall } \\
\text { Precision } \\
\text { F-Measure }\end{array}$ & $\begin{array}{l}\text { Accuracy } \\
\text { F-Measure } \\
\text { Precision } \\
\text { Recall }\end{array}$ & $\begin{array}{l}\text { Accuracy, } \\
\text { True Positive Rate, } \\
\text { False Positive Rate, } \\
\text { Precision, } \\
\text { Recall } \\
\text { F-Measure, } \\
\text { ROC Area }\end{array}$ & $\begin{array}{l}\text { Accuracy, } \\
\text { Precision, } \\
\text { Recall, } \\
\text { F1-Score, } \\
\text { AUC, } \\
\text { False Alarm Rate, Training Time, } \\
\text { Testing Time }\end{array}$ & $\begin{array}{l}\text { Detection Rate, } \\
\text { True Negative Rate, } \\
\text { False Alarm Rate, Accuracy, } \\
\text { Training Time, Testing Time }\end{array}$ \\
\hline $\begin{array}{l}\text { Dataset, Features and } \\
\text { Sample Size }\end{array}$ & $\begin{array}{l}\text { Dataset: NSL-KDD } \\
\text { Feature Selection Technique: } \\
\text { Sequential Floating Forward } \\
\text { Selection (SFFS), No of Features: } \\
26 \\
\text { Training instances: } \\
125,973 \\
\text { Testing instances: } 22,544\end{array}$ & $\begin{array}{l}\text { Dataset: CICIDS } 2017 \\
\text { Feature Selection Techniques: } \\
\text { Fisher Score, No of Features: } 30, \\
\text { Training instances: } 203,171 \\
\text { Testing instances: } 22,575\end{array}$ & $\begin{array}{l}\text { Dataset: KDD' } 99, \\
\text { NSL-KDD, } \\
\text { No. of features: All } \\
\text { Testing instances: } \\
\text { KDD'99 } \\
\text { Sample Size: } 494,021 \\
\text { NSL-KDD } \\
\text { Sample Size: } 125,973\end{array}$ & $\begin{array}{l}\text { Dataset: NSL-KDD } \\
\text { Separately evaluated on } \\
\text { Information Gain Feature } \\
\text { Selection and All Features, 10-fold } \\
\text { cross validation on instances of } \\
\text { the dataset }\end{array}$ & $\begin{array}{l}\text { Dataset: UNSW NB-15 } \\
\text { Feature Selection Scheme: Mutual } \\
\text { information } \\
\text { Training samples: 1,75,341 } \\
\text { Testing samples: 82,332 }\end{array}$ & $\begin{array}{l}\text { Dataset: CICIDS2017, } \\
\text { Feature Selection Techniques: } \\
\text { Manual feature selection. } \\
\text { Features having unique values for } \\
\text { each instance of the dataset has } \\
\text { been considered. } \\
\text { Training instances: } 40,000 \\
\text { Testing instances: } 40,000\end{array}$ \\
\hline Classification Type & $\begin{array}{l}\text { Multi-Class } \\
\text { Normal } \\
\text { DoS } \\
\text { Probe } \\
\text { U2R } \\
\text { R2L }\end{array}$ & $\begin{array}{l}\text { Binary } \\
\text { Benign } \\
\text { DoS }\end{array}$ & $\begin{array}{l}\text { Multi-Class } \\
\text { Normal } \\
\text { DoS } \\
\text { Probe } \\
\text { U2R } \\
\text { R2L }\end{array}$ & $\begin{array}{l}\text { Multi-Class } \\
\text { Normal } \\
\text { DoS } \\
\text { Probe } \\
\text { U2R } \\
\text { R2L }\end{array}$ & $\begin{array}{l}\text { Multi-Class } \\
\text { Normal, } \\
\text { Analysis, } \\
\text { Backdoor, } \\
\text { Reconnaissance, } \\
\text { Shellcode, } \\
\text { Worms, } \\
\text { DOS, } \\
\text { Fuzzers, } \\
\text { Generic, } \\
\text { Exploits }\end{array}$ & $\begin{array}{l}\text { Multi-Class } \\
\text { Benign, DoS, PortScan, Bot, Brute } \\
\text { Force, Web Attacks, Infiltration }\end{array}$ \\
\hline Classifiers Evaluated & $\begin{array}{l}\text { Naiive Bayes } \\
\text { BF Tree } \\
\text { J48 } \\
\text { Multilayer Perceptron } \\
\text { NB Tree } \\
\text { RFT }\end{array}$ & $\begin{array}{l}\text { SVM } \\
\text { IBk(k-NN) } \\
\text { Decision Tree }\end{array}$ & $\begin{array}{l}\text { Random Forest } \\
\text { J48(C4.5) } \\
\text { BayesNet } \\
\text { Naive Bayes } \\
\text { SVM }\end{array}$ & $\begin{array}{l}\text { Naïve Bayes, } \\
\text { Logistic Regression, } \\
\text { MLP, } \\
\text { SVM, } \\
\text { IBk, } \\
\text { J48 (C4.5) }\end{array}$ & $\begin{array}{l}\text { Average Perceptron, } \\
\text { Bayes point machine, } \\
\text { Boosted Decision Tree, } \\
\text { Decision Forest, } \\
\text { Decision Jungle, } \\
\text { Locally deep SVM, Logistic } \\
\text { Regression }\end{array}$ & $\begin{array}{l}\text { J48 (C4.5), } \\
\text { ForestPA, } \\
\text { Random Forest, } \\
\text { REP Tree, } \\
\text { Jrip, FURIA, } \\
\text { RIdor, MLP, RBF, LIBSVM, SVM, } \\
\text { Naive Bayes }\end{array}$ \\
\hline Author/Year/Reference & Aziz et al. (2017) [53] & Aksu et al. (2018) [54] & Nehra et al. (2019) [55] & Mahfouz et al. (2020) [56] & Rajagopal et al. (2020) [57] & Ahmim et al. (2020) [58] \\
\hline
\end{tabular}




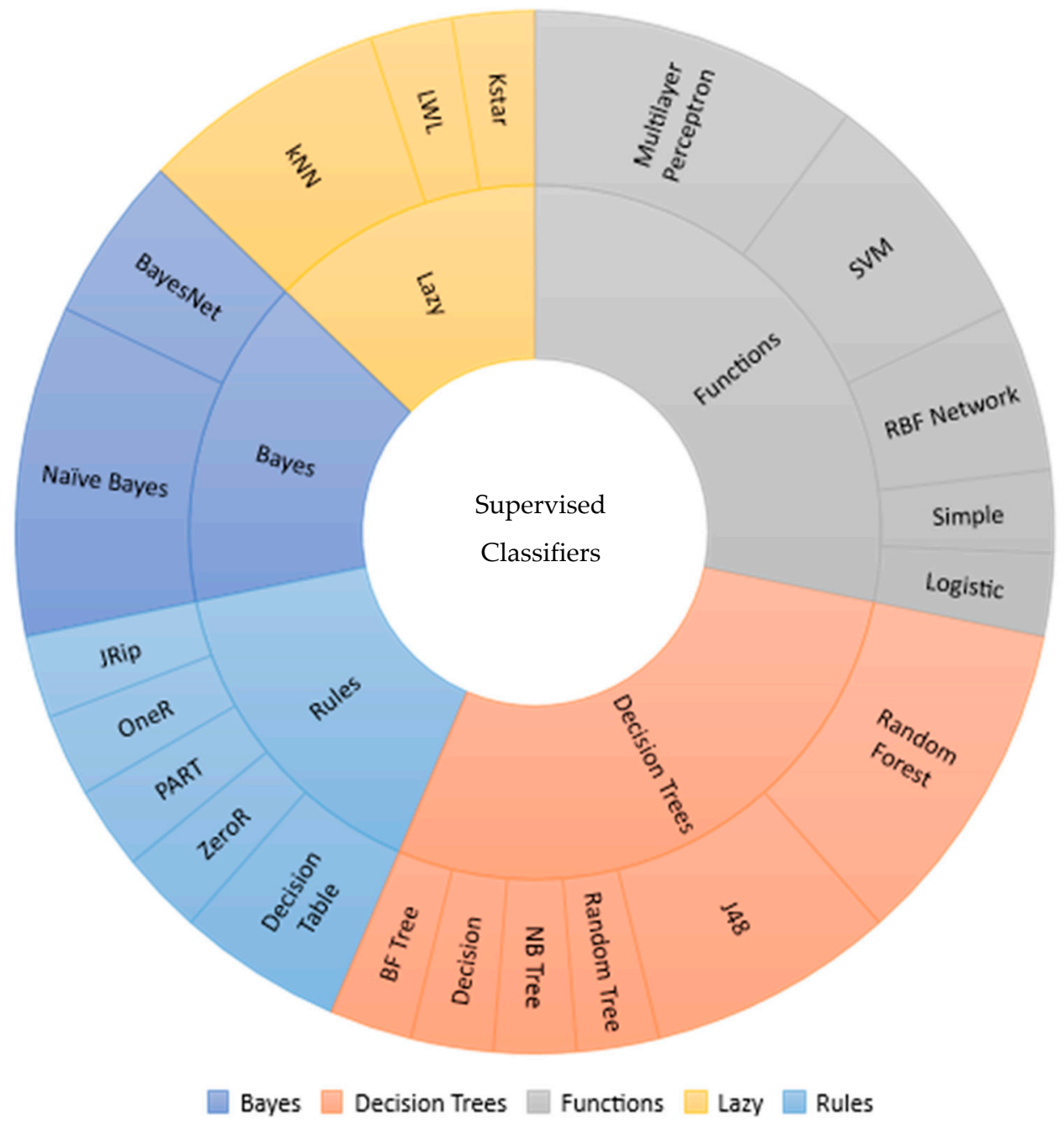

Figure 1. Usage statistics of supervised classifiers.

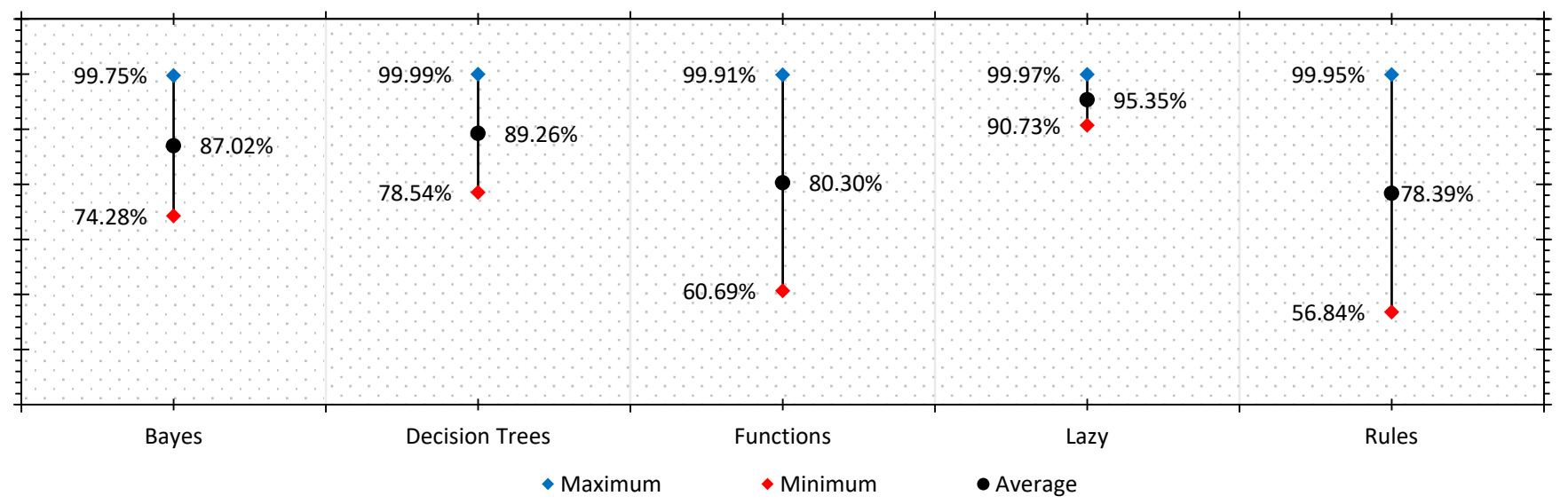

Figure 2. Comparison of classification accuracy in various classifier groups found in the literature.

Similarly, considering the average accuracy, the Lazy classifiers are far ahead of different groups of classifiers. Despite having an impressive accuracy rate, the Lazy group classifiers were deeply analyzed by a handful of researchers [48-50]. On the other hand, decision trees and function-based classifiers were the center point of many research papers. Consequently, in this paper, the authors have decided to explore multiple classifiers of all the classifier groups. In this work, fifty-four state-of-the-art classifiers of six different classi- 
fier groups were analyzed. The classifier groups were created based on their functionality and the guidelines presented by Frank et al. [59]. The classifiers under evaluation and their groups are presented in Tables 2-7 under six different classifier groups.

Table 2. Bayes classifiers for evaluation.

\begin{tabular}{cll}
\hline S1. No. & \multicolumn{1}{c}{ Name of Classifiers } & \multicolumn{1}{c}{ Short Name } \\
\hline 1 & Discriminative Multinomial Naive Bayes [60] & DMNB \\
2 & Hidden Markov Models [61,62] & HMM \\
3 & Naive Bayes [63,64] & SGM \\
4 & Sparse Generative Model [65] & SG \\
\hline
\end{tabular}

Table 3. Functions classifiers.

\begin{tabular}{cll}
\hline S1. No. & \multicolumn{1}{c}{ Name of Classifiers } & Short Name \\
\hline 1 & Linear Discriminant Analysis [66] & LDA \\
2 & LibLINEAR [67] & LLNR \\
3 & LibSVM [68] & LSVM \\
4 & Logistic Regression [69] & MLPH \\
5 & Multilayer Perceptron-With one hidden layer [70] & MLPB \\
6 & Multilayer Perceptron-Back Propagation Neural Network [71] & QDA \\
7 & Quadratic Discriminant Analysis [72] & RBF \\
8 & Radial Basis Function [73] & RBFN \\
9 & Radial Basis Function Network [74] & SLR \\
10 & Simple Logistic Regression [75] & SMO \\
\hline
\end{tabular}

Table 4. Lazy group classifiers.

\begin{tabular}{cll}
\hline S1. No. & \multicolumn{1}{c}{ Name of Classifiers } & Short Name \\
\hline 1 & IB1 (Nearest Neighbor approach) [78] & IB1 \\
2 & IBk (k-nearest neighbor approach) [78] & IBK \\
3 & IBkLG (k-nearest neighbor with Log and Gaussian kernel) [78] & IBKLG \\
4 & KStar [79] & KSTAR \\
5 & Local Knn [80] & LKNN \\
6 & Locally Weighted Learning [81,82] & RLKNN \\
7 & Rseslib Knn [80] & RLNN \\
\hline
\end{tabular}

Table 5. Rule-based classifiers.

\begin{tabular}{cll}
\hline S1. No. & \multicolumn{1}{c}{ Name of Classifiers } & Short Name \\
\hline 1 & Conjunctive Rule [83] & CR \\
2 & Decision Table [84] & DTBL \\
3 & Decision Table Naïve Bayes hybrid classifier [85] & DTNB \\
4 & Fuzzy Rule Induction [86] & FURIA \\
5 & JRip [87] & JRIP \\
6 & MODLEM [88] & MODLEM \\
7 & Nearest Neighbor with Generalization [89,90] \\
8 & Ordinal Learning Method [91] & OLM \\
9 & OneR [92] & ONER \\
10 & PART [93] & PART \\
11 & RIpple-DOwn Rule learner [94] & RIDOR \\
12 & Rough Set [95] & ROUGS \\
13 & ZeroR [96] & ZEROR \\
\hline
\end{tabular}


Table 6. Decision tree classifiers.

\begin{tabular}{cll}
\hline S1. No. & \multicolumn{1}{c}{ Name of Classifiers } & Short Name \\
\hline 1 & Best-First Decision Tree [97] & BFT \\
2 & Criteria Based Decision Tree [98] & CDT \\
3 & ForestPA [99] & FPA \\
4 & Functional Tree [100] & FT \\
5 & J48 [101] & J48 \\
6 & J48Consolidated [101-103] & J48C \\
7 & J48Graft [104] & LADT \\
8 & Logit Boost-based Alternating Decision Tree [105] & LMT \\
9 & Logistic Model Trees [106,107] & NBT \\
10 & Naïve Bayes based Decision Tree [108] & REPT \\
11 & Reduces Error Pruning Tree [109] & RF \\
12 & Random Forest [110,111] & RT \\
13 & Random Tree [111] & SC \\
14 & Simple Cart [112] & SF \\
\hline
\end{tabular}

Table 7. Miscellaneous classifiers.

\begin{tabular}{cll}
\hline S1. No. & \multicolumn{1}{c}{ Name of Classifiers } & \multicolumn{1}{c}{ Short Name } \\
\hline 1 & Composite Hypercubes on Iterated Random Projections [114] & CHIRP \\
2 & Fuzzy Lattice Reasoning [115] & FLR \\
3 & Hyper Pipes [116] & HP \\
4 & Voting Feature Intervals [117] & VFI \\
\hline
\end{tabular}

\section{Materials and Methods}

The authors used Weka 3.8.1 [59] software in a CentOS platform on the Param Shavak supercomputing facility provided by the Centre for Development of Advanced Computing (CDAC), India. The supercomputing system consists of 64 GB RAM with two multicore CPUs, each with 12 cores having a performance of 2.3 Teraflops. To evaluate all the classifiers of Tables 2-7, the authors have considered samples of NSLKDD [118-120], ISCXIDS2012 [121], and CICIDS2017 [122] datasets. The training and testing sample size for each dataset is outlined in Table 8 . The training and testing samples were generated with $66 \%$ and a $34 \%$ split of the total sample size.

Table 8. Miscellaneous classifiers.

\begin{tabular}{llll}
\hline Datasets & Sample Size & Training Instances & Testing Instances \\
\hline NSLKDD & 7781 & 5135 & 2646 \\
ISCXIDS2012 & 5494 & 3626 & 1868 \\
CICIDS2017 & 8917 & 5885 & 3032 \\
\hline
\end{tabular}

All three NSLKDD, CICIDS2017 and ISCXIDS2012, have a high-class imbalance. Additionally, NSLKDD and CICIDS2017 are multi-class, and the ISCXIDS2012 dataset contains binary class information. The performance of a classifier cannot be explored only through its accuracy and detection rate. Therefore, the authors have considered a variety of performance measures such as training time, testing time, model accuracy, misclassification rate, kappa, mean absolute error, root mean squared error, relative absolute error, root relative squared error, true positive rate, false-positive rate, precision, and receiver operating curve (ROC). The ROC value reveals the real performance on class imbalance datasets such as the CICIDS2017 and the NSL-KDD. Similarly, the Matthews correlation coefficient (MCC) and precision-recall curve (PRC) are useful for evaluating binary classification on the ISCXIDS2012 dataset. 
The experiment for evaluating classifiers covers five essential steps [123], such as dataset selection, classification, weight calculation using multi-criteria decision making, weight to rank transformation, and finally, global rank generation. Figure 3 shows the methodology used by the authors.

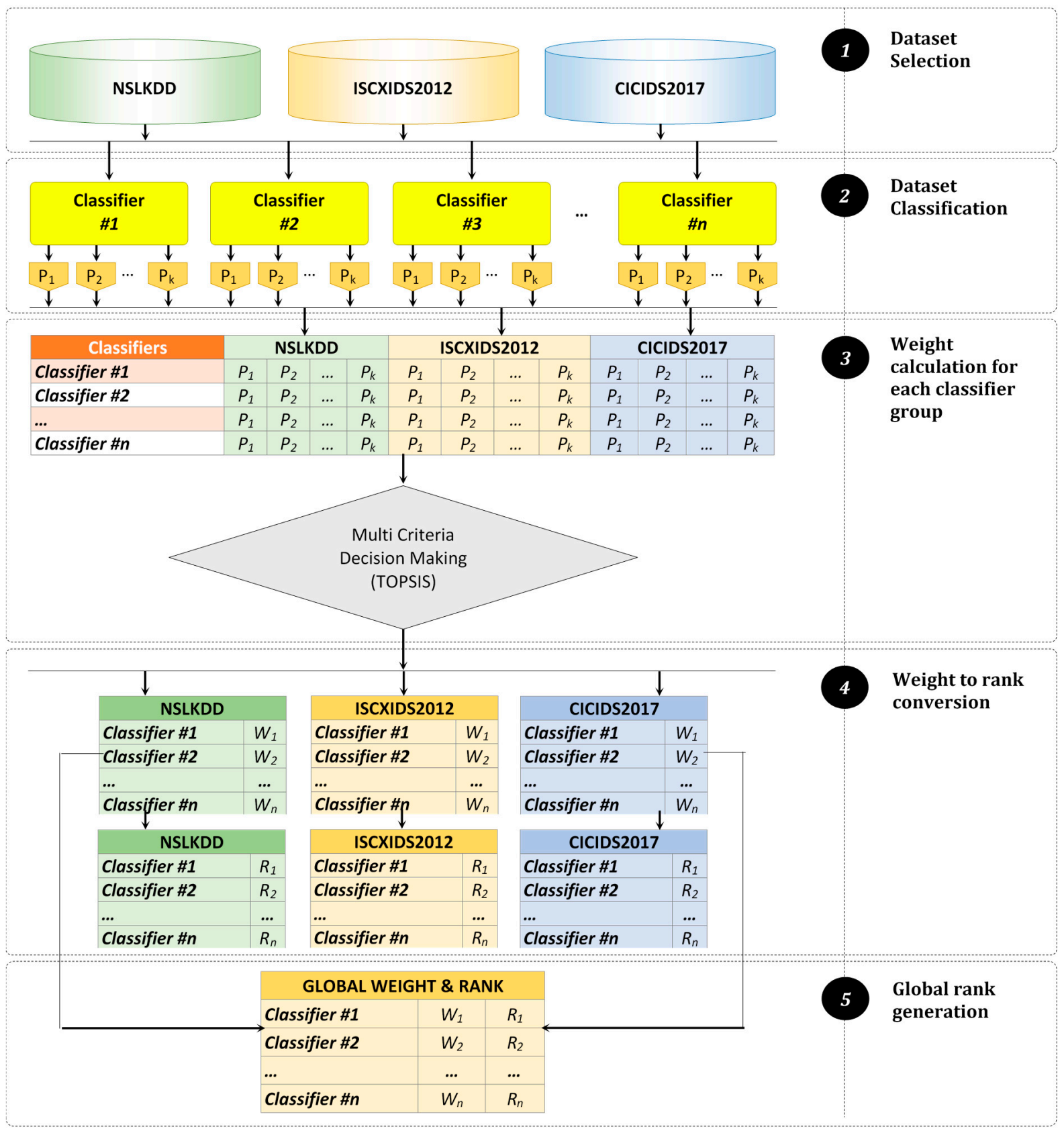

Figure 3. The methodology of classification to rank allocations of supervised classifiers.

The authors have conducted all five steps iteratively for all datasets and classifiers under evaluation. In the initial steps from the pool of datasets, a dataset has been selected. The dataset initially contains several tuples with variable class densities. From each dataset, the requisite number of random samples were generated. The output of this step has been presented in Table 8. This procedure was conducted deliberately to ensure that all the classifiers were not biased for a specific dataset. The second step began by classifying each dataset using each classifier that is presented in the classifier pool. The performance of each classifier was tabulated for future reference. The process has been recursively conducted for each dataset. 
The third and fourth steps jointly work to achieve the research objectives. In this process, the average performance score of each group of classifiers has been analyzed. Additionally, each group's ranking has also been calculated to retrieve the best classifier group specific to the dataset. All the group's classifiers with better results were considered to evaluate their consistent performance across the three datasets. Furthermore, considering the performances of the best performing group's classifiers, the authors have calculated the weight and rank of each classifier of that group, specific to each dataset. The authors aimed to provide a reliable evaluation of the best classifier for each dataset.

The final step involved global weight and rank calculation. At this stage, the global weight of a classifier of the best performing group was calculated based on the ranking received for each dataset. The average performance results of those included in the group with the better score across the three datasets were based on the individual score of each classifier. The scores were further arranged in ascending order to provide a clear presentation about the best performance classifier.

All the five steps of methodologies included a two-stage procedure. First, the best classifier group was selected, and the second-best classifier was proposed. The best classifier and classifier group were based on an extensively used conventional multiple-criteria decision-making (MCDM) method named TOPSIS. Before applying TOPSIS, the performance outcome of each classifier and each classifier group were calculated. Therefore, the authors have calculated 13 performance metrics of the classifiers.

Furthermore, the authors considered only eight performance measures, i.e., testing time per instance, accuracy, kappa value, mean absolute error, false-positive rate, precision, and receiver operating curve value for weighting and ranking purpose. On the one hand, these eight measures are in line with the aim of this research. On the other hand, all the other performance metrics can be calculated through one of these measures that are considered in this study. Consequently, the significance of those 17 measures did not affect the weighting and ranking process. The algorithmic method of the weighting of each classifier and classifier group based on TOPSIS has been demonstrated in Table 9.

It should be noted that in algoWeighting, $C_{1}, C_{2}, C_{3}, \ldots \ldots \ldots, C_{n}$ are the classifier or classifier group labels, and $P_{1}, P_{2}, P_{3}, \ldots \ldots \ldots, P_{k}$ are the performance or average performance score, respectively.

The algorithm begins with constructing a decision matrix $M_{d}$, where the $n$th classifier or classifier group is the performance outcome for $k$ th performance measure. The decision matrix is the basis for the evaluation of the best classifier. It helps the decision-making module (TOPSIS) to calculate the weight for each feature.

At the second stage, a weightage normalized decision matrix has been calculated, which is the weight of the $j$ th performance measures.

The idea behind allocating appropriate weight to performance measures is in its ability to rank classifiers specific to domain area and learning environment. For instance, in high class-imbalance learning, the performance measure Matthews correlation coefficient (MCC), Kappa, and receiver operating curve (ROC) value should be given more weightage than other performance matrices. The datasets used here were class imbalance in nature; therefore, more emphasis has been given to performance matrices suitable for the class imbalance environment. In this regard, eight performance matrices have been shortlisted, and corresponding weights have been allocated for TOPSIS processing. The weight for eight performance measures is presented in Table 10. Another reason for not considering all the performance matrices is because other performance measures themselves can be derived from the matrices presented in Table 10. For instance, detection accuracy can be calculated from True Positives (TP) and True Negatives (TN). Therefore, the True Positive Rate (TPR) and True Negative Rate (TNR) have been dropped from calculating weight for classifiers. In this way, out of the 13 performance measures, only eight performance measures have been selected. 
Table 9. The algorithm algoWeighting.

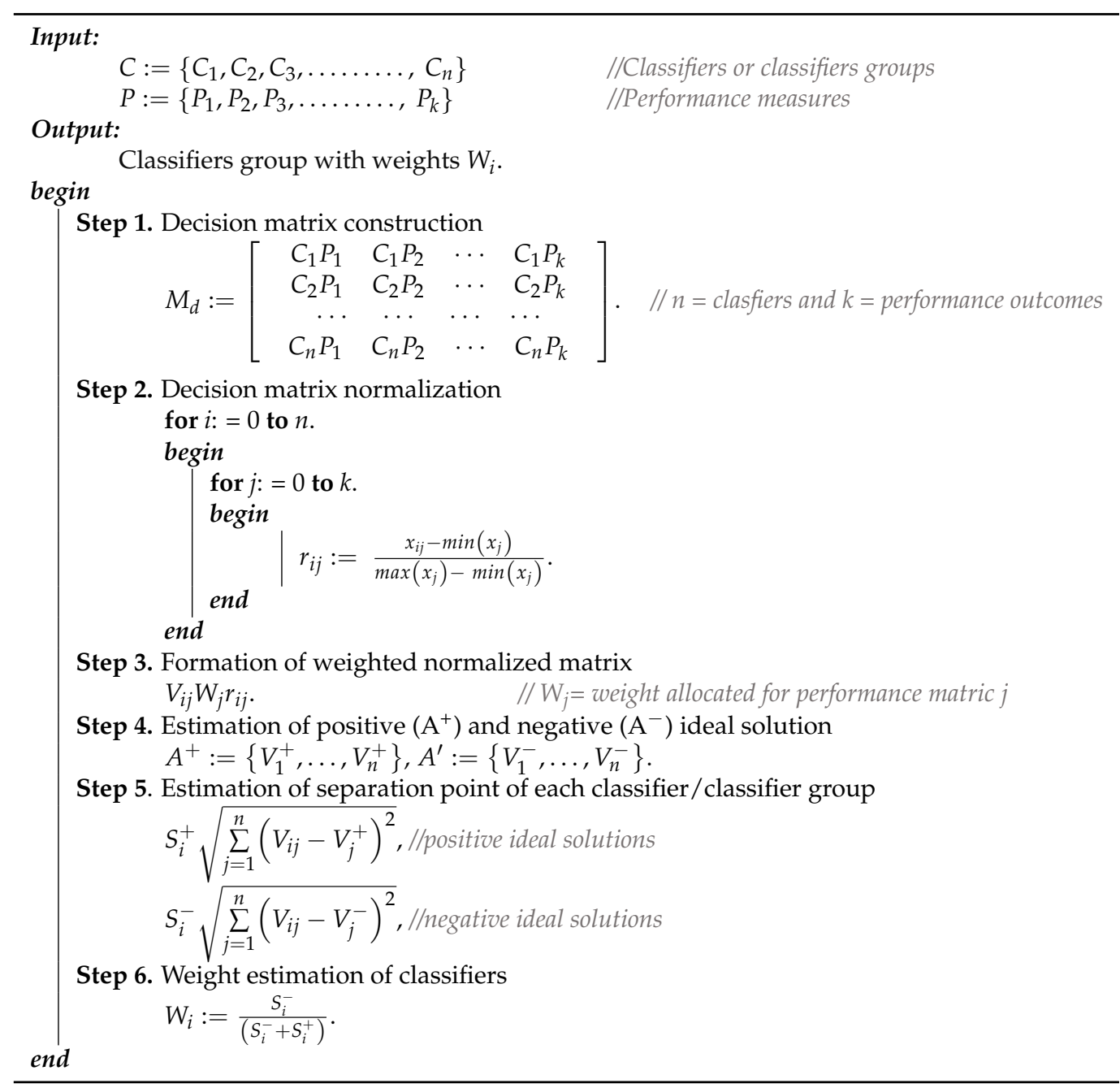

Table 10. Weights allocated to various performance measures.

\begin{tabular}{ll}
\hline Performance Measures & Weight Allocated \\
\hline Testing Time & 1 \\
Accuracy & 8 \\
Kappa & 4 \\
Mean Absolute Error (MAE) & 2 \\
False Positive Rate (FPR) & 5 \\
Precision & 7 \\
Receiver Operating Curve (ROC) Value & 6 \\
Matthews Correlation Coefficient (MCC) & 3 \\
\hline
\end{tabular}

The algorithm includes a positive and negative ideal solution to calculate the separation measure of each classifier/classifier group, which supports the calculation of each classifier or group's score. The scores are used to rank the classifiers. The procedure followed here for calculating the rank of classifiers has been presented in Table 11. 
Table 11. The algorithm rankClassifiers.

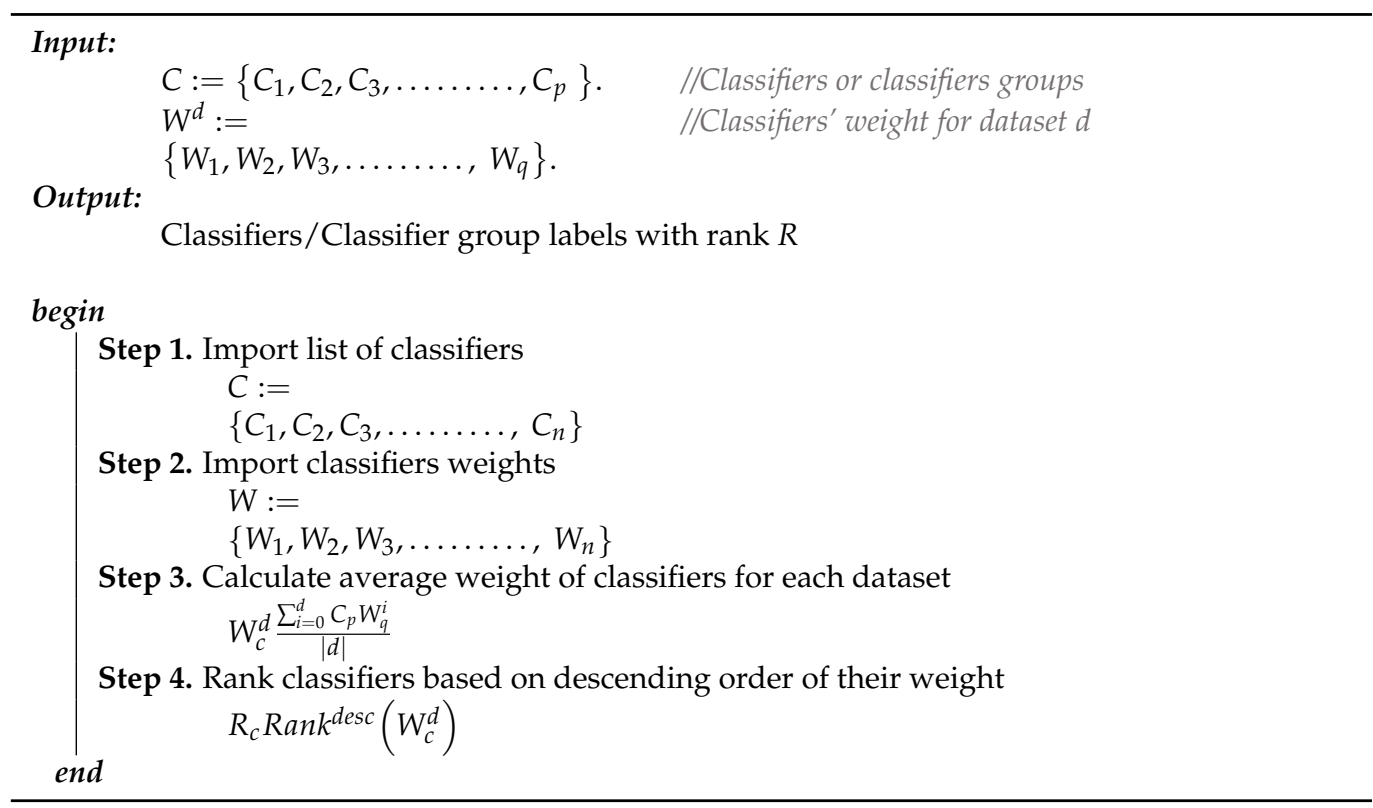

\section{Results and Discussion}

The presented analysis to reach the best classifier was conducted through a top-tobottom approach. Firstly, the best classifier group has been identified through intergroup analysis. Secondly, the best performing classifier of that best classifier group has been acknowledged through intragroup analysis.

\subsection{Intergroup Performance Analysis}

Under intergroup performance analysis, the authors have calculated the classifier group performance as a whole. The classifier's group performances for NSLKDD, ISCXIDS2012, and CICIDS2017 datasets have been listed in Tables 12-14, respectively.

According to Table 12, decision tree classifiers present reliable results in all the fields of performance metrics, except training and testing time. On the one hand, the decision tree classifiers consume training and testing times of $4.18 \mathrm{~s}$ and $0.03 \mathrm{~s}$, respectively. Similarly, the Bayes group of classifiers has a fast response in training and testing time but presents low-quality performance metrics. The ROC and MCC values are suitable for evaluating classifier groups' performance, considering the class imbalance learning. Therefore, by observing the average ROC and MCC of classifier groups on the NSL-KDD dataset, the authors have seen that the decision tree behaves far better than other classifier groups. The authors found a similar observation concerning the ISCXIDS2012 dataset. Table 6 shows the group performance of supervised classifiers for the ISCXIDS2012 dataset. The decision tree classifiers showed the highest amount of average accuracy of $97.3519 \%$, but the average testing time per instance was low and on par with Bayes and Miscellaneous classifiers. Nevertheless, decision tree classifiers were far ahead of their peer classifier groups, with a higher average ROC value of 0.985 . The authors have also conducted intergroup performance analysis on CICIDS2017. The average, maximum, and minimum performance reading has been outlined in Table 12. The decision tree classifiers reveal an impressive amount of accuracy and ROC values of 99.635 and 0.999 , respectively.

Furthermore, the decision tree classifiers present consistent performance metrics for all three intrusion detection datasets NSLKDD, ISCXIDS2012, and CICIDS2017. However, before concluding that decision trees are best for these datasets by considering a limited number of parameters, the authors have decided to identify all these classifier groups' actual weight and rank through TOPSIS. The classifier group with the highest weight and rank will be pointed out as the best classifier for these IDS datasets. This will improve the proposed study's relevance and background to find the best classifier within the winning classifier group. 
Table 12. Overall performance of classifier groups for NSLKDD dataset.

\begin{tabular}{|c|c|c|c|c|c|c|c|c|c|c|c|c|c|c|c|c|c|c|}
\hline \multirow{3}{*}{ Miscellaneous } & Avg & 1.410 & 0.020 & 49.698 & 50.302 & 0.372 & 0.245 & 0.393 & 80.759 & 100.762 & 0.955 & 0.045 & 95.464 & 95.464 & 95.464 & 0.745 & 0.437 & 0.552 \\
\hline & Max & 5.550 & 0.040 & 84.392 & 75.246 & 0.793 & 0.317 & 0.549 & 104.430 & 140.701 & 0.993 & 0.078 & 99.288 & 99.288 & 99.288 & 0.896 & 0.801 & 0.751 \\
\hline & Min & 0.010 & 0.010 & 24.754 & 15.609 & 0.071 & 0.062 & 0.250 & 20.571 & 64.082 & 0.922 & 0.007 & 92.167 & 92.167 & 92.167 & 0.538 & 0.180 & 0.285 \\
\hline \multirow{3}{*}{ Decision Tree } & Avg & 4.180 & 0.030 & 95.460 & 4.540 & 0.940 & 0.027 & 0.121 & 8.826 & 31.035 & 0.996 & 0.004 & 99.561 & 99.561 & 99.561 & 0.988 & 0.943 & 0.963 \\
\hline & Max & 39.970 & 0.130 & 97.619 & 13.568 & 0.969 & 0.094 & 0.200 & 30.903 & 51.334 & 0.999 & 0.020 & 99.938 & 99.938 & 99.938 & 0.998 & 0.970 & 0.993 \\
\hline & Min & 0.020 & 0.001 & 86.432 & 2.381 & 0.823 & 0.013 & 0.090 & 4.160 & 23.006 & 0.980 & 0.001 & 98.002 & 98.002 & 98.002 & 0.971 & 0.841 & 0.886 \\
\hline \multirow[b]{2}{*}{ Rules } & Avg & 1.590 & 0.040 & 82.121 & 17.859 & 0.763 & 0.081 & 0.200 & 26.846 & 51.314 & 0.988 & 0.012 & 98.754 & 98.754 & 98.754 & 0.898 & 0.767 & 0.799 \\
\hline & Max & 7.620 & 0.200 & 97.241 & 74.339 & 0.964 & 0.304 & 0.433 & 100.000 & 111.128 & 0.999 & 0.100 & 99.935 & 99.935 & 99.935 & 0.993 & 0.965 & 0.976 \\
\hline \multirow{3}{*}{ Lazy } & Avg & 48.960 & 15.560 & 90.730 & 9.270 & 0.876 & 0.050 & 0.165 & 16.474 & 42.355 & 0.996 & 0.004 & 99.601 & 99.601 & 99.601 & 0.969 & 0.876 & 0.919 \\
\hline & Max & 333.500 & 67.290 & 95.729 & 34.467 & 0.944 & 0.209 & 0.313 & 68.821 & 80.239 & 0.999 & 0.012 & 99.880 & 99.880 & 99.880 & 0.991 & 0.945 & 0.971 \\
\hline & Min & 0.001 & 0.140 & 65.533 & 4.271 & 0.534 & 0.020 & 0.122 & 6.724 & 31.167 & 0.988 & 0.001 & 98.775 & 98.775 & 98.775 & 0.927 & 0.525 & 0.825 \\
\hline \multirow{3}{*}{ Functions } & Avg & 2.990 & 0.120 & 72.061 & 27.939 & 0.629 & 0.155 & 0.292 & 50.928 & 74.868 & 0.991 & 0.009 & 99.130 & 99.130 & 99.130 & 0.887 & 0.639 & 0.737 \\
\hline & Max & 9.370 & 1.220 & 92.026 & 38.813 & 0.895 & 0.262 & 0.371 & 86.342 & 95.227 & 0.997 & 0.016 & 99.675 & 99.675 & 99.675 & 0.946 & 0.897 & 0.866 \\
\hline & Min & 0.020 & 0.001 & 61.187 & 7.974 & 0.501 & 0.032 & 0.179 & 10.509 & 45.804 & 0.984 & 0.003 & 98.400 & 98.400 & 98.400 & 0.770 & 0.520 & 0.510 \\
\hline \multirow[b]{2}{*}{ Bayes } & Avg & 0.040 & 0.010 & 41.043 & 58.957 & 0.266 & 0.258 & 0.369 & 84.979 & 94.696 & 0.966 & 0.034 & 96.596 & 96.596 & 96.596 & 0.694 & 0.282 & 0.479 \\
\hline & Max & 0.080 & 0.020 & 70.824 & 81.519 & 0.610 & 0.322 & 0.405 & 106.223 & 103.920 & 0.987 & 0.064 & 98.664 & 98.664 & 98.664 & 0.889 & 0.628 & 0.745 \\
\hline \multicolumn{2}{|c|}{ Performance Measures } & $\begin{array}{l}\text { Training } \\
\text { Time (s) }\end{array}$ & $\begin{array}{l}\text { Testing } \\
\text { Time (s) }\end{array}$ & $\begin{array}{c}\text { Model } \\
\text { Accuracy } \\
(\%)\end{array}$ & $\begin{array}{c}\text { M.C.R. } \\
(\%)\end{array}$ & $\begin{array}{c}\text { Kappa } \\
\text { Statistics }\end{array}$ & M.A.E. $r$ & R.M.S.E. & $\begin{array}{c}\text { R.A.E. } \\
(\%)\end{array}$ & $\begin{array}{c}\text { R.R.S.E. } \\
(\%)\end{array}$ & $\begin{array}{c}\text { True } \\
\text { Positive } \\
\text { Rate }\end{array}$ & $\begin{array}{c}\text { False } \\
\text { Positive } \\
\text { Rate }\end{array}$ & $\begin{array}{l}\text { Precision } \\
(\%)\end{array}$ & $\begin{array}{c}\text { Sensitivity } \\
(\%)\end{array}$ & $\begin{array}{c}\text { F- } \\
\text { Measure }\end{array}$ & $\begin{array}{l}\text { ROC } \\
\text { Value }\end{array}$ & $\begin{array}{l}\text { MCC } \\
\text { Value }\end{array}$ & $\begin{array}{l}\text { PRC } \\
\text { Area }\end{array}$ \\
\hline
\end{tabular}


Table 13. Overall performance of classifier groups for ISCXIDS2012 dataset.

\begin{tabular}{|c|c|c|c|c|c|c|c|c|c|c|c|c|c|c|c|c|c|c|}
\hline \multirow{3}{*}{ Miscellaneous } & Avg & 0.740 & 0.010 & 57.548 & 42.452 & 0.145 & 0.428 & 0.543 & 85.557 & 108.576 & 0.995 & 0.005 & 99.540 & 99.540 & 99.540 & 0.590 & 0.176 & 0.573 \\
\hline & $\operatorname{Max}$ & 2.940 & 0.030 & 77.356 & 49.090 & 0.545 & 0.499 & 0.701 & 99.813 & 140.098 & 0.997 & 0.006 & 99.699 & 99.699 & 99.699 & 0.771 & 0.570 & 0.717 \\
\hline & Min & 0.001 & 0.001 & 50.910 & 22.645 & 0.000 & 0.226 & 0.476 & 45.281 & 95.152 & 0.994 & 0.003 & 99.406 & 99.406 & 99.406 & 0.500 & 0.000 & 0.500 \\
\hline \multirow{2}{*}{ Decision Tree } & Avg & 5.170 & 0.010 & 97.352 & 2.648 & 0.947 & 0.036 & 0.152 & 7.197 & 30.338 & 1.000 & 0.000 & 99.973 & 99.973 & 99.973 & 0.985 & 0.947 & 0.980 \\
\hline & Min & 0.020 & 0.001 & 94.700 & 1.445 & 0.894 & 0.021 & 0.107 & 4.175 & 21.384 & 1.000 & 0.000 & 99.951 & 99.951 & 99.951 & 0.968 & 0.895 & 0.954 \\
\hline \multirow{3}{*}{ Rules } & Avg & 0.610 & 0.020 & 89.960 & 10.031 & 0.800 & 0.114 & 0.243 & 22.758 & 48.564 & 0.999 & 0.001 & 99.907 & 99.907 & 99.907 & 0.905 & 0.808 & 0.890 \\
\hline & Max & 3.430 & 0.160 & 97.912 & 50.910 & 0.958 & 0.500 & 0.529 & 100.000 & 105.702 & 1.000 & 0.004 & 99.982 & 99.982 & 99.982 & 0.992 & 0.959 & 0.991 \\
\hline & Min & 0.001 & 0.001 & 49.090 & 2.088 & 0.000 & 0.023 & 0.139 & 4.670 & 27.863 & 0.996 & 0.000 & 99.605 & 99.605 & 99.605 & 0.500 & 0.000 & 0.500 \\
\hline \multirow{3}{*}{ Lazy } & Avg & 14.070 & 9.220 & 92.551 & 7.449 & 0.851 & 0.089 & 0.252 & 17.747 & 50.293 & 0.999 & 0.001 & 99.923 & 99.923 & 99.923 & 0.940 & 0.855 & 0.920 \\
\hline & Max & 92.180 & 29.720 & 97.323 & 17.827 & 0.946 & 0.273 & 0.367 & 54.614 & 73.282 & 1.000 & 0.002 & 99.972 & 99.972 & 99.972 & 0.990 & 0.946 & 0.987 \\
\hline & Min & 0.001 & 0.010 & 82.173 & 2.677 & 0.641 & 0.030 & 0.153 & 5.995 & 30.560 & 0.998 & 0.000 & 99.825 & 99.825 & 99.825 & 0.884 & 0.674 & 0.866 \\
\hline \multirow{3}{*}{ Functions } & Avg & 2.340 & 0.170 & 70.873 & 29.127 & 0.413 & 0.343 & 0.471 & 68.686 & 94.124 & 0.997 & 0.003 & 99.730 & 99.730 & 99.730 & 0.739 & 0.451 & 0.731 \\
\hline & Max & 18.720 & 1.860 & 90.364 & 49.090 & 0.807 & 0.491 & 0.701 & 98.163 & 140.098 & 0.999 & 0.005 & 99.906 & 99.906 & 99.906 & 0.929 & 0.807 & 0.924 \\
\hline & Min & 0.010 & 0.001 & 50.910 & 9.636 & 0.000 & 0.170 & 0.302 & 33.986 & 60.396 & 0.995 & 0.001 & 99.498 & 99.498 & 99.498 & 0.500 & 0.000 & 0.500 \\
\hline \multirow[b]{2}{*}{ Bayes } & Avg & 0.020 & 0.010 & 50.669 & 49.331 & 0.004 & 0.498 & 0.552 & 99.558 & 110.331 & 0.995 & 0.005 & 99.486 & 99.486 & 99.486 & 0.576 & 0.004 & 0.563 \\
\hline & Max & 0.050 & 0.020 & 50.910 & 49.786 & 0.021 & 0.500 & 0.702 & 99.983 & 140.281 & 0.996 & 0.006 & 99.610 & 99.610 & 99.610 & 0.791 & 0.058 & 0.746 \\
\hline \multicolumn{2}{|c|}{ Performance Measures } & $\begin{array}{l}\text { Training } \\
\text { Time (s) }\end{array}$ & $\begin{array}{l}\text { Testing } \\
\text { Time (s) }\end{array}$ & $\begin{array}{c}\text { Model } \\
\text { Accuracy } \\
(\%)\end{array}$ & $\underset{(\%)}{\text { M.C.R. }}$ & $\begin{array}{c}\text { Kappa } \\
\text { Statistics }\end{array}$ & M.A.E. & R.M.S.E. & $\underset{(\%)}{\text { R.A.E. }}$ & $\begin{array}{c}\text { R.R.S.E. } \\
(\%)\end{array}$ & $\begin{array}{c}\text { True } \\
\text { Positive } \\
\text { Rate }\end{array}$ & $\begin{array}{c}\text { False } \\
\text { Positive } \\
\text { Rate }\end{array}$ & $\begin{array}{c}\text { Precision } \\
(\%)\end{array}$ & $\begin{array}{l}\text { Sensitivity } \\
(\%)\end{array}$ & $\begin{array}{c}\text { F- } \\
\text { Measure }\end{array}$ & $\begin{array}{l}\text { ROC } \\
\text { Value }\end{array}$ & $\begin{array}{l}\text { MCC } \\
\text { Value }\end{array}$ & $\begin{array}{l}\text { PRC } \\
\text { Area }\end{array}$ \\
\hline
\end{tabular}


Table 14. Overall performance of classifier groups for CICIDS2017 dataset.

\begin{tabular}{|c|c|c|c|c|c|c|c|c|c|c|c|c|c|c|c|c|c|c|}
\hline \multirow{3}{*}{ Miscellaneous } & Avg & 0.750 & 0.020 & 98.961 & 1.039 & 0.987 & 0.079 & 0.141 & 33.502 & 41.113 & 1.000 & 0.000 & 99.989 & 99.989 & 99.989 & 0.996 & 0.988 & 0.987 \\
\hline & $\operatorname{Max}$ & 2.900 & 0.030 & 99.835 & 1.847 & 0.998 & 0.225 & 0.323 & 95.108 & 93.957 & 1.000 & 0.000 & 99.998 & 99.998 & 99.998 & 1.000 & 0.998 & 0.999 \\
\hline & Min & 0.010 & 0.010 & 98.153 & 0.165 & 0.978 & 0.001 & 0.022 & 0.200 & 6.315 & 1.000 & 0.000 & 99.979 & 99.979 & 99.979 & 0.989 & 0.978 & 0.968 \\
\hline \multirow{3}{*}{ Decision Tree } & Avg & 19.150 & 0.040 & 99.635 & 0.365 & 0.996 & 0.002 & 0.030 & 0.856 & 8.847 & 1.000 & 0.000 & 99.996 & 99.996 & 99.996 & 0.999 & 0.996 & 0.997 \\
\hline & Max & 258.830 & 0.180 & 99.868 & 0.693 & 0.998 & 0.005 & 0.044 & 1.888 & 12.889 & 1.000 & 0.000 & 99.999 & 99.999 & 99.999 & 1.000 & 0.998 & 1.000 \\
\hline & Min & 0.030 & 0.000 & 99.307 & 0.132 & 0.992 & 0.000 & 0.019 & 0.160 & 5.648 & 1.000 & 0.000 & 99.993 & 99.993 & 99.993 & 0.997 & 0.992 & 0.990 \\
\hline \multirow[b]{2}{*}{ Rules } & Avg & 1.490 & 0.020 & 86.528 & 13.472 & 0.835 & 0.040 & 0.097 & 17.109 & 28.123 & 0.999 & 0.001 & 99.874 & 99.874 & 99.874 & 0.931 & 0.836 & 0.857 \\
\hline & Max & 8.790 & 0.050 & 99.868 & 81.300 & 0.998 & 0.236 & 0.344 & 100.000 & 100.000 & 1.000 & 0.007 & 99.999 & 99.999 & 99.999 & 1.000 & 0.998 & 1.000 \\
\hline \multirow{3}{*}{ Lazy } & Avg & 24.600 & 22.380 & 94.973 & 5.027 & 0.938 & 0.022 & 0.064 & 9.513 & 18.547 & 1.000 & 0.000 & 99.953 & 99.953 & 99.953 & 0.998 & 0.938 & 0.993 \\
\hline & Max & 158.190 & 74.390 & 99.802 & 31.860 & 0.998 & 0.148 & 0.254 & 62.516 & 73.749 & 1.000 & 0.003 & 99.998 & 99.998 & 99.998 & 1.000 & 0.998 & 0.999 \\
\hline & Min & 0.000 & 0.030 & 68.140 & 0.198 & 0.609 & 0.001 & 0.024 & 0.239 & 6.918 & 0.997 & 0.000 & 99.703 & 99.703 & 99.703 & 0.991 & 0.606 & 0.982 \\
\hline \multirow{3}{*}{ Functions } & Avg & 18.420 & 0.430 & 86.702 & 13.298 & 0.837 & 0.065 & 0.166 & 27.680 & 48.178 & 0.999 & 0.001 & 99.876 & 99.876 & 99.876 & 0.933 & 0.843 & 0.871 \\
\hline & Max & 115.950 & 4.470 & 99.373 & 73.450 & 0.992 & 0.210 & 0.458 & 88.857 & 133.270 & 1.000 & 0.007 & 99.995 & 99.995 & 99.995 & 0.999 & 0.992 & 0.998 \\
\hline & Min & 0.030 & 0.010 & 26.550 & 0.627 & 0.097 & 0.002 & 0.041 & 0.758 & 12.018 & 0.993 & 0.000 & 99.295 & 99.295 & 99.295 & 0.548 & 0.232 & 0.241 \\
\hline \multirow[b]{2}{*}{ Bayes } & Avg & 0.030 & 0.020 & 43.041 & 56.959 & 0.347 & 0.172 & 0.265 & 72.822 & 77.112 & 0.994 & 0.006 & 99.440 & 99.440 & 99.440 & 0.711 & 0.345 & 0.472 \\
\hline & Max & 0.070 & 0.070 & 98.318 & 89.116 & 0.980 & 0.246 & 0.353 & 104.155 & 102.627 & 1.000 & 0.010 & 99.985 & 99.985 & 99.985 & 0.999 & 0.979 & 0.996 \\
\hline \multicolumn{2}{|c|}{ Performance Measures } & $\begin{array}{l}\text { Training } \\
\text { Time (s) }\end{array}$ & $\begin{array}{l}\text { Testing } \\
\text { Time (s) }\end{array}$ & $\begin{array}{c}\text { Model } \\
\text { Accuracy } \\
(\%)\end{array}$ & $\begin{array}{c}\text { M.C.R. } \\
(\%)\end{array}$ & $\begin{array}{c}\text { Kappa } \\
\text { Statistics }\end{array}$ & M.A.E. & R.M.S.E. & $\begin{array}{c}\text { R.A.E. } \\
(\%)\end{array}$ & $\begin{array}{c}\text { R.R.S.E. } \\
(\%)\end{array}$ & $\begin{array}{c}\text { True } \\
\text { Positive } \\
\text { Rate }\end{array}$ & $\begin{array}{c}\text { False } \\
\text { Positive } \\
\text { Rate }\end{array}$ & $\begin{array}{l}\text { Precision } \\
(\%)\end{array}$ & $\begin{array}{c}\text { Sensitivity } \\
(\%)\end{array}$ & $\begin{array}{c}\text { F- } \\
\text { Measure }\end{array}$ & $\begin{array}{l}\text { ROC } \\
\text { Value }\end{array}$ & $\begin{array}{l}\text { MCC } \\
\text { Value }\end{array}$ & $\begin{array}{l}\text { PRC } \\
\text { Area }\end{array}$ \\
\hline
\end{tabular}


Figure 4 presents the weights and ranks of classifier groups for all three IDS datasets. The decision tree classifier presents the highest performance. Moreover, the decision trees present a consistent performance for all the IDS datasets. Therefore, the decision tree can be considered as the best method for the development of reliable IDSs.

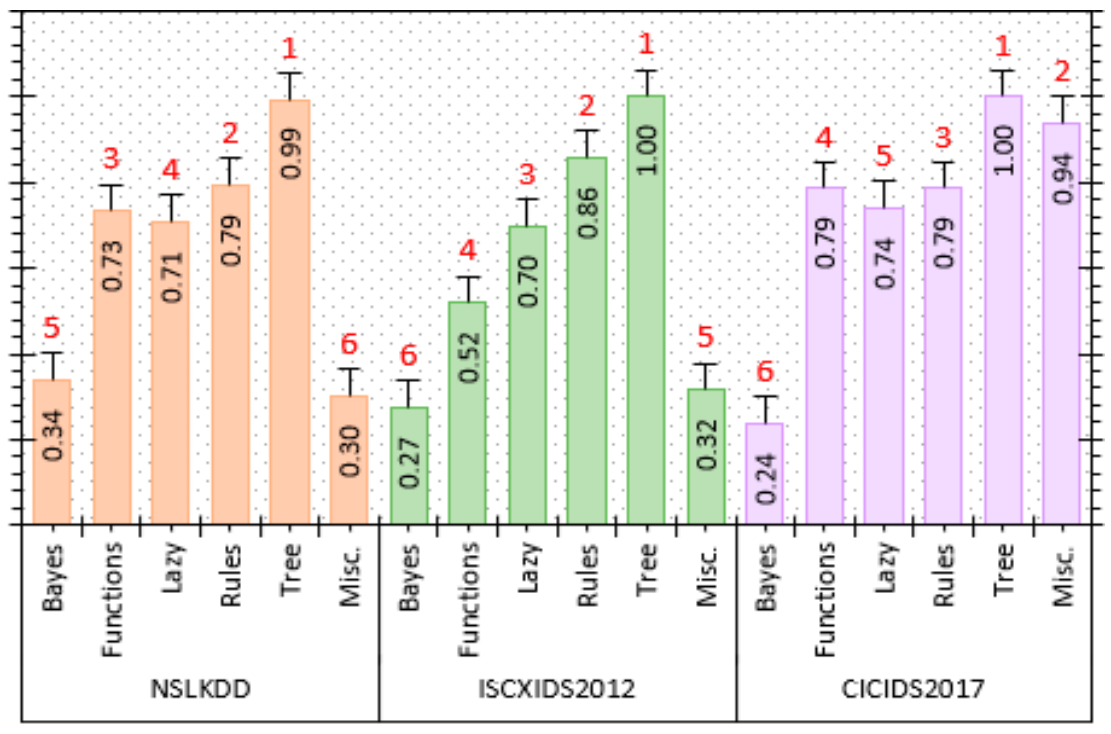

Datasets \& Classifier groups $\rightarrow$

Figure 4. Weights and ranks of supervised classifier groups.

\subsection{Intragroup Performance Analysis}

In the intergroup analysis, the authors conclude that decision tree classifiers reveal the best performance for imbalanced IDS datasets. The authors have decided to conduct an intragroup analysis of decision trees for NSLKDD, ISCXIDS2012, and CICIDS2017 datasets. The intragroup study aims to identify the best decision tree within the decision tree group of classifiers for the concerned datasets. Several performance outcomes of decision tree classifiers for NSLKDD, ISCXIDS2012, and CICIDS2017 datasets have been analyzed through Figures 5-7.
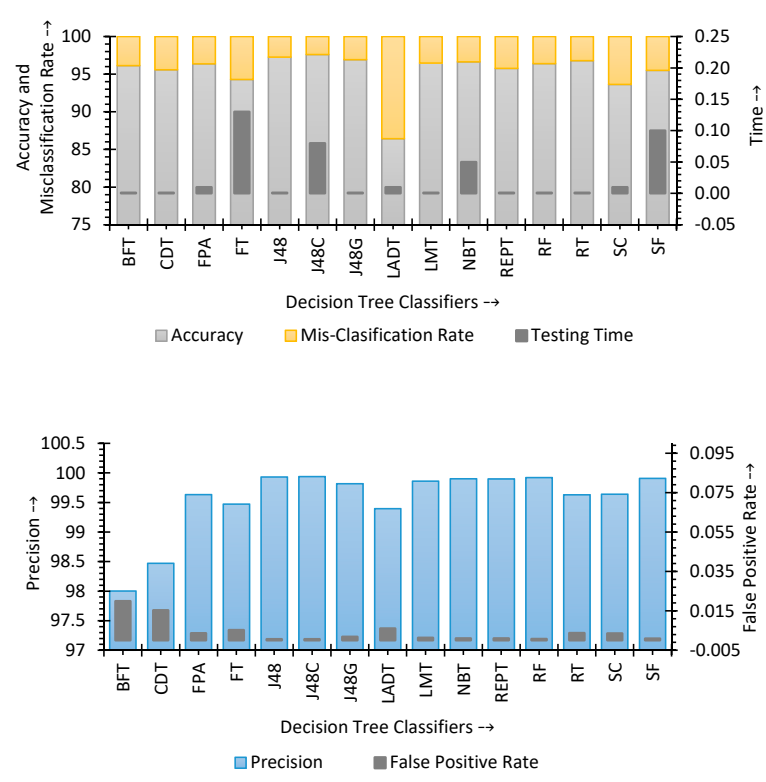
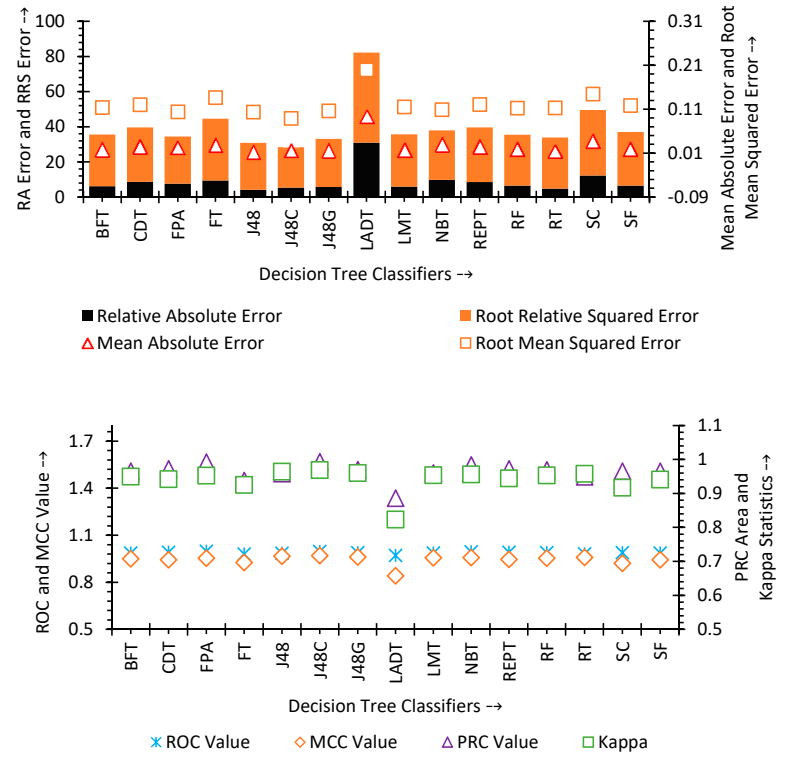

Figure 5. Performance of decision tree classifiers for NSLKDD dataset. 


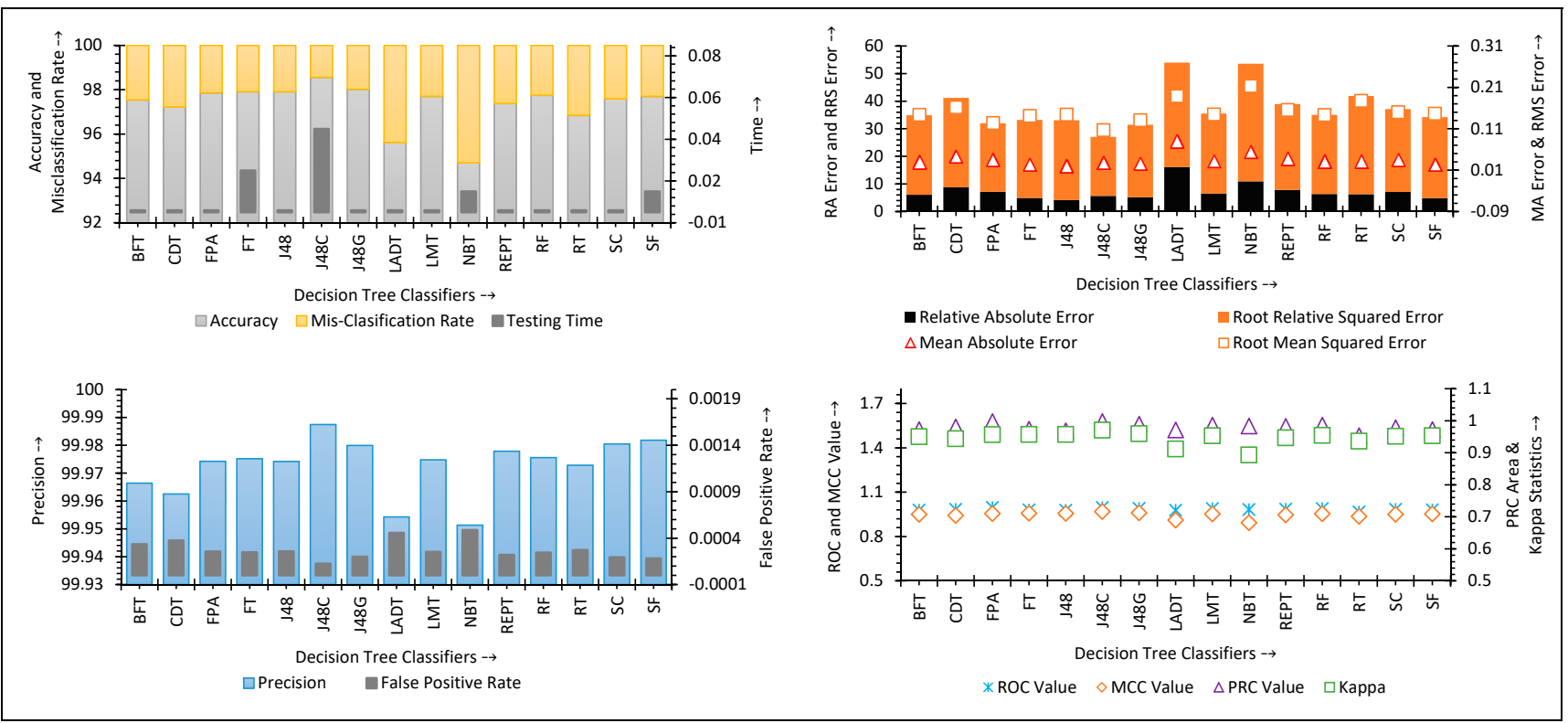

Figure 6. Performance of decision tree classifiers for ISCXIDS2012 dataset.

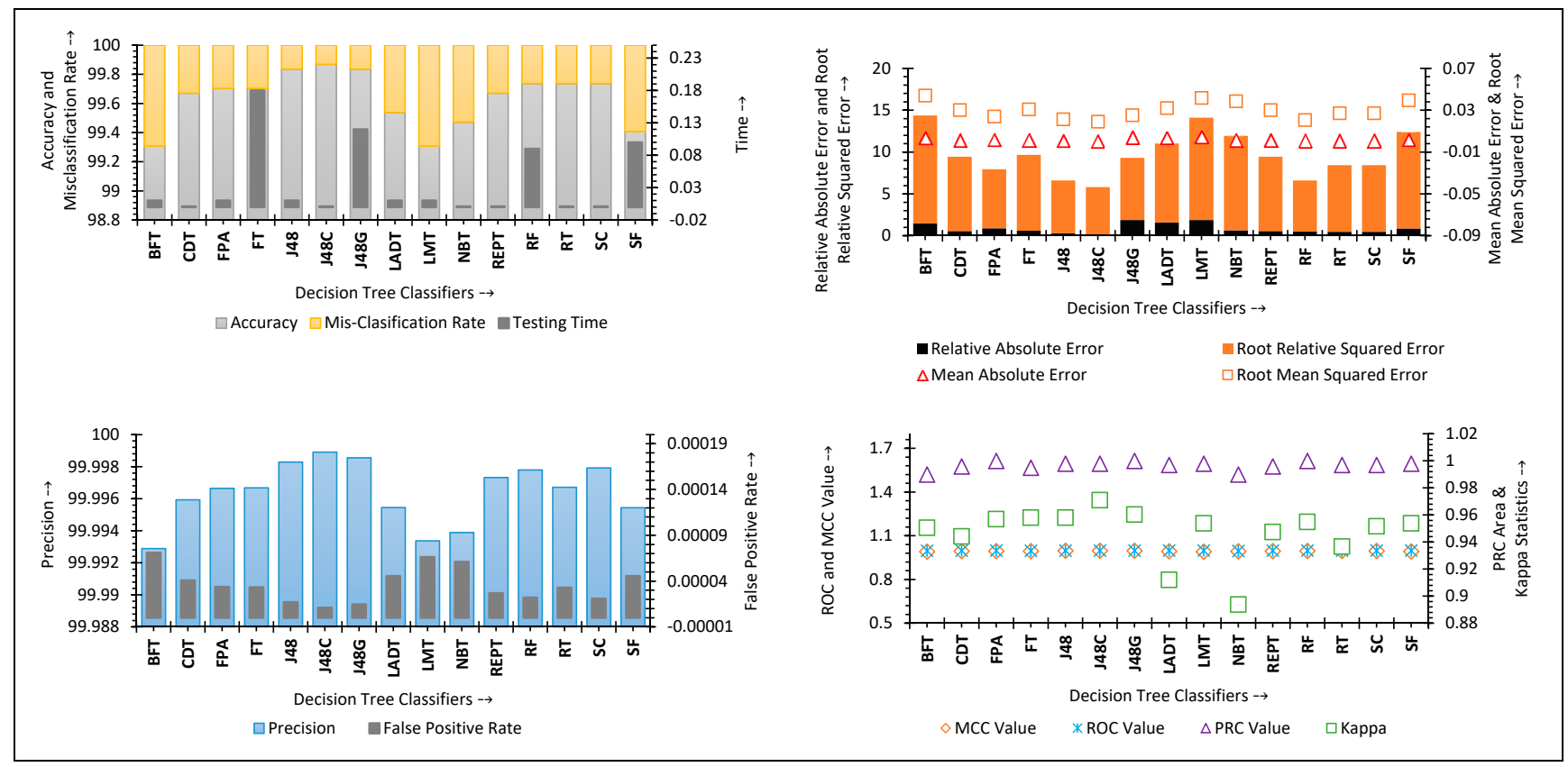

Figure 7. Performance of decision tree classifiers for CICIDS2017 dataset.

The J48Consolidated classifier shows better accuracy for the NSL-KDD dataset. The sample size of NSLKDD here is an imbalance in nature. Therefore, these measures play a significant role in finding the best classifier. Considering the ROC value, the ForestPA performs better as compared to J48Consolidated. Additionally, both ForestPA and J48Consolidated show similar performance in terms of the MCC value. Consequently, the authors did not find sufficient scope for deciding an ideal decision tree classifier for the NSLKDD dataset.

Furthermore, the decision tree classifiers' performance on a sample of the ISCXIDS2012 dataset is presented in Figure 6. The Functional Trees (FT), J48Consolidated, NBTree, and SysFor classifiers consumed a significant amount of computational time. Nevertheless, the rest of the decision trees consumed $0.001 \mathrm{~s}$ of testing time per instance. The J48Consolidated algorithm was limited by presenting the longest amount of time to detect an anomalous instance. However, this computation time consumption supports 
the fact that J48Consolidated provides the highest accuracy of $98.5546 \%$, which leads to the lowest misclassification rate of $1.4454 \%$. Moreover, J48Consolidated seems to lead the decision trees group with the best Kappa value (0.9711).

The test results of decision trees on a CICIDS2017 dataset are presented in Figure 7. The J48Consolidated algorithm provides high-quality results in the class imbalance instances of the CICIDS2017 dataset. J48Consolidated scores the highest accuracy with a low misclassification rate. However, considering the ROC and MCC values, the J48 presents better performance than the J48Consolidated. Therefore, it is not clear about the best classifiers, which can be considered as the base learner for future IDS.

In the case of ISCXIDS2012, J48Consolidated also presents consistent results in all performance measures. However, in the case of NSL-KDD and CICIDS2017, it was not possible to find the best classifier. Therefore, the authors have also considered TOPSIS to allocate individual decision tree classifiers' weight and rank. The average weight and rank of decision tree classifiers for all datasets have also been calculated to find the best classifier for all the datasets. The average weight and rank across all the datasets are not significant in identifying a suitable classifier because an IDS is designed considering a specific dataset or environment. However, average weight and rank will play a relevant role in the conclusion concerning the most versatile classifier conducted in this study. The average ranks and weights of all the classifiers for all the three IDS datasets are represented in Figure 8.

The J48Consolidated classifier has the highest rank across all the datasets. Moreover, J48Consolidated presents the highest weight of 0.964 for the ISCXIDS2012 dataset. The J48Consolidated decision tree classifier is best for the high-class imbalance NSLKDD and CICIDS2017 and ISCXIDS2012 datasets. Therefore, J48Consolidated will be a suitable classifier for designing IDS base learners using either NSLKDD, ISCXIDS2012, and CICIDS2017 datasets.
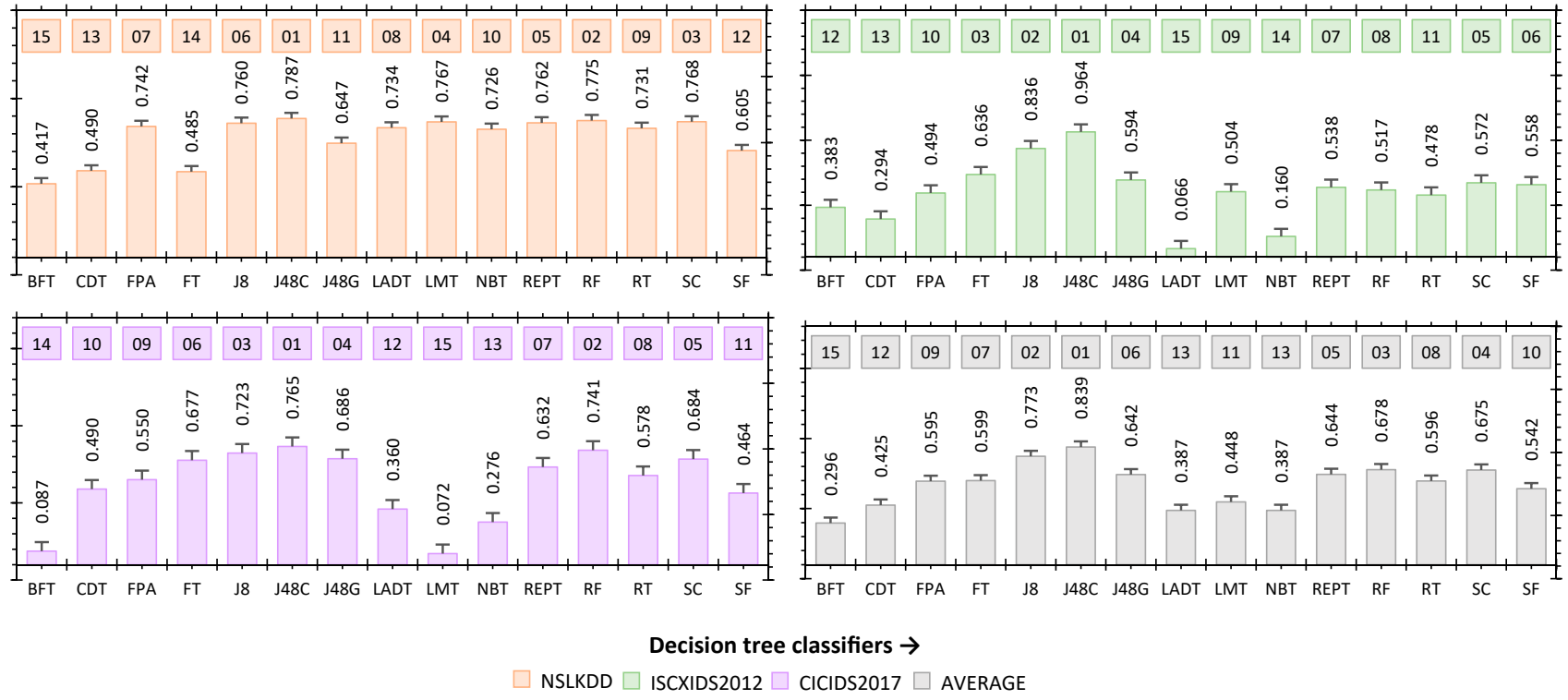

Figure 8. Techniques for Order Preference by Similarity to the Ideal Solution (TOPSIS) weights and ranks of decision tree classifiers for NSLKDD, ISCXIDS2012 and CICIIDS2017 dataset.

\subsection{Detailed Performance Reading of All the Classifiers}

Tables 15-17 provide a detailed insight of all the supervised classifiers in six distinct groups. These tables outlined thirteen performance metrics. However, the authors have identified the best classifier group (decision tree) and the best classifier (J48Consolidated). Nevertheless, other classifiers can have different performances considering other datasets. Therefore, while designing IDSs, the authors suggest further evaluation of supervised classifiers based on specific computing and network environments. 
Table 15. Performance outcome of supervised classifiers on NSL-KDD dataset.

\begin{tabular}{|c|c|c|c|c|c|c|c|c|c|c|c|c|c|c|c|c|c|c|c|c|c|c|c|c|c|c|c|c|c|c|}
\hline $\begin{array}{l}\text { PRC } \\
\end{array}$ & & 0.69 & 0.24 & 0.75 & 0.24 & & 0.75 & 0.51 & 0.87 & 0.84 & 0.69 & 0.84 & 0.73 & 0.71 & 0.76 & 0.84 & 0.58 & & 0.91 & 0.94 & 0.97 & 0.97 & 0.9 & 0.83 & 0.91 & & 0.43 & 0.97 & 0.98 & 0.97 \\
\hline MCC & & 0.63 & 0 & 0.5 & 0 & & 0.54 & 0.52 & 0.9 & 0.72 & 0.57 & 0.75 & 0.53 & 0.57 & 0.65 & 0.71 & 0.56 & & 0.93 & 0.94 & 0.94 & 0.95 & 0.93 & 0.53 & 0.93 & & 0.28 & 0.93 & 0.93 & 0.95 \\
\hline ROC & & 0.89 & 0.5 & 0.89 & 0.5 & & 0.89 & 0.77 & 0.95 & 0.94 & 0.87 & 0.93 & 0.88 & 0.88 & 0.91 & 0.94 & 0.83 & & 0.97 & 0.98 & 0.99 & 0.99 & 0.96 & 0.93 & 0.97 & & 0.78 & 0.99 & 0.99 & 0.99 \\
\hline PRE & & $\begin{array}{l}95.82 \\
31889\end{array}$ & $\begin{array}{l}93.59 \\
08483\end{array}$ & $\begin{array}{l}98.66 \\
36249\end{array}$ & $\begin{array}{l}98.30 \\
7638\end{array}$ & & $\begin{array}{l}98.39 \\
9922\end{array}$ & $\begin{array}{l}98.55 \\
60253 \\
6\end{array}$ & $\begin{array}{l}99.67 \\
48494\end{array}$ & $\begin{array}{l}99.19 \\
72477\end{array}$ & $\begin{array}{l}98.89 \\
33377\end{array}$ & $\begin{array}{l}99.37 \\
02418\end{array}$ & $\begin{array}{l}98.97 \\
77229\end{array}$ & $\begin{array}{l}99.20 \\
17755\end{array}$ & $\begin{array}{l}99.35 \\
70459\end{array}$ & $\begin{array}{l}99.52 \\
77488\end{array}$ & $\begin{array}{l}99.27 \\
14257\end{array}$ & & $\begin{array}{l}99.63 \\
10669\end{array}$ & $\begin{array}{l}99.6 \\
6243\end{array}$ & $\begin{array}{l}99.68 \\
28219\end{array}$ & $\begin{array}{l}99.79 \\
18892\end{array}$ & $\begin{array}{l}99.78 \\
39184\end{array}$ & $\begin{array}{l}98.77 \\
48687\end{array}$ & $\begin{array}{l}99.88 \\
02779 \\
0\end{array}$ & & $\begin{array}{l}89.99 \\
10501\end{array}$ & $\begin{array}{l}99.01 \\
83819\end{array}$ & $\begin{array}{l}99.28 \\
2802\end{array}$ & $\begin{array}{l}99.64 \\
97204\end{array}$ \\
\hline FPR & & $\begin{array}{l}0.041 \\
76811\end{array}$ & $\begin{array}{l}0.064 \\
09152\end{array}$ & $\begin{array}{l}0.013 \\
36375\end{array}$ & $\begin{array}{l}0.016 \\
92362\end{array}$ & & $\begin{array}{l}0.016 \\
00078\end{array}$ & $\begin{array}{l}0.014 \\
43975\end{array}$ & $\begin{array}{l}0.003 \\
25151\end{array}$ & $\begin{array}{l}0.008 \\
02752\end{array}$ & $\begin{array}{l}0.011 \\
066622\end{array}$ & $\begin{array}{l}0.006 \\
29758\end{array}$ & $\begin{array}{l}0.010 \\
22277\end{array}$ & $\begin{array}{l}0.007 \\
98225\end{array}$ & $\begin{array}{l}0.006 \\
42954\end{array}$ & $\begin{array}{l}0.004 \\
72251\end{array}$ & $\begin{array}{l}0.007 \\
28574\end{array}$ & & $\begin{array}{l}0.003 \\
68933\end{array}$ & $\begin{array}{l}0.00 \\
33757\end{array}$ & $\begin{array}{l}0.003 \\
17178\end{array}$ & $\begin{array}{l}0.002 \\
08111\end{array}$ & $\begin{array}{l}0.002 \\
16082\end{array}$ & $\begin{array}{l}0.012 \\
25131\end{array}$ & $\begin{array}{l}0.001 \\
19722\end{array}$ & & $\begin{array}{l}0.10 \\
00895\end{array}$ & $\begin{array}{l}0.009 \\
81618\end{array}$ & $\begin{array}{l}0.007 \\
17198\end{array}$ & $\begin{array}{l}0.00 \\
35028\end{array}$ \\
\hline RRSE & & 79.1399 & 102.586 & 93.1367 & 103.92 & & 81.8842 & 95.2269 & 45.804 & 66.1501 & 75.5902 & 62.0564 & 91.8191 & 76.9766 & 72.4047 & 66.2061 & 89.427 & & 36.6378 & 36.0546 & 36.0659 & 31.1672 & 38.7481 & 80.2386 & 37.5756 & & 87.5368 & 39.2184 & 36.9341 & 28.0692 \\
\hline RAE & & 70.4239 & 105.433 & 57.8345 & 106.223 & & 61.3275 & $\begin{array}{l}45.4247 \\
\end{array}$ & $\begin{array}{l}10.5094 \\
\end{array}$ & 47.2252 & 59.8444 & 29.678 & 56.3749 & 62.3526 & 53.7548 & 47.3792 & 86.3418 & & 6.7241 & 7.1712 & 7.1279 & 10.8788 & 7.521 & 68.8212 & 7.0727 & & 76.422 & 22.9807 & 19.5085 & 5.2622 \\
\hline RMSE & & 0.309 & 0.4 & 0.363 & 0.405 & & 0.319 & 0.371 & 0.179 & 0.258 & 0.295 & 0.242 & 0.358 & 0.3 & 0.282 & 0.258 & 0.349 & & 0.143 & 0.141 & 0.141 & 0.122 & 0.151 & 0.313 & 0.147 & & 0.341 & 0.153 & 0.144 & 0.109 \\
\hline MAE & & 0.214 & 0.32 & 0.176 & 0.322 & & 0.186 & 0.138 & 0.032 & 0.143 & 0.182 & 0.09 & 0.171 & 0.189 & 0.163 & 0.144 & 0.262 & & 0.02 & 0.022 & 0.022 & 0.033 & 0.023 & 0.209 & 0.022 & & 0.232 & 0.07 & 0.059 & 0.016 \\
\hline $\mathrm{KV}$ & & 0.61 & 0 & 0.452 & 0 & & 0.502 & 0.536 & 0.895 & 0.708 & 0.571 & 0.743 & 0.501 & 0.564 & 0.649 & 0.706 & 0.543 & & 0.933 & 0.934 & 0.934 & 0.944 & 0.925 & 0.534 & 0.929 & & 0.316 & 0.922 & 0.927 & 0.946 \\
\hline MCR & & 29.176 & 81.519 & 43.613 & 81.519 & & 37.188 & 34.467 & 7.9743 & 21.958 & 31.859 & 19.539 & 38.813 & 32.351 & 26.493 & 22.071 & 34.618 & & 5.102 & 4.9887 & 4.9887 & 4.2706 & 5.7067 & 34.467 & 5.3666 & & 50.718 & 5.9335 & 5.5178 & 4.1194 \\
\hline ACC & & 70.824 & 188.481 & 56.387 & 18.481 & & 62.812 & 65.533 & 92.026 & 78.042 & 68.141 & 80.461 & 61.187 & 67.649 & 73.507 & 77.929 & 65.382 & & $\begin{array}{l}94.898 \\
\end{array}$ & 95.011 & 95.011 & 95.729 & 94.293 & 65.533 & 94.633 & & $\begin{array}{l}49.282 \\
\end{array}$ & 94.067 & 94.482 & 95.881 \\
\hline TT & & 0.001 & 0.01 & 0.02 & 0.01 & & 0.02 & 0.01 & 1.22 & 0.01 & 0.01 & 0.01 & 0.01 & 0.01 & 0.02 & 0.001 & 0.01 & & 0.9 & 0.56 & 0.53 & 27.26 & 67.29 & 12.27 & 0.14 & & 0.001 & 0.01 & 0.01 & 0.02 \\
\hline 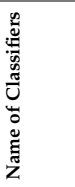 & 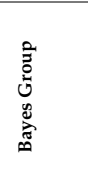 & $\sum_{\substack{\infty \\
\Delta}}^{\infty}$ & $\sum_{i}$ & 昙 & 忍 & 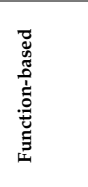 & 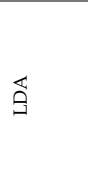 & 总 & 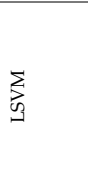 & $\because$ & 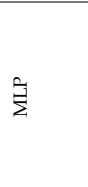 & $\overrightarrow{\tilde{z}}$ & $\overleftarrow{8}$ & 崖 & 㗹 & क्जे & 产 & 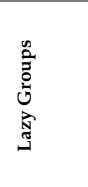 & $\vec{\theta}$ & 弟 & $\begin{array}{l}\text { U } \\
\stackrel{y}{\underline{a}}\end{array}$ & 魷 & 竞 & క్ & $\begin{array}{l}\text { Z } \\
\text { 㩊 }\end{array}$ & 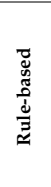 & $\approx$ & 崌 & 登 & 胥 \\
\hline PRC & 0.96 & 0.91 & 0.91 & 0.48 & 0.69 & 0.97 & 0.93 & 0.95 & 0.24 & & 0.97 & 0.97 & 0.99 & 0.94 & 0.96 & 0.99 & 0.97 & 0.89 & 0.96 & 0.98 & 0.97 & 0.97 & 0.95 & 0.97 & 0.97 & & 0.75 & 0.29 & 0.44 & 0.73 \\
\hline MCC & 0.96 & 0.94 & 0.93 & 0.46 & 0.74 & 0.97 & 0.95 & 0.96 & 0 & & 0.95 & 0.94 & 0.95 & 0.93 & 0.97 & 0.97 & 0.96 & 0.84 & 0.96 & 0.96 & 0.95 & 0.95 & 0.96 & 0.92 & 0.94 & & 0.8 & 0.18 & 0.18 & 0.59 \\
\hline ROC & 0.99 & 0.97 & 0.97 & 0.71 & 0.86 & 0.99 & 0.97 & 0.98 & 0.5 & & 0.99 & 0.99 & 1 & 0.98 & 0.99 & 1 & 0.99 & 0.97 & 0.99 & 0.99 & 0.99 & 0.99 & 0.98 & 0.99 & 0.99 & & 0.9 & 0.54 & 0.65 & 0.9 \\
\hline PRE & $\begin{array}{l}99.82 \\
79894\end{array}$ & $\begin{array}{l}99.83 \\
07215\end{array}$ & $\begin{array}{l}\begin{array}{l}99.841 \\
0367\end{array} \\
\end{array}$ & $\begin{array}{l}98.674 \\
7335\end{array}$ & $\begin{array}{l}99.41 \\
443\end{array}$ & $\begin{array}{l}99.924 \\
9049\end{array}$ & $\begin{array}{l}99.904 \\
8517\end{array}$ & $\begin{array}{l}99.934 \\
5042\end{array}$ & $\begin{array}{l}98.511 \\
9678\end{array}$ & & $\begin{array}{l}98.001 \\
9589\end{array}$ & $\begin{array}{l}98.47 \\
03883\end{array}$ & $\begin{array}{l}99.63 \\
1803\end{array}$ & $\begin{array}{l}99.47 \\
24522\end{array}$ & $\begin{array}{l}99.93 \\
12084\end{array}$ & $\begin{array}{l}99.93 \\
82843\end{array}$ & $\begin{array}{l}99.81 \\
64556\end{array}$ & $\begin{array}{l}99.39 \\
36835\end{array}$ & $\begin{array}{l}99.86 \\
18703\end{array}$ & $\begin{array}{l}99.89 \\
96154\end{array}$ & $\begin{array}{l}99.89 \\
90746\end{array}$ & $\begin{array}{l}99.92 \\
15602\end{array}$ & $\begin{array}{l}99.62 \\
81227\end{array}$ & $\begin{array}{l}99.64 \\
02261\end{array}$ & $\begin{array}{l}99.90 \\
69906\end{array}$ & & $\begin{array}{l}95.94 \\
22283\end{array}$ & $\begin{array}{l}92.16 \\
69683\end{array}$ & $\begin{array}{l}94.45 \\
9749\end{array}$ & $\begin{array}{l}99.287 \\
9644\end{array}$ \\
\hline FPR & $\begin{array}{l}0.001 \\
72011\end{array}$ & $\begin{array}{l}0.001 \\
69279\end{array}$ & $\begin{array}{l}0.0015 \\
8963\end{array}$ & $\begin{array}{l}0.0132 \\
5267\end{array}$ & $\begin{array}{l}0.005 \\
8557\end{array}$ & $\begin{array}{l}0.000 \\
75095\end{array}$ & $\begin{array}{l}0.000 \\
95148\end{array}$ & $\begin{array}{l}0.000 \\
65496\end{array}$ & $\begin{array}{l}0.0148 \\
8032\end{array}$ & & $\begin{array}{l}\begin{array}{l}0.0199 \\
8041\end{array} \\
\end{array}$ & $\begin{array}{l}0.0152 \\
9612\end{array}$ & $\begin{array}{l}0.0036 \\
8197\end{array}$ & $\begin{array}{l}0.0052 \\
7548\end{array}$ & $\begin{array}{l}0.000 \\
68792\end{array}$ & $\begin{array}{l}0.000 \\
61716\end{array}$ & $\begin{array}{l}0.0018 \\
3544\end{array}$ & $\begin{array}{l}0.0060 \\
6317\end{array}$ & $\begin{array}{l}0.001 \\
3813\end{array}$ & $\begin{array}{l}0.001 \\
00385\end{array}$ & $\begin{array}{l}\begin{array}{l}0.001 \\
00926\end{array} \\
0.09\end{array}$ & $\begin{array}{l}0.000 \\
7844\end{array}$ & $\begin{array}{l}0.003 \\
71877\end{array}$ & $\begin{array}{l}0.003 \\
59774\end{array}$ & $\begin{array}{l}0.000 \\
93009\end{array}$ & & $\begin{array}{l}0.040 \\
57772\end{array}$ & $\begin{array}{l}0.0783 \\
3032\end{array}$ & $\begin{array}{l}0.055 \\
40251\end{array}$ & $\begin{array}{l}0.0071 \\
2036\end{array}$ \\
\hline RRSE & 29.1536 & 36.2284 & 37.9705 & 111.128 & 74.42 & 26.0876 & 32.7698 & 27.5715 & 100 & & 29.3488 & 31.0348 & 26.7965 & 35.1255 & 26.726 & 23.0061 & 27.3993 & 51.3341 & 29.6896 & 28.125 & 31.0852 & 28.9906 & 29.0771 & 37.2188 & 30.567 & & 64.0822 & 140.701 & 101.664 & 96.6 \\
\hline RAE & 7.1175 & 6.5746 & 7.2221 & 61.8613 & 27.7429 & 5.1261 & 5.3792 & 3.8067 & 100 & & 6.1856 & 8.6064 & 7.66 & $\begin{array}{l}9.4388 \\
\end{array}$ & 4.16 & 5.3558 & 5.6998 & 30.9031 & 5.9875 & 9.7965 & 8.5333 & 6.4623 & 4.838 & 12.3021 & 6.4675 & & 20.5706 & 99.1673 & 104.43 & 98.8697 \\
\hline RMSE & 0.114 & 0.141 & 0.148 & 0.433 & 0.29 & 0.102 & 0.128 & 0.107 & 0.39 & & 0.114 & 0.121 & 0.105 & 0.137 & 0.104 & 0.09 & 0.107 & 0.2 & 0.116 & 0.11 & 0.121 & 0.113 & 0.113 & 0.145 & 0.119 & & 0.25 & 0.549 & 0.396 & 0.377 \\
\hline MAE & 0.022 & 0.02 & 0.022 & 0.188 & 0.084 & 0.016 & 0.016 & 0.012 & 0.304 & & 0.019 & 0.026 & 0.023 & 0.029 & 0.013 & 0.016 & 0.017 & 0.094 & 0.018 & 0.03 & 0.026 & 0.02 & 0.015 & 0.037 & 0.02 & & 0.062 & 0.301 & 0.317 & 0.3 \\
\hline KV & 0.956 & 0.934 & 0.928 & 0.401 & 0.72 & 0.964 & 0.946 & 0.962 & 0 & & 0.949 & 0.942 & 0.952 & 0.925 & 0.964 & 0.969 & 0.96 & 0.823 & 0.954 & 0.956 & 0.944 & 0.953 & 0.958 & 0.917 & 0.941 & & 0.793 & 0.071 & 0.071 & 0.553 \\
\hline MCR & 3.3636 & 4.9887 & 5.48 & 46.939 & 21.051 & 2.7589 & 4.0816 & 2.8723 & 74.339 & & 3.8549 & 4.4218 & 3.6281 & 5.7067 & 2.7211 & 2.381 & 3.0612 & 13.568 & 3.5147 & 3.3636 & 4.2328 & 3.5903 & 3.2124 & 6.3492 & 4.4974 & & 15.609 & 75.246 & 75.246 & 35.11 \\
\hline ACC & $\begin{array}{l}96.636 \\
\end{array}$ & $\begin{array}{l}95.011 \\
\end{array}$ & 94.52 & 53.061 & 78.949 & $\begin{array}{l}97.241 \\
\end{array}$ & 95.918 & 96.863 & 25.661 & & 96.145 & $\begin{array}{l}55.578 \\
\end{array}$ & 966.372 & 94.293 & 97.279 & 97.619 & 96.939 & 86.432 & 96.485 & 966.636 & $\begin{array}{l}95.767 \\
\end{array}$ & 96.41 & 96.788 & 93.651 & 95.503 & & 84.392 & 24.754 & 24.754 & 64.89 \\
\hline TT & 0.01 & 0.07 & 0.19 & 0.01 & 0.001 & 0.01 & 0.001 & 0.2 & 0.001 & & 0.001 & 0.001 & 0.01 & 0.13 & 0.001 & 0.08 & 0.001 & 0.01 & 0.001 & 0.05 & 0.001 & 0.001 & 0.001 & 0.01 & 0.1 & & 0.04 & 0.01 & 0.01 & 0.01 \\
\hline 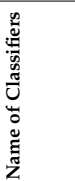 & 胥 & $\begin{array}{l}\sum_{i=1}^{\Sigma} \\
\overrightarrow{0} \\
\sum\end{array}$ & $\begin{array}{l}\text { W } \\
\text { Z }\end{array}$ & $\sum_{0}$ & 畄 & $\underset{\nwarrow}{\mathbb{a}}$ & $\begin{array}{l}\text { 号 } \\
\text { 空 }\end{array}$ & 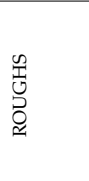 & 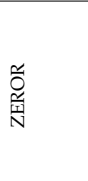 & 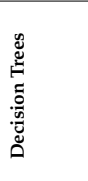 & 店 & ชี & 岥 & 早 & $\stackrel{\infty}{+\infty}$ & 嫼 & 总 & 戞 & $\sum_{3}$ & 产 & 言 & 洗 & $\underline{w}$ & u & 岕 & 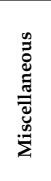 & 芼 & 獣 & 言 & 局 \\
\hline
\end{tabular}


Table 16. Performance outcome of supervised classifiers on ISCXIDS2012 dataset.

\begin{tabular}{|c|c|c|c|c|c|c|c|c|c|c|c|c|c|c|c|c|c|c|c|c|c|c|c|c|c|c|c|c|c|c|}
\hline $\begin{array}{l}\text { PRC } \\
\end{array}$ & & 0.51 & $\begin{array}{c}0.5 \\
\end{array}$ & 0.75 & 0.5 & & 0.88 & 0.5 & 0.54 & 0.89 & 0.92 & 0.58 & 0.88 & 0.68 & 0.76 & 0.89 & 0.52 & & 0.89 & 0.89 & 0.93 & 0.99 & 0.96 & 0.87 & 0.92 & & 0.78 & 0.96 & 0.99 & 0.98 \\
\hline MCC & & 0.06 & 0 & -0.04 & 0 & & 0.69 & 0 & 0.25 & 0.71 & 0.81 & 0.18 & 0.7 & 0.31 & 0.54 & 0.71 & 0.08 & & 0.85 & 0.85 & 0.85 & 0.95 & 0.94 & 0.67 & 0.89 & & 0.69 & 0.9 & 0.94 & 0.96 \\
\hline ROC & & 0.51 & 0.5 & 0.79 & 0.5 & & 0.9 & 0.5 & 0.56 & 0.9 & 0.93 & 0.54 & 0.89 & 0.69 & 0.78 & 0.9 & 0.53 & & 0.92 & 0.92 & 0.94 & 0.99 & 0.97 & 0.88 & 0.94 & & 0.83 & 0.97 & 0.99 & 0.98 \\
\hline PRE & & $\begin{array}{l}99.37 \\
28674\end{array}$ & $\begin{array}{l}99.42 \\
99533\end{array}$ & $\begin{array}{l}99.53 \\
15303\end{array}$ & $\begin{array}{l}99.60 \\
97789\end{array}$ & & $\begin{array}{l}99.82 \\
43482\end{array}$ & $\begin{array}{l}99.49 \\
77819\end{array}$ & $\begin{array}{l}99.55 \\
7592\end{array}$ & $\begin{array}{l}99.84 \\
30158\end{array}$ & $\begin{array}{l}99.90 \\
63948 \\
639\end{array}$ & $\begin{array}{l}99.5 \\
618\end{array}$ & $\begin{array}{l}99.85 \\
16314\end{array}$ & $\begin{array}{l}99.70 \\
34607\end{array}$ & $\begin{array}{l}99.79 \\
1891\end{array}$ & $\begin{array}{l}99.87 \\
48053\end{array}$ & $\begin{array}{l}99.62 \\
05372\end{array}$ & & $\begin{array}{l}999.91 \\
29747\end{array}$ & $\begin{array}{l}99.91 \\
38788\end{array}$ & $\begin{array}{l}99.91 \\
47643\end{array}$ & $\begin{array}{l}99.97 \\
18208\end{array}$ & $\begin{array}{l}99.96 \\
99616\end{array}$ & $\begin{array}{l}99.82 \\
54369\end{array}$ & $\begin{array}{l}99.95 \\
32906\end{array}$ & & $\begin{array}{l}99.77 \\
76012\end{array}$ & $\begin{array}{l}99.93 \\
58449\end{array}$ & $\begin{array}{l}99.96 \\
51549\end{array}$ & $\begin{array}{l}999.97 \\
54771\end{array}$ \\
\hline FPR & & $\begin{array}{l}0.006 \\
27133\end{array}$ & $\begin{array}{l}0.005 \\
70047\end{array}$ & $\begin{array}{l}0.00 \\
46847\end{array}$ & $\begin{array}{l}0.003 \\
90221\end{array}$ & & $\begin{array}{l}0.001 \\
75652\end{array}$ & $\begin{array}{l}0.005 \\
0.2218\end{array}$ & $\begin{array}{l}0.004 \\
42408\end{array}$ & $\begin{array}{l}0.001 \\
56984\end{array}$ & $\begin{array}{l}0.000 \\
93605\end{array}$ & $\begin{array}{l}0.00 \\
4382\end{array}$ & $\begin{array}{l}0.001 \\
48369\end{array}$ & $\begin{array}{l}0.002 \\
96539\end{array}$ & $\begin{array}{l}0.002 \\
08109\end{array}$ & $\begin{array}{l}0.001 \\
25195\end{array}$ & $\begin{array}{l}0.003 \\
79463\end{array}$ & & $\begin{array}{l}0.0008 \\
7025\end{array}$ & $\begin{array}{l}0.0008 \\
6121\end{array}$ & $\begin{array}{l}0.00085 \\
236\end{array}$ & $\begin{array}{l}0.0002 \\
8179\end{array}$ & $\begin{array}{l}0.0003 \\
0038\end{array}$ & $\begin{array}{l}0.001 \\
74563\end{array}$ & $\begin{array}{l}0.0004 \\
6709\end{array}$ & & $\begin{array}{l}0.0022 \\
2399\end{array}$ & $\begin{array}{l}0.0006 \\
4155\end{array}$ & $\begin{array}{l}0.0003 \\
4845\end{array}$ & $\begin{array}{l}0.0002 \\
4523\end{array}$ \\
\hline RRSE & & 99.9692 & 99.9786 & 140.281 & 101.097 & & 71.0846 & 140.098 & 131.834 & 69.0002 & 60.3961 & 96.3492 & 82.1845 & 97.0951 & 80.9554 & 68.5047 & 137.865 & & 55.3244 & 55.3091 & 55.3226 & 30.5601 & 34.6211 & 73.2824 & 47.6323 & & 72.0015 & 41.3656 & 31.888 & 27.8625 \\
\hline RAE & & 99.971 & 99.983 & 98.603 & 999.675 & & 50.171 & 98.163 & 86.923 & 51.026 & 34.658 & 92.162 & 33.986 & 95.649 & 64.472 & 53.276 & $\begin{array}{l}95.059 \\
\end{array}$ & & 15.308 & 15.355 & 15.313 & 6.3002 & 5.9947 & 54.614 & 11.347 & & 52.167 & 18.041 & 11.966 & 4.6704 \\
\hline RMSE & & 0.5 & 0.5 & 0.702 & 0.506 & & 0.356 & 0.701 & 0.659 & 0.345 & 0.302 & 0.482 & 0.411 & 0.486 & 0.405 & 0.343 & 0.69 & & 0.277 & 0.277 & 0.277 & 0.153 & 0.173 & 0.367 & 0.238 & & 0.36 & 0.207 & 0.16 & 0.139 \\
\hline MAE & & 0.5 & 0.5 & 0.493 & 0.499 & & 0.251 & 0.491 & 0.435 & 0.255 & 0.173 & 0.461 & 0.17 & 0.478 & 0.322 & 0.266 & 0.475 & & 0.077 & 0.077 & 0.077 & 0.032 & 0.03 & 0.273 & 0.057 & & 0.261 & 0.09 & 0.06 & 0.023 \\
\hline $\mathrm{KV}$ & & 0.021 & 0 & -0.005 & 0 & & 0.658 & 0 & 0.116 & 0.68 & 0.807 & 0.066 & 0.659 & 0.306 & 0.506 & 0.687 & 0.06 & & 0.847 & 0.847 & 0.847 & 0.946 & 0.94 & 0.641 & 0.887 & & 0.656 & 0.899 & 0.944 & 0.958 \\
\hline MCR & & 49.786 & 499.09 & 49.358 & 49.09 & & 17.024 & 49.09 & 43.469 & 15.899 & 9.636 & 45.932 & 16.97 & 34.743 & 24.518 & 15.578 & 47.538 & & 7.6552 & 7.6552 & 7.6552 & 2.6767 & 2.9979 & $\begin{array}{l}17.827 \\
\end{array}$ & 5.6745 & & 17.077 & 5.0321 & 2.7837 & 2.0878 \\
\hline ACC & & 50.214 & 50.91 & 50.642 & 50.91 & & 82.976 & 50.91 & 56.531 & 84.101 & 90.364 & 54.069 & 83.03 & 65.257 & 75.482 & 84.422 & 52.463 & & 92.345 & 92.345 & 92.345 & 97.323 & 97.002 & 82.173 & 94.326 & & 82.923 & 94.968 & 97.216 & 97.912 \\
\hline TT & & 0.001 & 0.001 & 0.02 & 0.01 & & 0.01 & 0.001 & 1.86 & 0.001 & 0.01 & 0.001 & 0.001 & 0.01 & 0.01 & 0.001 & 0.001 & & 0.43 & 0.42 & 0.43 & 25.96 & 29.72 & 7.6 & 0.01 & & 0.001 & 0.001 & 0.01 & 0.001 \\
\hline 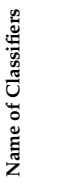 & 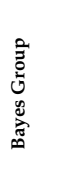 & $\sum_{\text {L }}^{0}$ & $\sum_{i}$ & 穵 & 忍 & 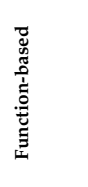 & 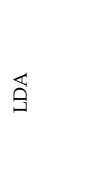 & 莺 & 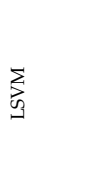 & $\because$ & 育 & $\overrightarrow{\tilde{z}}$ & $\overleftarrow{8}$ & 崖 & 㗹 & क्जे & $\sum_{\infty}^{\infty}$ & 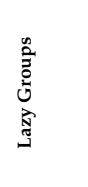 & $\vec{\theta}$ & 㒸 & $\begin{array}{l}\text { U } \\
\stackrel{y}{\underline{a}}\end{array}$ & 魷 & 竞 & క్ & 吕 & 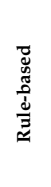 & $\tilde{z}$ & $\overrightarrow{\overrightarrow{0}}$ & 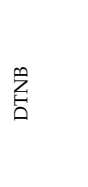 & 冚 \\
\hline PRC & 0.98 & 0.96 & 0.95 & 0.67 & 0.88 & 0.98 & 0.96 & 0.96 & 0.5 & & 0.97 & 0.98 & 1 & 0.97 & 0.97 & 1 & 0.99 & 0.97 & 0.99 & 0.98 & 0.98 & 0.99 & 0.95 & 0.98 & 0.97 & & 0.72 & 0.5 & 0.51 & 0.56 \\
\hline MCC & 0.95 & 0.94 & 0.94 & 0.5 & 0.84 & 0.96 & 0.95 & 0.94 & 0 & & 0.95 & 0.94 & 0.96 & 0.96 & 0.96 & 0.97 & 0.96 & 0.91 & 0.95 & 0.9 & 0.95 & 0.96 & 0.94 & 0.95 & 0.95 & & 0.57 & 0 & 0 & 0.13 \\
\hline ROC & 0.99 & 0.97 & 0.97 & 0.72 & 0.92 & 0.99 & 0.97 & 0.97 & 0.5 & & 0.98 & 0.99 & 1 & 0.98 & 0.98 & 1 & 0.99 & 0.98 & 0.99 & 0.98 & 0.99 & 0.99 & 0.97 & 0.99 & 0.98 & & 0.77 & 0.5 & 0.52 & 0.57 \\
\hline PRE & $\begin{array}{l}99.97 \\
1268\end{array}$ & $\begin{array}{l}99.97 \\
31938\end{array}$ & $\begin{array}{l}99.97 \\
12323\end{array}$ & $\begin{array}{l}99.74 \\
88586\end{array}$ & $\begin{array}{l}99.92 \\
63852\end{array}$ & $\begin{array}{l}99.98 \\
15088\end{array}$ & $\begin{array}{l}99.97 \\
67136\end{array}$ & $\begin{array}{l}99.97 \\
6457\end{array}$ & $\begin{array}{l}99.60 \\
49811\end{array}$ & & $\begin{array}{l}99.966 \\
4172\end{array}$ & $\begin{array}{l}99.962 \\
5352\end{array}$ & $\begin{array}{l}99.97 \\
42563\end{array}$ & $\begin{array}{l}99.97 \\
51918\end{array}$ & $\begin{array}{l}99.97 \\
41804\end{array}$ & $\begin{array}{l}99.98 \\
7454\end{array}$ & $\begin{array}{l}99.97 \\
99563\end{array}$ & $\begin{array}{l}99.95 \\
42549\end{array}$ & $\begin{array}{l}99.97 \\
4761\end{array}$ & $\begin{array}{l}99.95 \\
13088\end{array}$ & $\begin{array}{l}99.97 \\
78768\end{array}$ & $\begin{array}{l}99.97 \\
56092\end{array}$ & $\begin{array}{l}99.97 \\
28172\end{array}$ & $\begin{array}{l}99.98 \\
0487\end{array}$ & $\begin{array}{l}99.98 \\
18513\end{array}$ & & $\begin{array}{l}99.69 \\
91743\end{array}$ & $\begin{array}{l}99.40 \\
61919\end{array}$ & $\begin{array}{l}99.43 \\
8694\end{array}$ & $\begin{array}{l}99.61 \\
67652\end{array}$ \\
\hline FPR & $\begin{array}{l}0.0002 \\
8732\end{array}$ & $\begin{array}{l}0.0002 \\
6806\end{array}$ & $\begin{array}{l}0.0002 \\
8768\end{array}$ & $\begin{array}{l}0.0025 \\
1141\end{array}$ & $\begin{array}{l}0.0007 \\
3615\end{array}$ & $\begin{array}{l}0.0001 \\
8491\end{array}$ & $\begin{array}{l}0.0002 \\
3286\end{array}$ & $\begin{array}{l}0.0002 \\
3543\end{array}$ & $\begin{array}{l}0.0039 \\
5019\end{array}$ & & $\begin{array}{l}0.0003 \\
3583\end{array}$ & $\begin{array}{l}0.0003 \\
7465\end{array}$ & $\begin{array}{l}0.0002 \\
5744\end{array}$ & $\begin{array}{l}\begin{array}{l}0.0002 \\
4808\end{array} \\
\end{array}$ & $\begin{array}{l}0.000 \\
2582\end{array}$ & $\begin{array}{l}0.0001 \\
2546\end{array}$ & $\begin{array}{l}0.0002 \\
0044\end{array}$ & $\begin{array}{l}0.0004 \\
5745\end{array}$ & $\begin{array}{l}0.0002 \\
5239\end{array}$ & $\begin{array}{l}0.0004 \\
8691\end{array}$ & $\begin{array}{l}0.0002 \\
2123\end{array}$ & $\begin{array}{l}0.0002 \\
4391\end{array}$ & $\begin{array}{l}0.0002 \\
7183\end{array}$ & $\begin{array}{l}0.0001 \\
9513\end{array}$ & $\begin{array}{l}0.0001 \\
8149\end{array}$ & & $\begin{array}{l}\begin{array}{l}0.0030 \\
0826\end{array} \\
80\end{array}$ & $\begin{array}{l}0.0059 \\
3808\end{array}$ & $\begin{array}{l}\begin{array}{l}0.0056 \\
1306\end{array} \\
\end{array}$ & $\begin{array}{l}0.0038 \\
3235\end{array}$ \\
\hline RRSE & 30.8651 & 33.3618 & 35.5365 & 105.702 & 57.4128 & 28.2636 & 33.3618 & 33.7169 & 100 & & 28.84 & 32.3926 & 24.852 & 28.2722 & 28.8922 & 21.3836 & 26.2021 & 37.8522 & 29.0201 & 42.6491 & 31.1256 & 28.6718 & 35.5365 & 30.0486 & 29.3342 & & 95.1522 & 140.098 & 99.8206 & 99.2345 \\
\hline RAE & 7.8292 & 5.5665 & 6.3158 & 555.879 & 16.485 & 5.6777 & 5.5665 & 5.6857 & 100 & & 6.0636 & 8.7887 & 7.1535 & 4.9106 & 4.1749 & 5.6436 & 5.213 & 16.135 & 6.501 & 10.926 & 7.8099 & 6.3565 & 6.3158 & 7.0733 & 4.8823 & & 45.281 & 98.163 & $\begin{array}{l}99.813 \\
\end{array}$ & 98.97 \\
\hline RMSE & 0.154 & 0.167 & 0.178 & 0.529 & 0.287 & 0.141 & 0.167 & 0.169 & 0.5 & & 0.144 & 0.162 & 0.124 & 0.141 & 0.145 & 0.107 & 0.131 & 0.189 & 0.145 & 0.213 & 0.156 & 0.143 & 0.178 & 0.15 & 0.147 & & 0.476 & 0.701 & 0.499 & 0.496 \\
\hline MAE & 0.039 & 0.028 & 0.032 & 0.279 & 0.082 & 0.028 & 0.028 & 0.028 & 0.5 & & 0.03 & 0.044 & 0.036 & 0.025 & 0.021 & 0.028 & 0.026 & 0.081 & 0.033 & 0.055 & 0.039 & 0.032 & 0.032 & 0.035 & 0.024 & & 0.226 & 0.491 & 0.499 & 0.495 \\
\hline $\mathrm{KV}$ & 0.946 & 0.944 & 0.937 & 0.436 & 0.835 & 0.958 & 0.944 & 0.943 & 0 & & 0.951 & 0.944 & 0.957 & 0.958 & 0.958 & 0.971 & 0.96 & 0.912 & 0.954 & 0.894 & 0.948 & 0.955 & 0.937 & 0.952 & 0.954 & & 0.545 & 0 & 0 & 0.037 \\
\hline MCR & 2.6767 & 2.7837 & 3.1585 & 27.944 & 8.2441 & 2.0878 & 2.7837 & 2.8373 & 50.91 & & 2.4625 & 2.7837 & 2.1413 & 2.0878 & 2.0878 & 1.4454 & 1.9807 & 4.3897 & 2.3019 & 5.2998 & 2.6231 & 2.2484 & 3.1585 & 2.409 & 2.3019 & & 22.645 & 49.09 & 49.09 & 48.983 \\
\hline ACC & 97.323 & 97.216 & 966.842 & 72.056 & 91.756 & 97.912 & 97.216 & 97.056 & 49.09 & & $\begin{array}{l}97.538 \\
\end{array}$ & 97.216 & $\begin{array}{l}97.859 \\
\end{array}$ & 97.912 & 97.912 & 98.555 & 98.019 & 95.61 & $\begin{array}{l}97.698 \\
\end{array}$ & 94.7 & 97.377 & 97.752 & 96.842 & 97.591 & 97.698 & & 77.356 & 50.91 & 50.91 & 51.017 \\
\hline TT & 0.001 & 0.01 & 0.04 & 0.001 & 0.001 & 0.001 & 0.001 & 0.16 & 0.01 & & 0.001 & 0.001 & 0.001 & 0.02 & 0.001 & 0.04 & 0.001 & 0.001 & 0.001 & 0.01 & 0.001 & 0.001 & 0.001 & 0.001 & 0.01 & & 0.03 & 0.001 & 0.001 & 0.001 \\
\hline 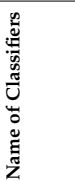 & 总 & 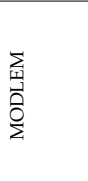 & $\begin{array}{l}\text { W } \\
\text { 㞱 }\end{array}$ & $\sum_{0}$ & 畄 & 㕁 & $\begin{array}{l}\text { 员 } \\
\text { 兽 }\end{array}$ & 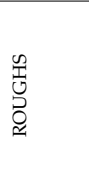 & 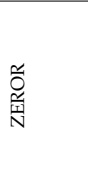 & 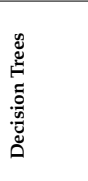 & 店 & ชี & 岥 & 早 & $\stackrel{\infty}{+\infty}$ & 嫼 & 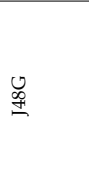 & 萝 & $\sum_{3}$ & 产 & 言 & 宦 & $\ddot{\underline{\mu}}$ & u & 岕 & 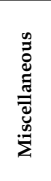 & 妾 & 䋗 & 主 & 局 \\
\hline
\end{tabular}


Table 17. Performance outcome of supervised classifiers on CICIDS2017 dataset.

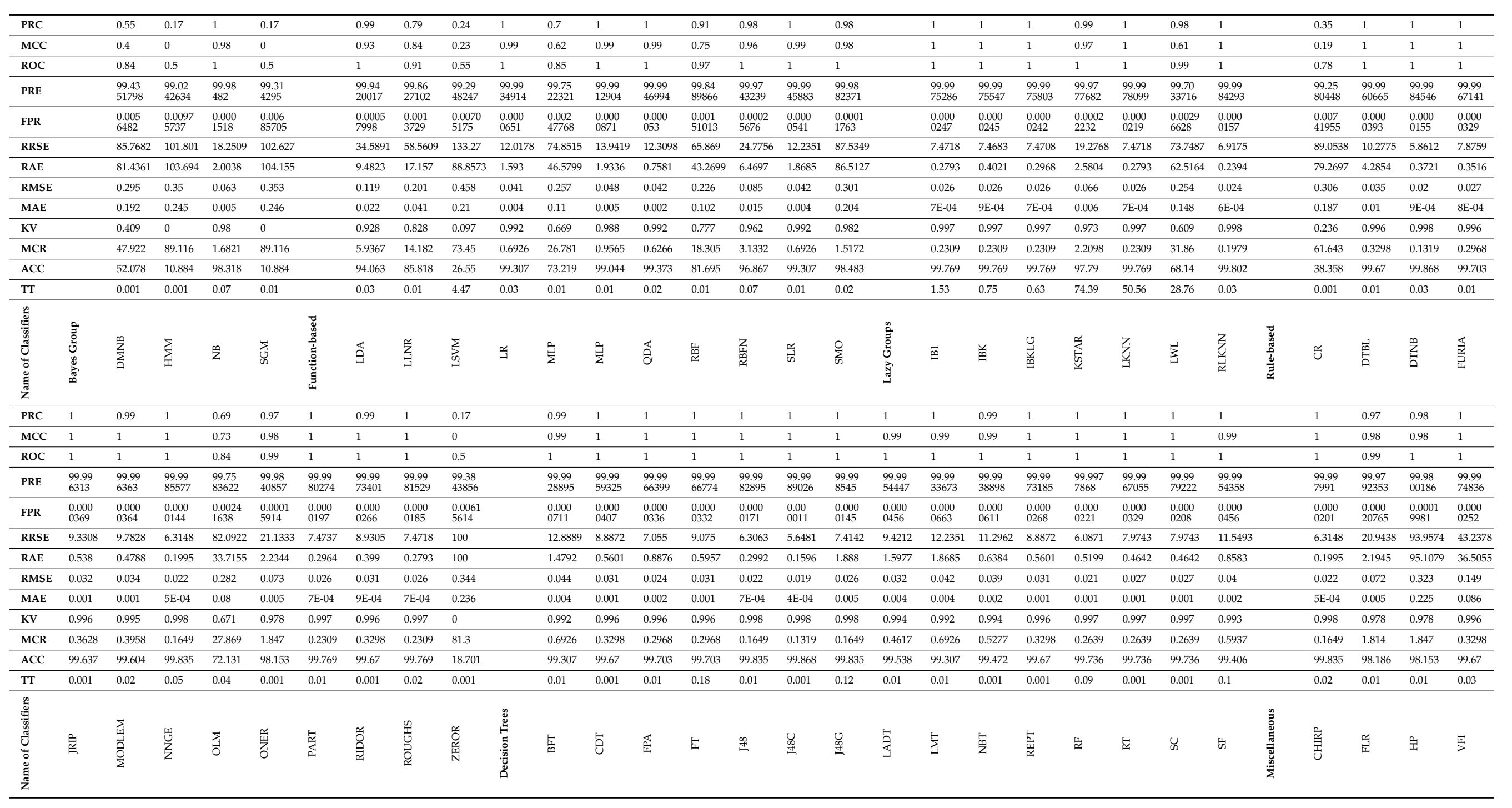




\section{J48Consolidated-A C4.5 Classifier Based on C4.5}

J48Consolidated has been presented as the best classifier considering the decision tree group. Therefore, this section provides an in-depth analysis of J48Consodated.

\subsection{Detection Capabilities of J48Consolidated}

In this section, the J48Consolidated classifier is analyzed, considering the classification of the attack detection process. The classification threshold and the percentage of detection have been taken into consideration while analyzing attack classes. The attack-wise classification output for NSLKDD, ISCXIDS, and CICIDS2017 datasets has been presented in Figures 9-11, respectively.

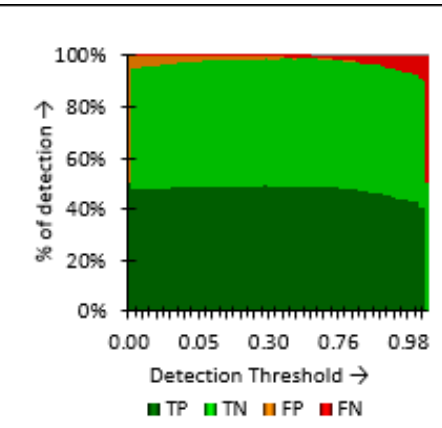

(a) Classified instances having class label: DoS

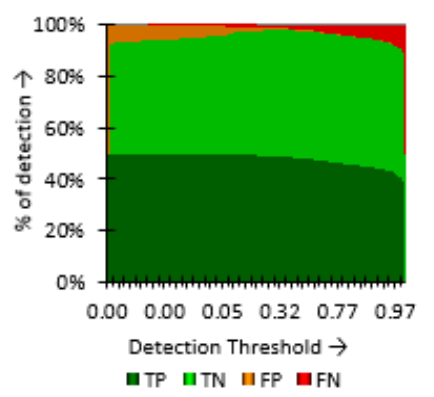

(e) Classified instances having class label: Normal

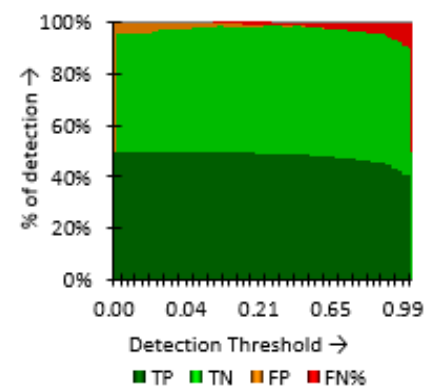

(b) Classified instances having class label: Probe

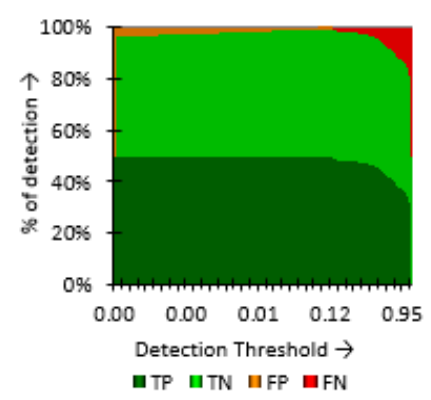

(d) Classified instances having class label: U2R

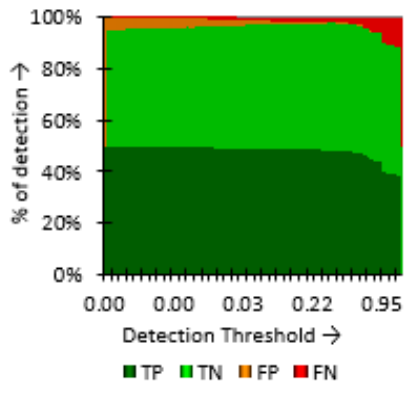

(c) Classified instances having class label: R2L

Figure 9. Detection (\%) of attacks and normal class labels of NSL-KDD multi-class dataset.

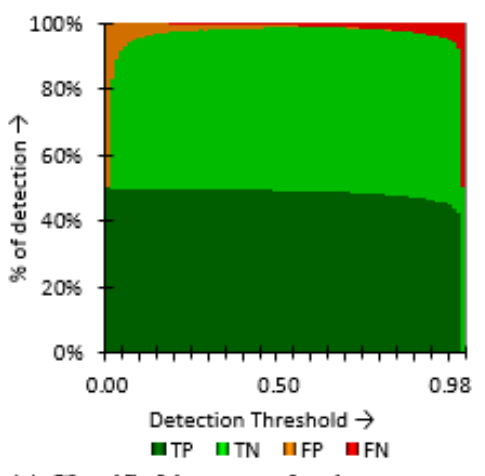

(a) Classified instances having class label: Attack

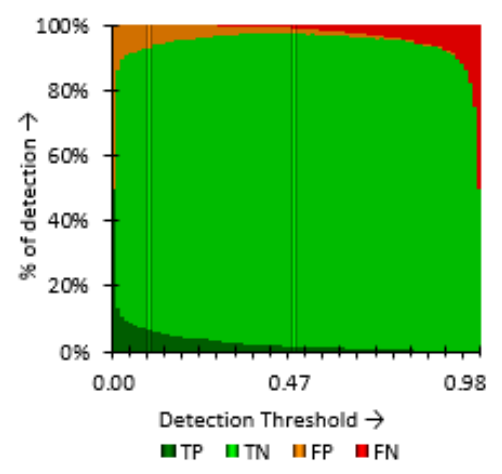

(b) Classified instances having class label: Normal

Figure 10. Detection (\%) of attacks and normal class labels of ISCXIDS2012 binary class dataset. 


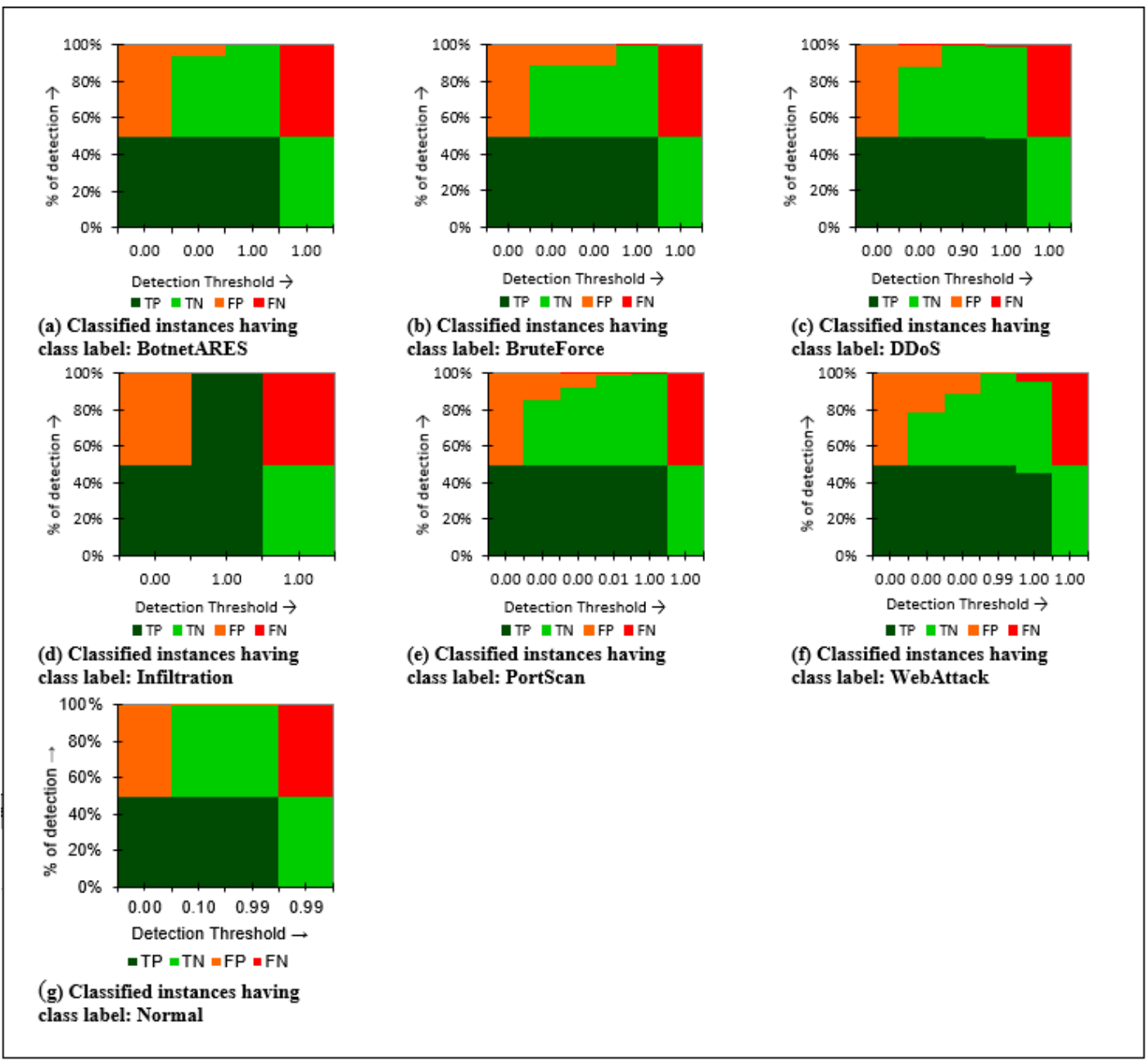

Figure 11. Detection (\%) of attacks and normal class labels of CICIDS2017 multi class dataset.

The detection output for the NSLKDD dataset remains consistently good for DoS, Probe, R2L, U2R, and Normal classes with the increase in detection threshold. The U2R attack class shows low false positives, whereas few regular instances are misclassified during the classification process. Overall, the J48Consolidated classifier exhibited satisfactory performance for the NSLKDD dataset.

ISCXIDS2012 is a binary class dataset; therefore, J48Consolidated seems to generate false alarms. However, the presented results are low compared to the number of correctly classified instances (true positives and true negatives).

Finally, the individual J48Consolidated evaluation presents an effective classification considering six attack groups of the CICIDS2017 dataset. The classifier also differentiates regular instances with attack instances during the classification process.

\subsection{Classification Output of J48Consolidated}

The three IDS datasets are considered for a specific environment. The correlation of attributes, attacks, and benign instances varied from dataset to dataset. Therefore, J48Consolidated shows a different classification performance considering different IDS datasets. The classification output of J48Consolidated for NSLKDD, ISCXIDS2012, and CICIDS2017 datasets has been outlined in Figures 12-14, respectively. 


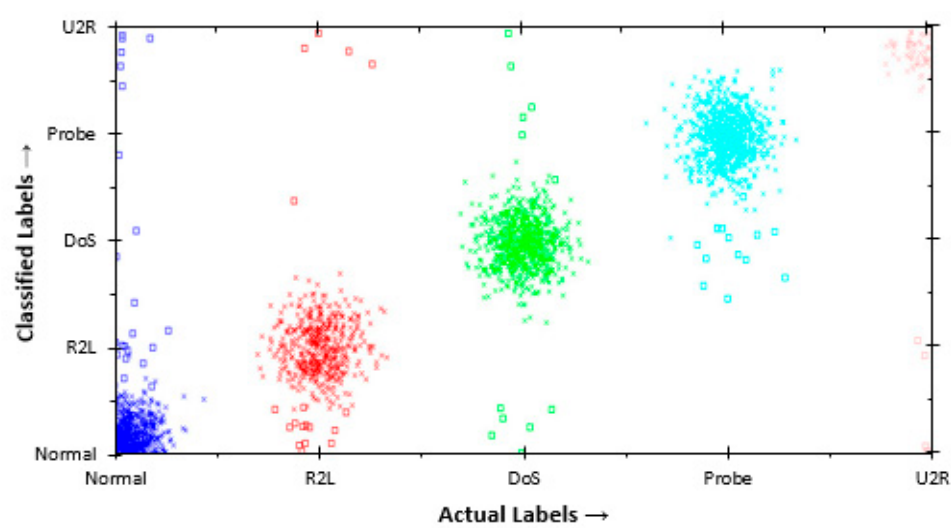

Figure 12. Classification of J48Consolidated on NSL-KDD dataset.

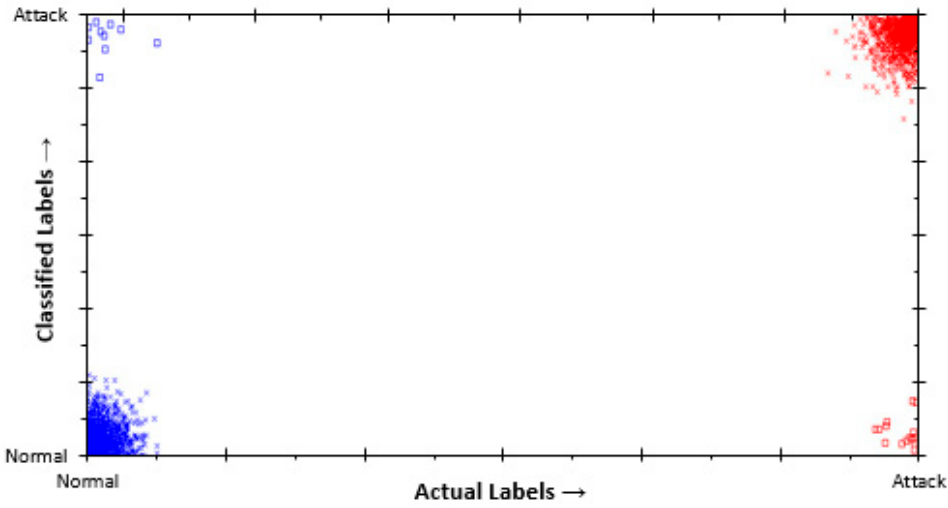

Figure 13. Classification of J48Consolidated on ISCXIDS2012 dataset.

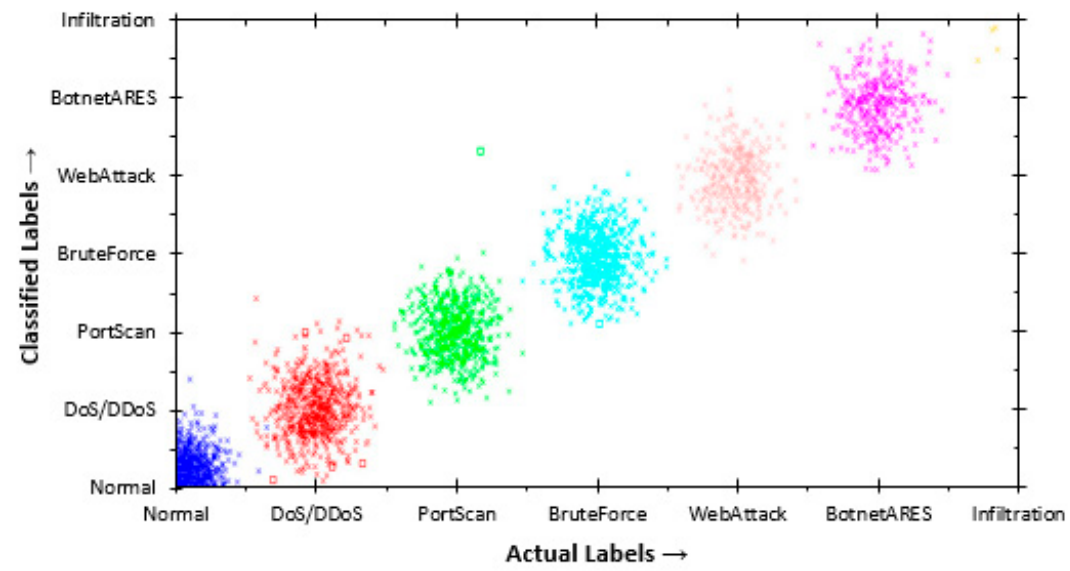

Figure 14. Classification of J48Consolidated on CICIDS2017 dataset.

Figure 12 shows that the J48Consolidated classifier presents a reliable classification in the NSLKDD dataset. Nevertheless, J48Consolidated also produced false alarms for positive and negative instances. Therefore, the authors recommend incorporating filter components such as data standardization and effective feature selection while designing IDSs using J48Considated. A filter component not only smooths the underlying data, but will also improve classification performance.

On the one hand, for the ISCXIDS2012 dataset, J48Consolidated dramatically showed improvement in classification. The classifier showed few false alarms. On the other hand, J48Consolidated successfully detected almost all the instances of the ISCXIDS2012 binary dataset. Therefore, the classifier achieved the highest TOPSIS score of 0.964 (Figure 8); thus, contributing to the highest average rank. 
Finally, for the CICIDS2017 dataset, the J48Consolidated classifier presented a low number of false alarms. The six attack groups of the CICIDS2017 dataset presented a consistent classification with a detection accuracy of $99.868 \%$ (Table 17) and a low false positive of 0.000011 .

A reliable IDS benchmark dataset must fulfill 11 criteria [122], such as complete network configuration, attack diversity, overall traffic, thorough interaction, labeled dataset, full capture, existing protocols, heterogeneity, feature set, anonymity, and metadata. The CICIDS2017 [123] dataset fulfills these criteria. Furthermore, CICIDS2017 is recent and focuses on the latest attack scenarios. The J48Consolidated classifier presented the best results for the CICIDS2017 dataset with an accuracy of $99.868 \%$. Consequently, the J48Consolidated classifier can be assumed as an effective IDS with the CICIDS2017 dataset. Nevertheless, the authors recommend the incorporation of feature selection procedures at the preprocessing stage to extract the most relevant features of the dataset and promote system performance.

\section{Conclusions}

This paper analyzed fifty-four widely used classifiers spanning six different groups. These classifiers were evaluated on the three most popular intrusion detection datasets, i.e., NSLKDD, ISCXIDS2012 and CICIDS2017. The authors have extracted a sufficient number of random samples from these datasets, which retained the same class imbalance property of the original datasets. Consequently, multi-criteria decision-making has been used to allocate weight to these classifiers for different datasets. The rank of the classifiers was also finalized using those weights. First, an intragroup analysis has been conducted to find the best classifier group. Secondly, an intragroup analysis of the best classifier group has been made to find the best classifiers for the intrusion detection datasets. The authors analyzed thirteen performance metrics. Therefore, the best classifier has been selected impartially. On the one hand, the intergroup analysis presented the decision tree group of classifiers as the best classifier group, followed by the Rule-based classifiers, whereas the intragroup study identified J48Consolidated as the best classifier for high-class imbalance considering NSLKDD, CICIDS2017 and ISCXIDS2012 datasets. The J48Consolidated classifier provided the highest accuracy of $99.868 \%$, a misclassification rate of $0.1319 \%$, and a Kappa value of 0.998 .

This study presented an in-depth analysis that provides numerous outcomes for IDS designers. Comparing fifty-four classifiers on intrusion detection datasets through thirteen performance matrices and ranking them is the main contributory work of this article. Nevertheless, the present study has limitations. Further investigation is required considering other datasets and other specific application domains. Moreover, the number of classes, class-wise performance observation, and classifiers' performance based on varying sample sizes should be carried out to understand the detailed aspects of the classifiers. The scalability and robustness of the classifiers were not tested. As a future work, many other IDS datasets can be used for ascertaining performance of the classifiers. Many recent ranking algorithms can be used as voting principle to obtain exact ranks of classifiers. Many other recent rule-based, decision forest classifiers were covered in this article; those classifiers can be analyzed to understand the real performance of the classifiers and classifier groups. Finally, J48Consolidated, which evolved as an ideal classifier out of this analysis, can be used along with a suitable feature selection technique to design robust intrusion detection systems.

Author Contributions: The individual contributions for this research are specified below: Conceptualization, R.P., S.B. and M.F.I.; Data curation, R.P. and M.F.I.; Formal analysis, A.K.B., M.P., C.L.C. and R.H.J.; Funding acquisition, R.H.J., C.L.C. and M.F.I.; Investigation; R.P., S.B., M.F.I. and A.K.B.; Methodology, R.P., S.B., C.L.C., M.F.I. and M.P.; Project administration, S.B., R.H.J., C.L.C. and A.K.B.; Resources, S.B., A.K.B., C.L.C. and M.P.; Software, R.P., C.L.C., M.F.I. and M.P.; Supervision, S.B., A.K.B., R.H.J.; Validation, R.P., M.F.I., C.L.C. and M.P.; Visualization, R.P., S.B., M.F.I., R.H.J. and A.K.B.; Writing-Review and editing, R.P., M.F.I., S.B., C.L.C., M.P., R.H.J. and A.K.B. All authors have read and agreed to the published version of the manuscript. 
Funding: This research was supported by the Sejong University research fund.

Institutional Review Board Statement: Not applicable.

Informed Consent Statement: Not applicable.

Data Availability Statement: Publicly available datasets were analyzed in this study. These data can be found here: NSL-KDD—https:/ / www.unb.ca/cic/datasets/nsl.html (accessed on 1 February 2021), ISCXIDS2012-https:/ / www.unb.ca/cic/datasets/ids.html (accessed on 1 February 2021), CICIDS2017-https:/ / www.unb.ca/cic/datasets/ids-2017.html (accessed on 1 February 2021).

Conflicts of Interest: The authors declare no conflict of interest.

\begin{tabular}{|c|c|}
\hline Abbreviation & \\
\hline Abbreviation & Description \\
\hline TT & Testing Time \\
\hline $\mathrm{ACC}$ & Accuracy \\
\hline KV & Kappa Value \\
\hline MAE & Mean Absolute Error \\
\hline RMSE & Root Mean Squared Error \\
\hline RAE & Relative Absolute Error \\
\hline RRSE & Root Relative Squared Error \\
\hline FPR & False Positive Rate \\
\hline PRE & Precession \\
\hline ROC & Receiver Operating Curve \\
\hline MCC & Matthews Correlation Coefficient \\
\hline PRC & Precision Recall Curve \\
\hline TOPSIS & Techniques for Order Preference by Similarity to the Ideal Solution \\
\hline IDS & Intrusion Detection System \\
\hline IoT & Internet of Things \\
\hline LWL & Locally Weighted Learning \\
\hline RLKNN & Rseslib K-Nearest Neighbor \\
\hline CR & Conjunctive Rule \\
\hline DTBL & Decision Table \\
\hline DTNB & Decision Table Naïve Bayes \\
\hline FURIA & Fuzzy Rule Induction \\
\hline NNGE & Nearest Neighbor with Generalization \\
\hline OLM & Ordinal Learning Method \\
\hline RIDOR & RIpple-DOwn Rule learner \\
\hline BFT & Best-First Decision Tree \\
\hline CDT & Criteria Based Decision Tree \\
\hline LADT & Logit Boost based Alternating Decision Tree \\
\hline LMT & Logistic Model Trees \\
\hline NBT & Naïve Bayes based Decision Tree \\
\hline REPT & Reduces Error Pruning Tree \\
\hline $\mathrm{RF}$ & Random Forest \\
\hline RT & Random Tree \\
\hline SC & Simple Cart \\
\hline CHIRP & Composite Hypercubes on Iterated Random Projections \\
\hline FLR & Fuzzy Lattice Reasoning \\
\hline $\mathrm{HP}$ & Hyper Pipes \\
\hline VFI & Voting Feature Intervals \\
\hline $\mathrm{TP}$ & True Positives \\
\hline $\mathrm{TN}$ & True Negatives \\
\hline TPR & True Positive Rate \\
\hline TNR & True Negative Rate \\
\hline FT & Functional Trees \\
\hline
\end{tabular}




\section{References}

1. Chavhan, S.; Gupta, D.; Chandana, B.N.; Khanna, A.; Rodrigues, J.J.P.C. IoT-based Context-Aware Intelligent Public Transport System in a metropolitan area. IEEE Internet Things J. 2019, 7, 6023-6034. [CrossRef]

2. Chen, Q.; Bridges, R.A. Automated behavioral analysis of malware: A case study of wannacry ransomware. In Proceedings of the 16th IEEE International Conference on Machine Learning and Applications, ICMLA 2017, Cancun, Mexico, 18-21 December 2017; Institute of Electrical and Electronics Engineers Inc.: New York, NY, USA, December 2017; Volume 2017, pp. 454-460.

3. Liang, W.; Li, K.C.; Long, J.; Kui, X.; Zomaya, A.Y. An Industrial Network Intrusion Detection Algorithm Based on Multifeature Data Clustering Optimization Model. IEEE Trans. Ind. Inform. 2020, 16, 2063-2071. [CrossRef]

4. Jiang, K.; Wang, W.; Wang, A.; Wu, H. Network Intrusion Detection Combined Hybrid Sampling with Deep Hierarchical Network. IEEE Access 2020, 8, 32464-32476. [CrossRef]

5. Zhang, Y.; Li, P.; Wang, X. Intrusion Detection for IoT Based on Improved Genetic Algorithm and Deep Belief Network. IEEE Access 2019, 7, 31711-31722. [CrossRef]

6. Yang, H.; Wang, F. Wireless Network Intrusion Detection Based on Improved Convolutional Neural Network. IEEE Access 2019, 7, 64366-64374. [CrossRef]

7. Lever, J.; Krzywinski, M.; Altman, N. Model selection and overfitting. Nat. Methods 2016, 13, 703-704. [CrossRef]

8. Krawczyk, B. Learning from imbalanced data: Open challenges and future directions. Prog. Artif. Intell. 2016, 5, 221-232. [CrossRef]

9. Pes, B. Learning from high-dimensional biomedical datasets: The issue of class imbalance. IEEE Access 2020, 8, 13527-13540. [CrossRef]

10. Wang, S.; Yao, X. Multiclass imbalance problems: Analysis and potential solutions. IEEE Trans. Syst. Man Cybern. Part B Cybern. 2012, 42, 1119-1130. [CrossRef] [PubMed]

11. Ho, T.K.; Basu, M. Complexity measures of supervised classification problems. IEEE Trans. Pattern Anal. Mach. Intell. 2002, 24, 289-300.

12. Kelly, M.G.; Hand, D.J.; Adams, N.M. Supervised classification problems: How to be both judge and jury. In Lecture Notes in Computer Science (Including Subseries Lecture Notes in Artificial Intelligence and Lecture Notes in Bioinformatics); Springer: Berlin, Germany, 1999; Volume 1642, pp. 235-244.

13. Kuncheva, L.I. Combining Pattern Classifiers: Methods and Algorithms: Second Edition; Wiley: Hoboken, NJ, USA, 2014; Volume 9781118315, ISBN 9781118914564.

14. Jain, A.K.; Duin, R.P.W.; Mao, J. Statistical pattern recognition: A review. IEEE Trans. Pattern Anal. Mach. Intell. 2000, 22 , 4-37. [CrossRef]

15. Lashkari, A.H.; Gil, G.D.; Mamun, M.S.I.; Ghorbani, A.A. Characterization of tor traffic using time based features. In Proceedings of the ICISSP 2017 3rd International Conference on Information Systems Security and Privacy, Porto, Portugal, 19-21 February 2017; SciTePress: Setúbal, Portugal, 2017; Volume 2017-Janua, pp. 253-262.

16. Robert, C. Machine Learning, a Probabilistic Perspective. CHANCE 2014, 27, 62-63. [CrossRef]

17. Maindonald, J. Pattern Recognition and Machine Learning; Journal of Statistical Software: Los Angeles, CA, USA, 2007 ; Volume 17.

18. Frasca, T.M.; Sestito, A.G.; Versek, C.; Dow, D.E.; Husowitz, B.C.; Derbinsky, N. A Comparison of Supervised Learning Algorithms for Telerobotic Control Using Electromyography Signals. In Proceedings of the 30th AAAI Conference on Artificial Intelligence, AAAI 2016, Phoenix, AZ, USA, 12-17 February 2016; pp. 4208-4209. Available online: www.aaai.org (accessed on 12 May 2020).

19. Soru, T.; Ngomo, A.C.N. A comparison of supervised learning classifiers for link discovery. ACM Int. Conf. Proceeding Ser. 2014, 41-44. [CrossRef]

20. Arriaga-Gómez, M.F.; De Mendizábal-Vázquez, I.; Ros-Gómez, R.; Sánchez-Ávila, C. A comparative survey on supervised classifiers for face recognition. In Proceedings of the International Carnahan Conference on Security Technology, Hatfield, UK, 13-16 October 2014; Volume 2014, pp. 1-6.

21. Shiraishi, T.; Motohka, T.; Thapa, R.B.; Watanabe, M.; Shimada, M. Comparative assessment of supervised classifiers for land useland cover classification in a tropical region using time-series PALSAR mosaic data. IEEE J. Sel. Top. Appl. Earth Obs. Remote Sens. 2014, 7, 1186-1199. [CrossRef]

22. Micó, L.; Oncina, J. Comparison of fast nearest neighbour classifiers for handwritten character recognition. Pattern Recognit. Lett. 1998, 19, 351-356. [CrossRef]

23. Sianaki, O.A. Intelligent Decision Support System for Energy Management in Demand Response Programs and Residential and Industrial Sectors of the Smart Grid. Ph.D. Thesis, Curtin University, Bentley, WA, Australia, 2015.

24. Hwang, C.; Masud, A. Multiple Objective Decision Making-Methods and Applications: A State-Of-The-Art Survey; Springer: New York, NY, USA, 2012.

25. Radanliev, P.; De Roure, D.; Page, K.; Van Kleek, M.; Santos, O.; Maddox, L.; Burnap, P.; Anthi, E.; Maple, C. Design of a dynamic and self-adapting system, supported with artificial intelligence, machine learning and real-time intelligence for predictive cyber risk analytics in extreme environments-Cyber risk in the colonisation of Mars. Saf. Extrem. Environ. 2021, 1-12. [CrossRef]

26. Wu, X.; Kumar, V.; Ross, Q.J.; Ghosh, J.; Yang, Q.; Motoda, H.; McLachlan, G.J.; Ng, A.; Liu, B.; Yu, P.S.; et al. Top 10 algorithms in data mining. Knowl. Inf. Syst. 2008, 14, 1-37. [CrossRef]

27. Kotsiantis, S.B.; Zaharakis, I.; Pintelas, P. Supervised machine learning: A review of classification techniques. Emerg. Artif. Intell. Appl. Comput. Eng. 2007, 160, 3-24. 
28. Demusar, J. Statistical Comparisons of Classifiers over Multiple Data Sets. J. Mach. Learn. Res. 2006, 7, 1-30.

29. Chand, N.; Mishra, P.; Krishna, C.R.; Pilli, E.S.; Govil, M.C. A comparative analysis of SVM and its stacking with other classification algorithm for intrusion detection. In Proceedings of the 2016 International Conference on Advances in Computing, Communication and Automation, ICACCA, Dehradun, India, 8-9 April 2016; IEEE: Piscataway, NJ, USA, 2016 ; pp. 1-6.

30. Htike, K.K.; Khalifa, O.O. Comparison of supervised and unsupervised learning classifiers for human posture recognition. In Proceedings of the International Conference on Computer and Communication Engineering (ICCCE 2010), Kuala Lumpur, Malaysia, 11-13 May 2010. [CrossRef]

31. Tuysuzoglu, G.; Yaslan, Y. Gözetimli Siniflandiricilar ve Topluluk Temelli Sözlükler ile Biyomedikal Veri Siniflandirilmasi. In Proceedings of the 25th Signal Processing and Communications Applications Conference, SIU 2017, Antalya, Turkey, 15-18 May 2017; pp. 1-4. [CrossRef]

32. Gu, S.; Jin, Y. Multi-train: A semi-supervised heterogeneous ensemble classifier. Neurocomputing 2017, 249, 202-211. [CrossRef]

33. Labatut, V.; Cherifi, H. Accuracy Measures for the Comparison of Classifiers. arXiv 2012, arXiv:abs/1207.3790.

34. Caruana, R.; Niculescu-Mizil, A. An empirical comparison of supervised learning algorithms. In Proceedings of the 23rd International Conference on Machine Learning, Hong Kong, China, 18-22 December 2006; Volume 148, pp. 161-168.

35. Amancio, D.R.; Comin, C.H.; Casanova, D.; Travieso, G.; Bruno, O.M.; Rodrigues, F.A.; Da Fontoura Costa, L. A systematic comparison of supervised classifiers. PLoS ONE 2014, 9, e94137. [CrossRef]

36. Araar, A.; Bouslama, R. A comparative study of classification models for detection in ip networks intrusions. J. Theor. Appl. Inf. Technol. 2014, 64, 107-114.

37. Gharibian, F.; Ghorbani, A.A. Comparative study of supervised machine learning techniques for intrusion detection. In Proceedings of the Fifth Annual Conference on Communication Networks and Services Research (CNSR 2007), Fredericton, NB, Canada, 14-17 May 2007; pp. 350-355.

38. Panda, M.; Patra, M.R. A comparative study of data mining algorithms for network intrusion detection. In Proceedings of the 1st International Conference on Emerging Trends in Engineering and Technology, ICETET 2008, Maharashtra, India, 16-18 July 2008; pp. 504-507.

39. Srinivasulu, P.; Nagaraju, D.; Kumar, P.R.; Rao, K.N. Classifying the network intrusion attacks using data mining classification methods and their performance comparison. Int. J. Comput. Sci. Netw. Secur. 2009, 9, 11-18.

40. Wu, S.Y.; Yen, E. Data mining-based intrusion detectors. Expert Syst. Appl. 2009, 36, 5605-5612. [CrossRef]

41. Jalil, K.A.; Kamarudin, M.H.; Masrek, M.N. Comparison of machine learning algorithms performance in detecting network intrusion. In Proceedings of the 2010 International Conference on Networking and Information Technology, Manila, Philippines, 11-12 June 2010; pp. 221-226. [CrossRef]

42. Amudha, P.; Rauf, H.A. Performance analysis of data mining approaches in intrusion detection. In Proceedings of the 2011 International Conference on Process Automation, Control and Computing, Coimbatore, India, 20-22 July 2011.

43. China Appala Naidu, R.; Avadhani, P.S. A comparison of data mining techniques for intrusion detection. In Proceedings of the IEEE International Conference on Advanced Communication Control and Computing Technologies (ICACCCT), Ramanathapuram, India, 23-25 August 2012; pp. 41-44.

44. Kalyani, G. Performance Assessment of Different Classification Techniques for Intrusion Detection. IOSR J. Comput. Eng. 2012, 7, 25-29. [CrossRef]

45. Thaseen, S.; Kumar, C.A. An analysis of supervised tree based classifiers for intrusion detection system. In Proceedings of the 2013 International Conference on Pattern Recognition, Informatics and Mobile Engineering, Salem, India, 21-22 February 2013, pp. 294-299.

46. Revathi, S.; Malathi, A. A Detailed Analysis on NSL-KDD Dataset Using Various Machine Learning Techniques for Intrusion Detection. Int. J. Eng. Res. Technol. 2013, 2, 1848-1853.

47. Robinson, R.R.R.; Thomas, C. Ranking of machine learning algorithms based on the performance in classifying DDoS attacks. In Proceedings of the 2015 IEEE Recent Advances in Intelligent Computational Systems, RAICS 2015, Trivandrum, Kerala, 10-12 December 2015; pp. 185-190.

48. Choudhury, S.; Bhowal, A. Comparative analysis of machine learning algorithms along with classifiers for network intrusion detection. In Proceedings of the 2015 International Conference on Smart Technologies and Management for Computing, Communication, Controls, Energy and Materials (ICSTM), Avadi, India, 6-8 May 2015; pp. 89-95.

49. Jain, A.; Rana, J.L. Classifier Selection Models for Intrusion Detection System (Ids). Inform. Eng. Int. J. 2016, 4, 1-11.

50. Bostani, H.; Sheikhan, M. Modification of supervised OPF-based intrusion detection systems using unsupervised learning and social network concept. Pattern Recognit. 2017, 62, 56-72. [CrossRef]

51. Belavagi, M.C.; Muniyal, B. Performance Evaluation of Supervised Machine Learning Algorithms for Intrusion Detection. Procedia Comput. Sci. 2016, 89, 117-123. [CrossRef]

52. Almseidin, M.; Alzubi, M.; Kovacs, S.; Alkasassbeh, M. Evaluation of Machine Learning Algorithms for Intrusion Detection System. In Proceedings of the 2017 IEEE 15th International Symposium on Intelligent Systems and Informatics (SISY), Subotica, Serbia, 14-16 September 2017.

53. Amira, A.S.; Hanafi, S.E.O.; Hassanien, A.E. Comparison of classification techniques applied for network intrusion detection and classification. J. Appl. Log. 2017, 24, 109-118. 
54. Aksu, D.; Üstebay, S.; Aydin, M.A.; Atmaca, T. Intrusion detection with comparative analysis of supervised learning techniques and fisher score feature selection algorithm. In Communications in Computer and Information Science; Springer: Berlin, Germany, 2018; Volume 935, pp. 141-149.

55. Nehra, D.; Kumar, K.; Mangat, V. Pragmatic Analysis of Machine Learning Techniques in Network Based IDS. In Proceedings of the International Conference on Advanced Informatics for Computing Research; Springer: Berlin/Heidelberg, Germany, 2019; pp. 422-430.

56. Mahfouz, A.M.; Venugopal, D.; Shiva, S.G. Comparative Analysis of ML Classifiers for Network Intrusion Detection; Springer: Berlin/Heidelberg, Germany, 2020; pp. 193-207.

57. Rajagopal, S.; Siddaramappa Hareesha, K.; Panduranga Kundapur, P. Performance analysis of binary and multiclass models using azure machine learning. Int. J. Electr. Comput. Eng. 2020, 10, 978. [CrossRef]

58. Ahmim, A.; Ferrag, M.A.; Maglaras, L.; Derdour, M.; Janicke, H. A Detailed Analysis of Using Supervised Machine Learning for Intrusion Detection; Springer: Berlin/Heidelberg, Germany, 2020; pp. 629-639.

59. Frank, E.; Hall, M.A.; Witten, I.H. The WEKA Workbench. Online Appendix for "Data Mining: Practical Machine Learning Tools and Techniques."; Morgan Kaufmann: Burlington, VT, USA, 2016; p. 128.

60. Su, J.; Zhang, H.; Ling, C.X.; Matwin, S. Discriminative parameter learning for Bayesian networks. In Proceedings of the 25th International Conference on Machine Learning, Helsinki, Finland, 5-9 July 2008; pp. 1016-1023.

61. Yu, S.-Z. Hidden semi-Markov models. Artif. Intell. 2010, 174, 215-243. [CrossRef]

62. Ghahramani, Z. An introduction to Hidden Markov Models and Bayesian Networks. In Hidden Markov Models; World Scientific: Singapore, 2001; Volume 15.

63. Zhang, H. Exploring conditions for the optimality of naïve bayes. Proc. Int. J. Pattern Recognit. Artif. Intell. 2005, 19, 183-198. [CrossRef]

64. John, G.H.; Langley, P. Estimating Continuous Distributions in Bayesian Classifiers George. Proc. Elev. Conf. Uncertain. Artif. Intell. 1995, 42, 338-345.

65. Puurula, A. Scalable Text Classification with Sparse Generative Modeling. In Lecture Notes in Computer Science; Springer: New York, NY, USA, 2012; pp. 458-469.

66. Balakrishnama, S.; Ganapathiraju, A. Linear Discriminant Analysis-A Brief Tutorial; Institute for Signal and information Processing: Philadelphia, PA, USA, 1998; Volume 18, pp. 1-8.

67. Fan, R.E.; Chang, K.W.; Hsieh, C.J.; Wang, X.R.; Lin, C.J. LIBLINEAR: A library for large Linear Classification. J. Mach. Learn. Res. 2008, 9, 1871-1874.

68. Chang, C.C.; Lin, C.J. LIBSVM: A Library for support vector machines. ACM Trans. Intell. Syst. Technol. 2011, 2, 1-27. [CrossRef]

69. Kleinbaum, D.G.; Klein, M. Introduction to Logistic Regression; Springer: New York, NY, USA, 2010; pp. 1-39.

70. Windeatt, T. Accuracy/diversity and ensemble MLP classifier design. IEEE Trans. Neural Netw. 2006, 17, 1194-1211. [CrossRef]

71. Hertz, J.; Krogh, A.; Palmer, R.G. Introduction to the Theory of Neural Computation; Elsevier Science Publishers: Amsterdam, The Netherlands, 2018; ISBN 9780429968211.

72. Yang, Q.; Cheng, G. Quadratic Discriminant Analysis under Moderate Dimension. Stat. Theory. 2018. Available online: http: / / arxiv.org/abs/1808.10065 (accessed on 12 May 2020).

73. Frank, E. Fully Supervised Training of Gaussian Radial Basis Function Networks in WEKA; University of Waikato: Hamilton, New Zealand, 2014; Volume 04.

74. Schwenker, F.; Kestler, H.A.; Palm, G. Unsupervised and Supervised Learning in Radial-Basis-Function Networks. In SelfOrganizing Neural Networks; Physica Verlag: Heidelberg, Germany, 2002; pp. 217-243.

75. Kyburg, H.E. Probabilistic Reasoning in Intelligent Systems: Networks of Plausible Inference by Judea Pearl. J. Philos. 1991, 88, 434-437. [CrossRef]

76. Kecman, V. Support Vector Machines-An Introduction; Springer: Berlin/Heidelberg, Germany, 2005; pp. 1-47.

77. Keerthi, S.S.; Shevade, S.K.; Bhattacharyya, C.; Murthy, K.R.K. Improvements to Platt's SMO algorithm for SVM classifier design. Neural Comput. 2001, 13, 637-649. [CrossRef]

78. Aha, D.W.; Kibler, D.; Albert, M.K. Instance-Based Learning Algorithms. In Machine Learning; Springer: Berlin, Germany, 1991; Volume 6, pp. 37-66.

79. Cleary, J.G.; Trigg, L.E. $K^{*}$ : An Instance-based Learner Using an Entropic Distance Measure. In Machine Learning Proceedings 1995; Morgan Kaufmann: New York, NY, USA, 1995.

80. Wojna, A.; Latkowski, R. Rseslib 3: Library of rough set and machine learning methods with extensible architecture. In Lecture Notes in Computer Science (Including Subseries Lecture Notes in Artificial Intelligence and Lecture Notes in Bioinformatics); Springer: Berlin/Heidelberg, Germany, 2019; Volume 10810 LNCS, pp. 301-323.

81. Frank, E.; Hall, M.; Pfahringer, B. Locally Weighted Naive Bayes; University of Waikato: Hamilton, New Zealand, 2012.

82. Atkeson, C.G.; Moore, A.W.; Schaal, S. Locally Weighted Learning. Artif. Intell. Rev. 1997, 11, 11-73. [CrossRef]

83. Zimek EM (Documentation for extended WEKA including Ensembles of Hierarchically Nested Dichotomies). Available online: http:/ / www.dbs.ifi.lmu.de/ \{\}zimek/diplomathesis/implementations/EHNDs/doc/weka/clusterers/FarthestFirst.html (accessed on 12 May 2020).

84. Kohavi, R. The power of decision tables. In Proceedings of the Lecture Notes in Computer Science (Including Subseries Lecture Notes in Artificial Intelligence and Lecture Notes in Bioinformatics); Springer: Berlin/Heidelberg, Germany, 1995; Volume 912, pp. 174-189. 
85. Hall, M.A.; Frank, E. Combining naive bayes and decision tables. In Proceedings of the FLAIRS Conference, Coconut Grove, FL, USA, 15-17 May 2008; Volume 2118, pp. 318-319.

86. Hühn, J.; Hüllermeier, E. FURIA: An algorithm for unordered fuzzy rule induction. Data Min. Knowl. Discov. 2009, 19, 293-319. [CrossRef]

87. Cohen, W.W. Fast Effective Rule Induction. In Proceedings of the Twelfth International Conference on Machine Learning, Tahoe City, CA, USA, 9-12 July 1995.

88. Stefanowski, J. Rough set based rule induction techniques for classification problems. In Rough Set Based Rule Induction Techniques for Classification Problems; Intelligent Techniques \& Soft Computing: Aachen, Germany, 1998; Volume 1, pp. 109-113.

89. Sylvain, R. Nearest Neighbor with Generalization; University of Canterbury: Christchurch, New Zealand, 2002.

90. Martin, B. Instance-Based Learning: Nearest Neighbor with Generalization; University of Waikato: Hamilton, New Zealand, 1995.

91. Ben-David, A. Automatic Generation of Symbolic Multiattribute Ordinal Knowledge-Based DSSs: Methodology and Applications. Decis. Sci. 1992, 23, 1357-1372. [CrossRef]

92. Holte, R.C. Very Simple Classification Rules Perform Well on Most Commonly Used Datasets. Mach. Learn. 1993, 11, 63-90. [CrossRef]

93. Frank, E.; Wang, Y.; Inglis, S.; Holmes, G.; Witten, I.H. Using model trees for classification. Mach. Learn. 1998, 32, 63-76. [CrossRef]

94. Thangaraj, M. Vijayalakshmi Performance Study on Rule-based Classification Techniques across Multiple Database Relations. Int. J. Appl. Inf. Syst. 2013, 5, 1-7.

95. Pawlak, Z. Rough set theory and its applications to data analysis. Cybern. Syst. 1998, 29, 661-688. [CrossRef]

96. Frank, E. ZeroR. Weka 3.8 Documentation. 2019. Available online: https://weka.sourceforge.io/doc.stable-3-8/weka/classifiers/ rules/ZeroR.html (accessed on 12 May 2020).

97. Suthaharan, S. Decision Tree Learning. In Machine Learning Models and Algorithms for Big Data Classification. Integrated Series in Information Systems; Springer: Berlin/Heidelberg, Germany, 2016; pp. 237-269.

98. Abellán, J.; Moral, S. Building Classification Trees Using the Total Uncertainty Criterion. Int. J. Intell. Syst. 2003, 18, 1215-1225. [CrossRef]

99. Adnan, M.N.; Islam, M.Z. Forest PA: Constructing a decision forest by penalizing attributes used in previous trees. Expert Syst. Appl. 2017, 89, 389-403. [CrossRef]

100. Gama, J. Functional trees. Mach. Learn. 2004, 55, 219-250. [CrossRef]

101. Salzberg, S.L. C4.5: Programs for Machine Learning by J. Ross Quinlan. In Machine Learning; Morgan Kaufmann Publishers, Inc.: New York, NY, USA, 1993; Volume 16, pp. 235-240.

102. Ibarguren, I.; Pérez, J.M.; Muguerza, J.; Gurrutxaga, I.; Arbelaitz, O. Coverage-based resampling: Building robust consolidated decision trees. Knowledge-Based Syst. 2015, 79, 51-67. [CrossRef]

103. Hayashi, Y.; Tanaka, Y.; Takagi, T.; Saito, T.; Iiduka, H.; Kikuchi, H.; Bologna, G.; Mitra, S. Recursive-rule extraction algorithm with J48graft and applications to generating credit scores. J. Artif. Intell. Soft Comput. Res. 2016, 6, 35-44. [CrossRef]

104. Holmes, G.; Pfahringer, B.; Kirkby, R.; Frank, E.; Hall, M. Multiclass alternating decision trees. In Proceedings of the Lecture Notes in Computer Science (Including Subseries Lecture Notes in Artificial Intelligence and Lecture Notes in Bioinformatics); Springer: Berlin/Heidelberg, Germany, 2002; Volume 2430, pp. 161-172.

105. Landwehr, N.; Hall, M.; Frank, E. Logistic model trees. Mach. Learn. 2005, 59, 161-205. [CrossRef]

106. Sumner, M.; Frank, E.; Hall, M. Speeding up Logistic Model Tree induction. In Proceedings of the Lecture Notes in Computer Science (Including Subseries Lecture Notes in Artificial Intelligence and Lecture Notes in Bioinformatics), Samos, Greece, 18-20 July 2005; Volume 3721 LNAI, pp. 675-683.

107. Jiang, L.; Li, C. Scaling up the accuracy of decision-tree classifiers: A naive-bayes combination. J. Comput. 2011, 6, 1325-1331. [CrossRef]

108. Kalmegh, S. Analysis of WEKA Data Mining Algorithm REPTree, Simple Cart and RandomTree for Classification of Indian News. Int. J. Innov. Sci. Eng. Technol. 2015, 2, 438-446.

109. Breiman, L. Bagging predictors. Mach. Learn. 1996, 24, 123-140. [CrossRef]

110. Breiman, L. Random Forests. Mach. Learn. 2001, 45, 5-32. [CrossRef]

111. Witten, I.H.; Frank, E.; Hall, M.A.; Pal, C.J. Data Mining: Practical Machine Learning Tools and Techniques; Elsevier: Amsterdam, The Netherlands, 2016; ISBN 9780128042915.

112. Islam, Z.; Giggins, H. Knowledge Discovery through SysFor: A Systematically Developed Forest of Multiple Decision Trees kDMI: A Novel Method for Missing Values Imputation Using Two Levels of Horizontal Partitioning in a Data set View project A Hybrid Clustering Technique Combining a Novel Genetic Algorithm with K-Means View project Knowledge Discovery through SysFor-a Systematically Developed Forest of Multiple Decision Trees. 2011. Available online: https:/ /www.researchgate.net/ publication/236894348 (accessed on 11 May 2020).

113. Wilkinson, L.; Anand, A.; Tuan, D.N. CHIRP: A new classifier based on composite hypercubes on iterated random projections. In Proceedings of the Proceedings of the ACM SIGKDD International Conference on Knowledge Discovery and Data Mining, San Diego, CA, USA, 21-24 August 2011; pp. 6-14. 
114. Athanasiadis, I.N.; Kaburlasos, V.G.; Mitkas, P.A.; Petridis, V. Applying Machine Learning Techniques on Air Quality Data for Real-Time Decision Support 1 Introduction 2 Decision support systems for assessing air quality in real—time 3 The $\sigma-F L N M A P$ Classifier. First Int. Symp. Inf. Technol. Environ. Eng. 2003, 2-7. Available online: http://www.academia.edu/download/530838 86/Applying_machine_learning_techniques_on_20170511-3627-1jgoy73.pdf (accessed on 11 May 2020).

115. Deeb, Z.A.; Devine, T. Randomized Decimation HyperPipes; Penn State University: University Park, PA, USA, 2010.

116. Demiröz, G.; Altay Güvenir, H. Classification by voting feature intervals. In Proceedings of the Lecture Notes in Computer Science (Including Subseries Lecture Notes in Artificial Intelligence and Lecture Notes in Bioinformatics); Springer: Berlin/Heidelberg, Germany, 1997; Volume 1224, pp. 85-92.

117. Ingre, B.; Yadav, A. Performance analysis of NSL-KDD dataset using ANN. In Proceedings of the 2015 International Conference on Signal Processing and Communication Engineering Systems, Guntur, India, 2-3 January 2015; pp. 92-96. [CrossRef]

118. Ibrahim, L.M.; Taha, D.B.; Mahmod, M.S. A comparison study for intrusion database (KDD99, NSL-KDD) based on self organization map (SOM) artificial neural network. J. Eng. Sci. Technol. 2013, 8, 107-119.

119. Tavallaee, M.; Bagheri, E.; Lu, W.; Ghorbani, A.A. A detailed analysis of the KDD CUP 99 data set. In Proceedings of the 2009 IEEE Symposium on Computational Intelligence for Security and Defense Applications, Ottawa, ON, Canada, 8-10 July 2009; pp. 1-6.

120. Shiravi, A.; Shiravi, H.; Tavallaee, M.; Ghorbani, A.A. Toward developing a systematic approach to generate benchmark datasets for intrusion detection. Comput. Secur. 2012, 31, 357-374. [CrossRef]

121. Gharib, A.; Sharafaldin, I.; Lashkari, A.H.; Ghorbani, A.A. An Evaluation Framework for Intrusion Detection Dataset. In Proceedings of the ICISS 2016-2016 International Conference on Information Science and Security, Jaipur, India, 19-22 December 2016; Institute of Electrical and Electronics Engineers Inc.: Piscataway, NJ, USA, 2017.

122. Panigrahi, R.; Borah, S. Design and Development of a Host Based Intrusion Detection System with Classification of Alerts; Sikkim Manipal University: Sikkim, India, 2020.

123. Sharafaldin, I.; Lashkari, A.H.; Ghorbani, A.A. Toward Generating a New Intrusion Detection Dataset and Intrusion Traffic Characterization. In Proceedings of the ICISSP 2018, Madeira, Portugal, 22-24 January 2018; pp. 108-116. 